Y.

\title{
Die Behandlung des angeborenen Klumpfusses im ersten Kindesalter.
}

Randbemerkungen zu den Aufsätzen von Prof. Schultze und Lange.

Von

Dr. Max Herz, Auckland (Neuseeland).

Der Frage der Therapie von alten und älteren Klumpfüssen hat Lor e nz im modellierenden Redressement die entscheidende Antwort gefunden. Nur über die Details gibt es noch Kontroverse, über die Dauer des Verbandes, die Nachbehandlung und dergl.

Nicht zur Ruhe kommen will dagegen die Behandlung der in den Füsssen deformierten Babies. Finckh, r. Oettingen, jetzt $\mathrm{L}$ ange bringen neue Vorschlïge.

Reformatoren sind männiglich ein Zeichen dafür, dass "something is rotten in the state of Danemark ${ }^{4}$, oder doch, dass es in deren Auffassung so ist.

Dem Gipsverband beim Baby gehen alle zn Leibe. Warun?

Lange, der letate Rufer im Streit, gibt im 3. Hefte des VI. Bandes dieses Archivs diese Gründe: der starre Verband bringt bäufig Decubitus, Nekrosen, die Teile, wichtige Teile des Fusses zerstören und die Behandlung zum mindesten abbrechen; macht die Haut ekzematös, da "sehr riele Mütter es nicht fertig bringen können, 2 oder 3 Wochen lang die Gipsverbände der Säuglinge urinfrei und trocken zu halten". Die Behandlung muss auch hier unterbrochen, verschoben werden; inzwischen gibt es ein Rezidiv und das Spiel: Narkose, Verband, Decubitus, Ekzem beginnt von neuem con grazia ad infinitum. Ein weiterer Nachteil ist, „dass die kleinen Kinder lange Zeit unter ärztlicher Aufsicht bleiben müssen". Alle 2-3 Wochen ist Revision nötig, die unbemittelten Eltern erhebliche Umstände, grosse Kosten usw. bringt.

Darum empfieblt Lange die Redression, den Gipsverband ron 2-7 Tagen und die Schienenbehandlung bei Tag und Nacht. Dies Verfahren "wird unverändert fortgeführt, bis das Kind seine ersten Stehrersuche macht, in der Regel also bis zum Ende des ersten Lebensjahres"; und manchmal (wie die Gehschienen beweisen) noch länger. 
Sir Horace Walpole pHegte zu sagen: wenn die Franzosen rom Garten Eden sprechen, denken sie an Versailles.

Wenn jemand von einer guten Behandlungsmethode spricht, denkt er immer an seine eigene. Sieht er Fehler in einem anderen Vertahren, denkt er immer an die Torzüglichkeit seines eigenen.

Ich bin nun in der glücklichen Lage, weder eine neue Klumpiusstherapie noch Verbesserungen einer anderen erfunden zu haben. Muss gestehen, dass weder ein Redresseur noch eine Schiene Athenen gleich meinem Hitupte entsprang. Bin also völlig objektiv. Cod stütze mich anf eine gute Erfahrnng an grossem Material.

Zu prüfen wären die ron Lange vorgebrachten Anklagen, mit denen sich Schultze schon beschäftigt hat.

Eines muss gleich auffallen. Das ist der Einwurf der benötigten langen irztlichen Aufsicht der gipsbehandelten Babies. Diese Gipsbehandlung dauert 3-4 Monate, wenns hoch kommt 6 . La nge geht bis zu den Stehversuchen des Kindes und darüber. Braucht also im Durchschnitt zwölf Munate. „Die Klumpiussbehandlung in den ersten Lebensjahren," sagt Lange selbst, "stellt immer grosse Anforderungen an die Geschicklichkeit des Arztes and die Geduld und Ausdauer der Eltern. Das gilt nicht nur für die Gipsbehandlung, sondern ebenso für die Schienenbehandlung." Nun wobl? Wann wird diese Geduld und Ausdaner der Eltern eher erlahmen idie Geschicklichkeit des Arztes schläft noch schlummert nicht), wann werden also die Eltern eher gleichgültig werden, bei einer Behandlung von drei oder bei einem Verfahren von zwölf Monaten: Die tägliche C̈bung erschlafft die Aufmerksamkeit, wie die tïgliche Berührung mit der Gefahr unvorsichtig macht. Und wenn es auf die elterliche Ausdaner und Geduld so sehr ankommt, wenn deren Anhalten, wenn ibre Wachsamkeit so sehr den Ausschlag nach der Seite des Erfolges gibt, welches Veriahren ist dann vorzuziehen: eines, das die Tätigkeit der Eltern ausschliesst, oder eine Behandlung, die auf die Teilnahme, auf wesentliche Witarbeit ron Laien angewiesen ist, die nie wissen können, trotz allem Zeigen und Belehren, worauf es wirklich ankommt? Sicherlich muss Lang e seine Patienten alle 3-4 Wochen sehen, um die Fussstellung zu revidieren, korrigieren. Muss sie notgedrungen sogar öfter sehen als Gipsbehandelte, da die Schiene ihm die gewollte Stellung nicht so unbedingt sichert wie ein Gipsverband. Und vergleicht man dann die Summen der ärztlichen Besuche in den drei Monaten der Gips- und zwölf der Schienenbehandlung, den Unterschied dürfte man kaum allzu gross finden.

Der Gipsverband einmal g $\mathbf{t}$ t angelegt, hält den Fuss unverrückbar fest; kann 6 Wochen liegen bleiben, wird dann erneuert and bält sich bis zum Ende der Behandlung, weitere 6 Wochen. Für die Regel genügt das. 'Zwei (leichte und kurze) Narkosen werden gebraucht, die noch keinem Baby etwas geschadet haben. Vor dem Durchnässen schützt eine dicke Flanellbinde, die (namentlich um das obere Ende) über den Verband gerollt wird.

Kürzer als die Schienenbehandlung ist die Gipstherapie. 
Ein weiterer Einwurf. "Der Gipsverband bringt die Atrophie namentlich der Wade, bringt die zündholzähnlichen Unterschenkel. Wir wissen aus Joachimsthals Untersuchungen und Experimenten, dass die Atrophie der Wade physiologisch hegründet ist, dass diese Atrophie in Wirklichkeit keine Atrophie ist, sondern eine Anpassung an den (gegen den normalen) verlängerten Hebelarm der Ferse. Die nie operierten Kinder zeigen alle die bohe schmale Wade, diese "Zündhölzer". Der Gipsverband bringt diese $\Lambda$ trophie also nicht erst, sie ist längst da und beim Baby unter dicken Fettkissen verborgen. Was die dreimonatige Einschliessung in den Gipsverband an Muskelfasern und Kraft vermindert, wird rasch nachher wieder gut gemacht.

Bleibt als wichtigste Anklage: Decubitus und Ekzem. Der Gipsverband an sich bringt diese Störungen auch nicht. Sie müssen nicht entsteben. Ihr Auftreten liegt in mangelhafter T'echnik. Es stünde mir schlecht an, einem Mlanne wie Lange, der unserer Wissenscbaft so viele entscheidenden Anregungen und originellen Ideen gegeben hat, Unfähigkeit in der Verbandtechnil vorzuwerfen. Das liegt mir fern. Nur denke ich, haben die üblen Erfahrungen, die wohl jeder in den Lebrjahren hat durchmachen müssen, ihn so stark gegen den Gipsverband eingenommen, dass er auf seine Abschaffung statt auf seine Inderung gesonnen hat.

Und rerbessert kann die Technik werden bis zu dem Grade, dass Decubitus und Elkzema nahezu ausgeschlossen sind.

Gegen das Ekrem schützt ein dichtes Einpudern der Hant in allen ibren Falten mittelst Borstreupulver oder Bestreichen mit Zinkpaste.

Der Gipsverband an einem kleinen Klumpfuss ist ein Kunststïck, das wohl gelernt sein will. Sonst können Decubitus auftreten, sonst kann es rorkommen, dass am Tage nach der Operation die Mutter exscheint auf dem rechten Arme das Baby, anf dem linken den abgestossenen Gipsverband. Aber die Technik lässt sich erlernen, die üblen Zufälle lassen sich vermeiden. Über die Grundprinzipien der Operation ist man sich ja einig. "Wachsweich mobilisieren, Sinus tarsi (d. h. den Gibbus) ausmodellieren, im Gipsverband überkorrigieren" heisst es bei Schultze. Dem wird wobl niemand widersprechen. Bei der Verbandanlage nun ist das kleinste Detail wichtig. Das Bein ist im Knie gestreckt: eine Hand des Assistenten rotiert es möglichst einwärts, die andere umgreift mit der ron Daumen und Zeigefinger gebildeten Gabel die Zehenballen. Der Fuss wird so in überkorrigierter Stellnng gebalten. Jetzt erst rollt man eine Schicht geleimter Watte darüber, so glatt wie nur irgend müglich. Dadurch wird vermieden, dass die Watte in die Hautfalten eingeklemmt wird und Druckgangrän erzeugt; deshalb müssen auch Knoten- und Klumpenbildungen in der Watte ängstlich verhindert werden. Darüber kommt der Gips. Nur schmale Binden dürfen verwandt werden. Die ersten Lagen müssen glatt, ohne Falten angelegt werden. Yit einiger Wühe gelingt das. Namentlich um die Ferse herum müssen die Binden gut sitzen, um oberhalb des Calcaneus einen Halt zu finden. Die glatte, faltenlose Anlegung ron Watte und Binden ist kategorischer Imperatir. 
Das klingt sehr einfach und wenig. Ist aber in Wirklichkeit mühselige und peinliche Arbeit. Der Lohn ist die Verhinderung von Decubitus in 99 unter 100 Fällen.

Und doch - eben um dieses einen Falles willen wäre der Gipsverband zu verwerfen, wenn die Schienenbehandlung ein Gleiches leistete wie er mit absolutem Ausschluss des Decubitus.

Das tut sie aber nicht. Bestimmt nicht. Schulze hat das Lange schon vorgehalten. Ich kann es nur wiederholen. Keine Schienenbehandlung, kein Verfahren mit abnebmbaren Verbänden vermag heute die absolute Sicherung der gewollten Stellung zu gewährleisten. Weder der Finckhsche noch der v. Oettingensche Verband, noch Langes Schiene. Sie lassen dem Fuss zu viel Spielraum, lassen ihm den Weg offen zur Rückkehr in die alte Stellung. Davon ganz zu schweigen, dass Laien sie anzulegen haben, dass Laien sie abnehmen können, wenn Baby unruhig wird, schreit, weint, heult. Sie werden eine Mutter nur schwer davon ülerzeugen, dass ihre Liebe Affenliebe ist; sie wird Ihnen vielleicht wirklich glauben, dass sie dem Kinde schadet, sie wird es aber nicht übers Herz bringen, das Baby wimmern und leiden zu lassen, wenn sie ihm ihrer Meinung nach Erleichterung schaffen kann. leistet?

Lnd der Beweis, dass auch die Lange sche Schiene das Gewollte nicht

Den Beweis bringen Langes in dem erwähnten Aufsatz veröffentlichte Photographien. Es ist kein Vorwurf, wenn ich annehme, dass L ange seine besten Bilder ausgesucht hat. Auf sie werfe man nun mehr als einen Blick. NIan sehe sie sich genau an. Dann wird man finden, ganz deutlich finden, dass keiner der abgebildeten Fälle ein Heilresultat darstellt, das man ideal zu nennen berechtigt ist, mit dem eine Therapie sich zufrieden stellen sollte und dürfte.

Figur A 13, R 15, Z 16, Fig. Kr. 18, K. 20, Mu 24, M 97 : kurz alle abgebildeten Füsse zeigen eine deutliche Adduktion des Vorfusses, einen Rest der alten Deformität, der nicht geheilt ist. Die Knie sind nicht dargestellt, aber man möchte glauben, dass die Richtungslinie von der Patellarmitte nicht durch die zweite Zehe läuft, sondern durch die dritte. Das geht so deutlich aus allen Bildern hervor, dass man sich wundert, dass Lange das nicht gesehen haben sollte. So evident ist das. Alle Kinder sind, wie der Engländer sagt, pidgeontoed: taubenzehig. Die Zehen zeigen einwärts, in die Varität. Und wenn diese Kinder mit auswürts gekehrten Füssen gehen, dann tan sie es nur mit grösster Auswärts-Rotation des Oberschenkels, die sie im Laufen oder bei sonst abgelenkter Aufmerksamkeit kaum aufrecht erbalten können. Zudem ist wohl diese Adduktion des Vorfusses eine dauernde Gefahr. Das Rezidiv ist sozusagen schon eingeleitet.

Eine ideale Fussstellung, eine vollkommene Heilung des Klumpfusses kann solch Resultat nicht genannt werden. 
52 Max Herz, Dio Behandlung des angeborenen Klumpfusses im ersten Kindesalter.

Diese ideale Fussstellung, diese vollkommene Heilung des Pes var. cong. ist aber erreichbar, absolut erreichbar: durch und im Gipsverband. Erreichbar ist hier in 3 Monaten, was die Schiene in 12 nicht zu leisten vermag.

Auch zur Nachbehandlung, wenn die Vorsicht sie gebietet, will mir die Langesche Schiene zu unständlich scheinen; denn dafür kenne ich nichts Besseres, nichts Einfacheres als die Heusnersche Serpentin-Drahtfeder, die jeder Schlosser machen kann.

Der Spruch einer unparteiischen Jury wird in Sachen Schultze c.la. Lange zugunsten $\mathrm{Sch}$ altzes und des Gipsverbandes lauten. 


\section{Beriehte.}

I.

\section{Die kongenitale Luxation des Hüftgelenks.}

Sammelreferat bis einschliesslich 1903

ron

Prof. Dr. Ferd. Schultze,

chirurgischem Oberarzt am St. Vincenz-Hospital in Duisiurg.

„Die Luxation schon ron Hippokrates erwähnt, von Paletta genauer angegeben, wurde zuerst ron Dupuytren mit der gehörigen Sorgfalt betrieben," sagt Chelius in seinem Handbuch der Chirurgie vom Jahre 1833. Galen Avicenna, Paré erwahnen ebenfalls die Luxatio congenitalis.

Eine grosse Anzahl ron Arbeiten rerdanken wir der französischen Schule H a mbert und Jacquier, Gerdy, Breschet, Guérin und besonders Pravaz welcher sich wesentliche Verdienste nach dieser Richtung erworben hat.

Epochemachende Leistungen sind zeitlebens gebunden an die Namen eines Paci, Hoffa und Lorenz.

\section{Itiologie und Frequenz.}

Bei Hippokrates finden wir die Entstehung durch intrauterines Traum vertreten. Es sind von den einzelnen Autoren eine Anzabl von Theorien, welch die Entstehung der kongenitalen Luxationen erklären sollen, aufgestellt worden Paré hält das Leiden für einen Bildungsfebler, der erblich ist. Er sagt: Die Hinkenden erzeugen nicht nur oft, sondern meistens Hinkende.

Dupuytren hat auf die starke Beugung des fötalen Oberschenkels als Ursacbe der Luxation hingeriesen. Der Druck des Kopfes gegen die hintere schwüchste Kapselwand babe eine Dehnung derselben zur Folge und ein geringer Anlass genüge zur rollendeten Luxation.

Pravaz, Parise, Malgaigne haben den einfachen Hydrops des Gelenkes als Uraache der Luxation angesprochen.

v. A $m$ m on fasst die kongenitale Luxation als eine Folge der gestörten Entwickelung auf.

W. Roser äussert sich 1844 in seinem Lehrbuch über die Entstehung der angeborenen Verrenkung. Nach Guérin entsteht dieselbe durch Muskelkontraktur, nach Breschet und Gerdy ist sie hauptsächlich eine Folge mangelhafter und gestörter Entwickelung der Knochen, nach Parise soll eine Gelenkwassersucht im Fötusalter die Ersache bilden. Dass diese drei Lirsachen sümtlich zuweilen die angeborene Luxation bedingen, ist die Ansicht W. Roser's. Die zusammengebogene Lage des Fötus erscheine günstig für eine Dislokation. Später in Jahre 1879 wiederholt W. Roser auf dem Chirurgen-Kongress seine bereits vor 15 Jahren 
ausgesprochene Ansicht, dass die Luxatio congenitalis von einer kranlhaften Adduktionsstellung des kindlichen Schenkels im Mutterleibe abzuleiten sei.

Die Seltenheit der Luxation im männlichen Geschlecht ist nach Roser darauf zurückzufübren, dass die durch die starke Adduktion gedrückten Hoden Reflexbewegungen hervorrufen, hingegen kann beim weiblichen Geschlecht die enge Lage des Fötus bei Fruchtwassermangel eher dic Hüftluxation bewirken.

Guérin stellte die neuropathiscbe Theorie auf. Er lässt die Verrenkung durch Muskelkontraktionen entstehen, welch' letztere durch Defekte im Nervenzentrum bedingt seien. Infolge des gestörten Muskelantagonismus, der Retraktion der Muskeln der einen Seite und der paralytischen Störung der anderen Seite, entstehe die Luxation.

Die Entstehung durch intrauterines Trauma wird auch ron Cruveilhier, J. L. Petit gestütat. - D'Outrepont, Brodhurst und Phelps leren dem geburtahilflichen Trauma, einer gewaltsamen Traktion, Wert bei, und erklären dadurch die Entstehung der Tuxation.

Durch die Versuche von Hofmokl und Valette ist der Nachweis geliefert, dass durch die gewaltsamen Traktionen wohl Frakturen und Lösungen der Epiphysen zustande kommen, aber keine Luxationen.

Krukenberg äussert sich dahin, dass die einseitige Hüftluxation in einer Anzahl von Fällen durch abnormen Druck erzeugt wird und alsdann eine schräge Verschiebung des Beckens bewirkt. In einer Anzahl anderer Fälle soll primare Veränderung der Gelenkhöhle und der Gelenkknorpel zur Luxation führen.

Die Entstehung einer Hüft- und Knie-Verrenkung will $\mathrm{A}$. Barth in einem Falle auf einen Unfall der Mutter im VII. Monat zurückführen. Der Unfall bestand in Sturz auf das linke Knie und Druck des ()berschenkels auf den nach vorn geneigten Leib.

Verneuil präzisiert auf Grund seiver seit 18 o 1 gemachten Untersuchungen seinen Standpunkt dahin, dass noch kein Fall einer im Moment der Geburt konstatierten Verrenkung aufgedeckt sei, während im Gegensatze dazu, im spüteren Alter die kongenitalen Luxationen kein allzu seltenes Vorkommnis bildeten. Nach Verneuil handelt es sich immer um paralytische Luxalionen. Denn die Annahme, dass das anatomische Substrat schon bei der Geburt rorbanden, dieses selbst aber erst bei den ersten Gehversuchen sich herstelle, sei unbaltbar. Zum Beweis für die Sicherheit seiner Auffassung bietet Verneuil für jedes unanfechtbare Präparat einer echten kongenitalen Luxation 300 Fr., mit der rorsichtigen Einschränkung „bis zu zehn Exemplaren innerbalb eines laufenden Jabres".

Die von Verneuil aufgestellte neuropathische Theorie wurde ron Bouvier und Broca beftig bekämptt.

In Anschluss an die von Verneuil vertretene Ansicht wies auch Volkmann darauf hin, dass es sich bei der kongenitalen Luxation nicht un eine Lähmung der Muskeln, sondern um eine Atrophie derselben handle, bedingt durch mangelhafte Funktion. Er will die Luxatio congenitalis streng von der Luxatio paralytica getrennt wissen.

Eine von Dollinger aufgestellte Theorie beziebt sich auf die Wachstumshemmung. Die Verrenkung soll entstehen durch rorzeitige Verknöcherung der Pfanne, der ron dem Limbus nicht fest wie beim Erwachsenen umschlossene Kopf werde aus der im Wachstum nicht gleichen Schritt haltenden Pfanne herausgedrängt.

Tillmann ist der Ansicht, dass ein zu voluminöses Lig. teres die fötale Pfanne ausfülle, allmählich den Kopf aus der Pfanne treibe und so die Luxation herbeifübre.

Die Ursache der Luxation glaubt Grawitz in einer Hemmungsbildung des y-förmigen Knorpels gefunden zu haben, während der Schenkelkopf von dieser 
Störung weniger oder gar nicht betroffen werde. Es wird diese Ansicht belegt durch histologische Untersuchungen. In einigen Füllen bot der Kuorpel das Bild eines in Degeneration begriffenen Gewebes.

Das erbliche Vorkommen der Hüftverrenkung wird von Maissiat, Dupuytren, Bouvier, Ferneuil, Statfeldt, Krönlein, Schreger, Camper, Marjolin, Volkmann, Lorenz durch viele Fülle belegt.

Als Effekt einer hereditären Tuberkulose hat Pfender die kongenitale Luxation hingestellt.

Heusner hält mit Paletta die angeborene Hüftluxation für eir Vitium primae formationia, $d$. h. die Bildung einer zu flachen Pfanne und eines zu schlaffen Gelenkes in der Zeit, wo die grossen Gelenke sich bilden, d. h. im III. Fötalmonat. Noch während des Fötallebens oder späteztens bei den ersten Gebversuchen kamn in einem solchen Falle der Schenkelkopf die Pfanne verlassen. Bei 26 Föten faud $\mathrm{Heus}$ er die Hüftgelenke der weiblichen durchgehends schlaffer und verschieblicher als die der mäunlichen, woraus sich das Cberwiegen der Defornität beim reiblichen Geschlecht erklärt.

Auch Adams spricht sich gegen die trammatische Entstehung der Iuxation wäbrend der Geburt aus auf Grund einer Beobachtungsserie von t5 Fällen mit notierten Geburtsrerlauf.

Lorenz prüfte an den Hüften Neugeborener die Luxationsfähigkeit, indem er das Becken mit der einen und die Diaphyse des Oberschenkels mit der anderen Hand fasste und den Schenkelkopf unter Adduktion mit allmählich gesteigerter Kraft nach hinten oben presste. Eine Luxation kam nicht zustande. Gerade durch den Bau des Gelenks, durch das vollstünlig knorpelige und im höchsten Crade elastische Gebäuse ist die Immunität des Gelenkes gegenüber der traumatischen Luxation bedingt.

Lorenz betont jedocb, dass man den fötalen Zwangshaltungen des Hüftgrelenkes eine grosse Bedeutung für das Zustandekonmen der Luxation zuerkennen müsse. Nach seiner Ansicht kann es sich ätiologisch nur um zwei Theorien handeln, die von der originären Entwickelungsbemmung der Pfanne oder des Kopfes orler die der primären Luxation durch intrauterine Zwangshaltungen der Oberschenkel.

Lorenz präzisiert dann weiter seinen Standpunkt dabin, las der primären intrauterinen oder frühzeitigen postpartualen, durch mechanische Einflüsse bewirkten und durch rlie knorpelige Bescbaffenheit und Widerstandstähigkeit des plastischen (rachitischen) hinteren Pfannenrandes bearünstigten, allmäblich zustande kommenden Subluxation des Schenkelkopfes, welche durch die spätere Belastung oder durch Muskelwirkung sehr rasch zu eintr vollständigen Verrenkung wird, in der Ätiologie der kongenitalen Luxationen neben der originären Hemmungsbildung ler Pfanne eine grössere Bedeutung beizulegen sein wird, als es bisher geschehen ist.

Hirsch hält die Annahme, dass die kongeniale Luxation eine originäre Hemmungsbildung sei, für unvereinbar mit den Erfolgen der Lorenz'schen Therapie. Fr hält sie wie Dupuytren, Roser, Lorenz für eine intrauterine Belastungsdeformitüt. Bei fullendem Fruchtwasser und bei dauender extremer Flexionsstellung der Oberschenkel sei das Längenwachstum diejenige $\mathrm{Kraft}$, welche den Femurkopf allmählich äber den hinteren unteren Pfinnenrand hinausdränge. Dit abweichende Form des fötalen weiblichen Beckens erklärt das Prävalieren des weiblichen Geschlechtes. Die Erblichkeit der Deformitait erklärt sich durch Vererbung des Fruchtwassermangels.

Gegenüber Als berg betont $\mathrm{Hirsch}$ unter anderm, dass infolge der geringen Beckenneigung des Fötus ler später hinten liegende Teil des Pfannenrandes mehr nach unten sehe und dass der luxierte Schenkelkopf durch Mruskelkräfte sekundär nach oben gezogen würde. 
Einen anderen Standpunkt nimmt Lannelongue eiu. Er ist der Ansicht, dass die kongentiale Luxation eine Erkrankung des Zentralnervensystems sei. Belegen will er dies durch einen Sektionsbefund, welcher eine reichlich ditumendicke Verbreiterung der Cervicobrachial-Anschwellung des Rückenmarks ergab. Die Nervenfasern waren hier etwas zarter, die graue Substanz der Vorder- und Hinterhörner wohl erhalten.

Schanz tritt für die mechanische Theorie der Entstehung der Hüftverrenkung ein. Der Druck des tterus bei geringen Fruchtwasser und bei flektierten und abduzierten und nach innen rotierten Bein soll eine Dehnung der Hüftgelenkkapsel und allmählich eine Luxation verursachea. Er beobachtete abnorme Schlaffheit der Gelenke und Rinnen von der Schulter zum unteren Sternum verlaufend, verursacht durch die im Uterus gegen den Thorax gepressten Arme, ebenfalls eine Folge des Fruchtwassermangels.

Für die mechanizche Theorie im Sinne Lorenz spricht sich Drehmann aus, er kouzediert jedloch nicht allen Luxationen diese Erklärung.

Codivilla meint, dass bei der Geburt selber eine ausgebildete Luxation vorliege, auch keine unvollständige, man könne nur von Disposition zur Luxation sprechen. Disposition sei gegeben durch Formveränderung der Pfanne und des Femur. Die Pfanne sei platt und steil, das obere Femurende nach a us sen gedreht, so dass der Schenkelhals gegen die Sagitalebene grelagert. Die Ursache dieser Formveränderung sei ein in intrauterinen Leben ausgeübter vermehrter Druck. Bei nornaler Lagerung des Fötus bringe ein Druck auf die Knie vermehrle Flexion und Adduktion und Rotation nach innen. Dies bewirke eine besondere Form der Pfanne und eine Torsion des unteren Fenurendes nach innen, das obere Fenurende erscheine damn nach aussen gedreht. Die Torsion des Femurendes wäre also angeboren und bilde die Hauptursache der nach der Geburt stattfindenden Luxation.

Die Frage „Kann die Röntgenphotographie Aufschluss geben über die Ätiologie der angeborenen Hüftrerrenkung?" sucht Bade zu beantworten. 56 Föten wurden durchleuchtet, Veränderungen, welche für die Luxation und für die $\mathrm{U}_{r}$ sachen der Luxation bei Föten sprechen. wurden nicht gefunden. Ferner wurden 150 Kinder durchleuchtet, wovon 206 Gelenke krank, 94 normal waren.

94 Fälle einseitiger Luxation ergaben $25 \mathrm{mal}$ Veränderung der gesunden Seite, wie wir solche bei angeborenen Hüftluxationen finden. Schlussfolgerung: Es gehen am Hüftgelenk primär schon in trübester Zeit Erkrankungen unbekannter Ursachen vor sich, welche zu den entsprechenden Veränderungen führen.

Auf Grund ron 76 Fällen berichtet Codivilla über die Ätiologie der kongenitalen Luxation. Er hält es für ausser Zweifel stehend, dass die Kinder mit der $\mathrm{D}$ isposition geboren werden und nicht nit ausgebildeter Luxation.

Die forzierte Stellung, die der Femur durch vermehrten Druck einnimmt, führt zu Veränderungen am Femur und Pfanne. Gehen und Stehen steigert die Verschiebung, aus Luxatio supracotyloidea wird Luxatio iliaca. Eine ganze Rolle spielt beim Vers. die Verwachsung der Kapsel mit dem Periost des Darmbeines, wodurch eine Retention nach erfolgter Reposition verhindert wird.

Bender beobacbtet ein drei Wochen altes Mädchen mit linker Luxation, welche er als intrauterine Belastungsdeformität deutet. Vorhanden waren geringe Mengen Fruchtwasser. Nach häufigem Heben ron Lasten hatte die Frau das Gefühl bekommen, wie wenn das Kind zwisehen Kreuzbein und Genitalöffnung eingeklemmt sei. Bender hält die Ursachen für verschieden. Nur auf Bildungsbemmung die Luxition zurückzuführen, bült er nicht für richtig.

Die Beobachtungen ron Dupuytren erstrecken sich auf nur 20 Fälle in 18 Jahren; er hält die doppelseitige Luxation für bäufiger. Letzterer Ansicht ist auch von $A \mathrm{mmon}$. 
Nach Carnochan (1845) war die kongenitale Luxation in Amerika zu dieser Zeit kaum bekannt.

Adams beobachtete dann in 25 .Jabren 60 Fälle, mit 47 weiblichen und 13 mïnnlichen Luxationen.

In der Statistik von $\mathrm{K}$ rönlein nehmen unter den angeborenen Luxationen die der Hüfte den ersten Platz ein. Cinter 90 kongenitalen Luxationen der Hüfte gab es 5 kongenitale des Humerus, 2 des Capitulum radii und 1 des Kniegelenkes.

Weitere Statistik entnehmen wir Pravaz d. .J., welcher ron 1863-1878 107 Fälle sammelte, davon waren 11 männlich und 96 weiblich, 27 links, 27 rechts und 51 doppelseitig.

Drehmann hat von 1865-1880 77 Fälle notiert, 10 männlich, 67 weiblich, links und rechts je 24 und 29 doppelseitig.

Krönlein's Statistik von $1875-1850$ beläuft sich auf 90 Fälle, $1 \pm$ männlich und 76 weiblich, links 32 , rechts 22 und 31 doppelseitig.

Diese 3 Statistiken ergeben eine Summe von 274 Fällen mit $87,6^{\circ} 0$ weiblicher und nur 12,4\% männlicher Beteiligung. Die einseitige Luxation beträgt $60^{\prime \prime} \%$, die doppelseitige $40^{\circ} \%$. Rechte und linke Seite ergeben keine Differenz.

Dop p fand unter 23 Ped. eq. var. einen Fall von Luxation der Hüfte, ebenso Hof of a unter 25 angeborenen Khumpfüssen.

Die grösste Statistik liefert uns Lorenz, von $188 t-1894$ mit 253 Fällen, 30 männlicbe und 223 weibliche. Von den männlichen waren 16 einseitig $(9$ links, 9 rechts) und 12 doppelseitig. Von den weiblichen waren 158 einseitig ( 91 links, 67 rechts) und 65 doppelseitig. In deinselben Zeitraum von 10 Jahren konnte L orenz nur 77 angeborene Klumpfüsse notieren, ein Verhältnis, welches gegenüber den kongenitalen Luxationen wesentlich durch den starken Zug:ang bedingt war, indem er in den beiden letzten Jahren 158 Fälle verzeichnen konnte.

Hoffa beobachtete von 1887-1893 62 Fälle, 8 mäunlich, 54 weiblich, 22 links, 1+ rechts, 26 doppelseitig.

Die Fälle von Kirmiss on betragen 82 , dayon 9 männlich und 73 weiblich.

Nach L orenz, welcher die Statistiken summiert, ergibt sich folgendes Resultat: Auf 671 kongenitale Luxationen der Hüfte kommen

8.2 $(12,2 \%)$ männliche und

$589(87,8 \% 0)$ weibliche, ist $7 \mathrm{mal}$ häufigere Belastung. hänfig.

Auf 245 doppelseitige kommen $\$ 21$ einseitige, letztere daher fast doppelt so

225 links, 196 rechts - links somit häufiger als rechts.

\section{Pathologische Anatomie und Symptomatologie.}

\section{Pathologische Anatomie.}

Die Erfahrungen über die pathologische Anatomie setzen sich zusammen aus den Sektions- und Operationsbefunden. Letztere haben rerade in dieses dunkle Kapitel grössere Klarheit gebracht. Pa $\mathrm{c}$ i sowohl, als auch besonders $\mathrm{FI}$ of $\mathrm{f}$ a und Lorenz u. a. geben uns auf Grund des reichen Operationsmaterials eingehenden Bericht über die anatomischen Verbältnisse.

Knöcherne Prominenzen in der Pfanne beschreibt Paletta (1820). Fr fand das Iig. teres rom horizontalen Schambeinast ausgrehend und zum Schenkelhals verlautend. Fernerhin beobachtete er bereits die pathologische Richtungsrerïnderung des Schenkelhalses.

Moreau und Dupuytren machten ähnliche Beobachtungen; bei einem 74 jäbrigen Mann fand man die Pfanne gross und wohlgeformt, im Durchmesser über 1 Zoll gross. 
Tortual (1831) beschreibt eine angeborene Luxation nach unten innen bei 7 monatlichem, nit zahlreichen Missbildungen behafteten Fötus.

Eine Ausüllung der Pfanne mit Knochenmassen wurde von Cruveilhier (1849) beschrieben, er konnte ïber ein das 3-4 fache der Norm betrargendes Ligamentum teres berichten. Weiterhin beschreibt derselbe Autor die verlassene Hüftpfanne bei einem 18 jährigen Mädchen als gleichscbenkeliges Drejeck, deren Höhle Fett enthielt und so gross war, dass sie $2 ; 3$ des Schenkelkopfes hätto aufnehmen können.

Carnochan (1850) beschreibt einen Fall mit völligem Mangel von Schenkelkopf und Schenkelhals auf beiden Seiten.

Gurlt (1853) berichtet ebenfalls über die Deformität des Kopfes, dessen Aussehen unförmlich und äusserlich von einer dünmen brüchigen Knochenschale bederkt, mit darunter befindlichem schwammigem Knochengewebe. Der Knorpelüberzug war nur in geringer Ausdehnung vorhanden.

M algaigne (1853) erblickt eine unverbescerliche traache der Beinverkürzung in der Senkung des Kopfes, welche clurch eine Neigung des Kopfes hervorgerufen.

Werner (1858) beschreibt einen beiderseitigen Mangel von Kopf und Pfanne bei einem $\&$ Tage alten Kind.

Bonmarige (1867) konstatierte bei einem von einer 75 juhrigen Frau herrührenden Präparat das vollständige Fehlen der Schenkelböpfe, nur kleine unregelmässige Stümpfe waren von den Schenkelhälsen vorhanden. Ad ams.

Uther ein stark gedehntes Ligament bei einem 18 jährigen Wädchen berichtet

Vollkommen normale Verhältnisse am kongenital luxierten Kopt bei einer 48 jubrigen Frau fand Schreger. statieren

Hutten konnte ein 4 Zoll langes Band von Dicke der Achillessehne kon-

Tillmanns (1873) fand bei einem Präparat (1/2 jähriges Mädchen) den Schenkelhuls sehr verkürzt, fast in vollständig direkter Fortsetzung des Femurschaftes verlaufend, und mit diesem einen bedeutend grösseren Winkel als normal bildend. Ebenso erwähnt Tillmanns das grosse Volumen des Jig. teres.

Die Richtungsveränderung, die pathologische Anteversion des Schenkelhalses wurde von $\mathrm{H}$ utten, von Ammon (1842), Sandifort beobachtet.

Bennett hat 1885 durch die Sektion die schlauchförmige Erweiterung der Gelenkkapsel nachgewiesen, ferner las bandartig ausgezogene Lig. teres. Yon fötaler Gelenkerkrankung war keine Spur vorhanden. Es bestand kein Defekt in der triradialen Anordnung der Knochen des Acetabulum. Das Ossifikationszentrum in der Schenkelbalsepiphyse war dem Alter des Kindes entsprechend.

Ridlon (1889) beobachtete eine kongenitale Luxation, wo der Kopf dem Schambein auflag.

Phelps (1891) beschreibt ebenfals zwei Fïlle mit der Luxation nach yorwärts und aufwärts.

Santou (1893) hebt hervor, dass das Becken an dem Pfannengrunde am dünnsten ist und dass es somit unzweckmässig ist, die künstliche Pfanne am normalen Pfannenort zu bilien.

$\mathrm{Pa}$ ci berichtet (1894) über zahIreiche Exostosen in der Pfanne der kongenital luxierten Hüftgelenke.

In der Ira der blutigen Reposition wurde zuerst von Schede, dann ron Hoffa und Lorenz auf diese pathologischen Veränderungen hingewiesen.

Eine eingehende Darstellung über die pathologisch-anatomischen Verhältnisse der Hüfte rerdanken wir Lorenz (1895) auf Grund seines Materiales von blutig operierten Hüftgelenken. Es bezieht sich die Darstellung auf Pfanne, Schenkel- 
kopf und Schenkelbals, dann auf das Ligamentum teres und die Gelenktapsel, und endlich auf die Mushulatur.

Die Pfanne ist stets mdimentär und selten fehlend. Die Fläche des Pfannenorts bleibt erhalten, die Rinder zeigen eine mehr oder weniger deutliche Differenzierung, so dass man nicht zweifelhaft sein kann, wo die künstliche Pfanne angelegt werden muss. Am Pfannenort findet sich im I. Dezennium ein die Kuppe der Fingerbeere aufnehmendes Grübchen. Die Knorpellage ist mächtig; es sieht aus, als ob die normale Pfannenhöhle bis oben mit Knorpelmasse vollgelaufen sei. Die Dicke der Pfannenwand an Pfannenorte imponiert jedesmal ron neuem.

Am Schenkelkopf, dessen Veränlerungen für den Erfolg von grosser Bedeutung sind, beobachtete Lorenz Atrophie, Deformierung, Abplattung des Kopfes (Pufferkopf). Auffallend ist die Kleinheit des Kopfes, sowie dio Gestaltsverinderungen desselben. Letztere ist bedingt durch den Kontakt des Kopfes mit der ausseren Darmbeinflïche, die nelioposteriore Rundung des Caput femoris erfährt eine Abplattung. Der Kopf kann hochgradig deformieren. so fand I, orenz eine Entartung, welche er Pufferkopf nennt.

Die Uberknorpelung bleibt in der Regel ziemlich normal. Die Abplattung des Kopfes kann so hochgradior verden, dass die normale Konfiguration fast verschwunclen ist.

Der Schenkelhals erscheint stets auffallend verkürzt, Die Neigung weicht meist nicht von der Norm ab. Vou praktischer Bedeutung ist die Richtungsabweichung des Schenkelhalses, die nicht allzu selten vorkommende pathologisch verstärkte Anteversion.

Lorenz fand bei seinen Operationen, dass die Anteversion des Kopfes eher auf die starke medioposteriore Abplattung des Kopfes zurückzuführen war, als auf eine starke Vorndrehung des Schenkelhalses, beide legen der operativen Reposition gleiche Schwierigkeiten in den Weg.

Das Ligamentum teres ist ursprünglicb normal, erfährt aber mit Fort entwickelung der Luxation Veränderungen und geht vom 5. Lebensjahre an zu Grunde.

Lorenz führt auf Grund seiner Statistik den Nachweis, dass das runde Band schon im 3. Jabre ebensooft fehlt, als es noch vorhanden ist, schon vom 4. Jahre $a b$ ist die Destruktion Regel. Bei doppelseitiger Luxation scheint das Band noch früher zugrunile zu gehen.

Die Hypertrophie des Bandes steht zweifellos fest, dasselbe wirkt mit Muskel und Kapsel als Tragband. Den gesteigerten Forderungen hält es jedoch nicht stand. Es erleidet mit der fortschreitenden Dislokation des Kopfes eine Verlängerung, Dehnung und Zerrung seiner Fasern, dazu kommt noch die fortwährende Reibung gegen den Steg des hinteren Pfannenwalls. Unter dem Einfluss dieser Belastung kommt das Ligamentum teres allmählich zur vollständigen Auflösung.

An der Gelenkkapsel finden sich nicht unwesentliche Veränderungen. Die Kapsel ist zu einem Schlauch ausgezogen, dessen Länge nach dem Grade der Dislokition des Kopfes variert, dessen Kichtung gerade der Norm entgegengesetzt, nach hinten oben aufsteigt. Bei alteren Kindern hat die Kapsel eine sebnenartige Beschaffeuheit. Der synoviale Überzug, sowie die synoviale Flüssigkeit zeigt keine Veränderung. Unvollständige Luxationen hat Lorenz nie beobachtet.

Der Schenkelkopf überschreitet in der Regel den Pfannenrand in der Richtung nach hinten und oben. Es wird eine neue Pfanne gebildet, welche fibrōs und nicht knöchern ist und als Kopfkappe die verdickte Kapsel trägt. Der knöcherne Teil dieser neuen Pfanne ist nur eine seichte Vertiefung des Darmbeines.

Das Verhalten der Muskulatur ist vielfach gekennzeichnet durch die nutritive Verkürzung. Die Muskelverkürzung ist das wichtigste Hindernis für die Reduktion. 
Die dem Oberschenkel parailel laufenden Muskeln erfahren eine Verkürzung entsprechend der Verschiebungsgrösse des Kopfes. Die anderen Muskeln erfahren eine Verlängerung. Die pelvitrochanteren sind verlängert, die pelFikruralen verkürzt, die pelvifemoralen meist verlängert.

Lorenz sieht in der Verkürzung der pelvikruralen Muskeln das einzig in Betracht kommende Hindernis der Reduktion des dislocierten Kopfes. Die Eynährungsstörung der Muskulatur beziebt sich rorwiegend auf die Glutealmuskulatur, besonders bei ältern Individuen.

Wie Köliker und Hoffa nachgewiesen, ist nach Schanz (1897) die Iux. cox. cong. meist eine supracotyloide. Die mechanische Theorie spricht nicht dagegen. Im intrnuteriuen Leben bildet sich zunächst die Lux. iliaco infolge der Beuge- und Rotationsstellung, erst durch Strecksstellung bildet sich die Lux. supracotyloide.

Kirmisson (1894) hat bei 2 Föten die Lux. cong. coxae beschrieben. Weiterhin verfügt er über 82 Fäle und zwar 73 Mädchen und 9 Knaben. Davon waren 51 einseitig und 31 doppelseitig. $\mathrm{Kirm}$ is s o n beobachtete Verkurzung mit zunebmendem Alter, ein Berveis, lass die Belastung eine grosse Rolle spielt. Es bestand bei 28 Kindern, $1^{1 / 3}-4 \mathrm{Jahr}$, eine Verkürzung ron $1-1^{1 / 2} \mathrm{~cm} .3 \mathrm{mal}$ war $2 \mathrm{~cm}$ und 1 mal $5 \mathrm{~cm}$ Verkürzung zu konstatieren. Bei $18 \mathrm{Kindern,} 4$ bis 10 Jahre, bestand $3 \mathrm{mal} 1-1 \frac{1}{2} \mathrm{~cm}, 4 \mathrm{mal} 2 \mathrm{~cm}, 9 \mathrm{mal} 2-3 \mathrm{~cm}, 1 \mathrm{mal} 4 \mathrm{~cm}$, $1 \mathrm{mal} 6 \mathrm{~cm}$ Verkürzung.

Bei Kinderu über 10 Jahren war $1 \mathrm{mal} 3 \mathrm{~cm}, 2 \mathrm{mal} 4 \mathrm{~cm}$, $1 \mathrm{mal} 6 \mathrm{~cm}$ $1 \mathrm{mal} 10 \mathrm{~cm}, 1 \mathrm{mal} 12 \mathrm{~cm}$ Verkürzung nachzuweisen.

Unter 31 Fällen fand sich $11 \mathrm{mal}$ ein verschiedenes Längenmase der Beine, Verkürzung von $1-2$ und $3-4 \mathrm{~cm}$.

Halsted (1894) hat 113 Fälle beobachtet und kommt zu folgenden Schlüssen: Etwa 31\% werden, besonders in der rascheren Wachstumsperiode, nach Cberanstrengungen von Schmerzen befallen, die unter Bettruhe rasch verschwinden, aber mejst stiiktere Verbüzungen zur Folge haben.

Wiach $\mathrm{H}$ alsted ist die Verkürzung als Regel eine mit den Alter zunchmencle,

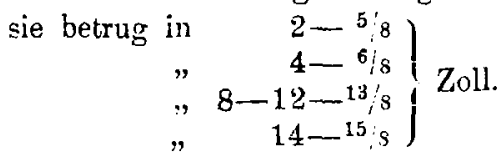

Der Grad des Hinkens ist nicht stets gleich, er kann bei starken Verkürzungen gering sein und umgekehrt. Alle mit zeitweiser Extension und Gehapparat behandelten Patienten werden später rückfällig.

In einer sorgfältigen Arbeit erläntert Guelain (1896) die Verïnderungen der äusseren Körperform bei einseitiger und doppelseitiger angeborener Verenkung, über den normalen und pathologischen Gang, sowie über die sekundären Formveränderungen des Beckens.

Lorenz (1894) betont $\mathbf{K} \ddot{o} \mathbf{n} \mathbf{i g}$ gegenüber, dass man bei blutiger Operation häufig die Pfanne sehr gut ausgebildet gefunden hat. Lorenz verfügt über 6 Fälle, wo nach Ablauf eines Jahres die Heilung vollendet war.

H in sberg (1899) beschreibt das Präparat einer 70jährigen Frau entnommenen doppelseitigen Lux. cong.

Ducroquet (1898) demonstriert nach den Röntgenbilde die anatomischen Verhältnisse bei kong. Luxation.

Rager (1901) hat die Luxationsbecken des Wiener pathologischen Institutes durchmustert und will eine Kombination von Coxa vara der einen und Subluxation der anderen Seite gefunden haben. 
Hildebrand (1900) hat den Beweis geliefert, dass die bisherige Darstellung des Röntgenbildes nur ein Totbehelf, dass die Stereoskop-Bilder eine deutliche Übersicht der kleinsten Details geben.

Lepage und Grosse (1901) fand bei einem Kind (Steingelurt), welches nach 14 Tagen starb, die Lux. congenit. dextr. zugleich mit einer Anzahl ron Deformitäten, Gaumenspalte, Kryptonbismus und Pes. eq. var. dextr.

Obduktion: 1. Knorpel normal,

2. Pfanne wenig tief und atrophisch,

3. Erweiterung der Gelenkkapsel,

4. 7wergsackform,

j. Lig. teres, r. $10: 6 \mathrm{~cm}$ links,

6. Gelenkliopf war nur angedeutet.

Heusner (1902) hat unter einer grösseren Anzahl von Föten 2 mal Iux. cong. konstatiert. Pravaz, Paci irerden besonders gewürdigt. Zathlreiche sehr instruktive Abbildungen beziehen sich auf die pathologische Anatomie.

10 ausgezeichnete Röntgenbilder, die typischen Formen der kongenitalen I axation wiedergebend, finden wir in dem Atlas von Hildebrand, Sebolz und Wieting (1902).

Joachinsthal studierte 5 anatomiscbe Präparate unbehandelter Luxation, wie solche sich im späteren Alter ausbilden an: Pfanne, Kopf, Schenkelhals, hapsel.

1. Pfanne, kleiner und flacher als normal, häufig rertief, wallartiger Vörsprung an unteren Rand, mit Protuberanzen im Pfannengrund.

2. Der Kopf steht in einer am oberen hinteren Plannenrand gelegenen Vertiefung, weit grösser als der Kopf.

3. Der Kopf ist athropisch, bis zum völligen Schwund.

4. Verbiegung des Schenkelhalses im Sinne der Coxa rara.

5. Taschenförmige Erweiterung der Kapsel.

Ludloff (1902) hat an 25 fötalen Leichen eine auffallende Disposition zur Oberschenkelverrenkung gefunden, bedingt dureh

1. Flachbeit der Pfanne,

2. Missverhältnis zwischen Kopf und Pfanne,

3. Mangelbafte Festigkeit der Kapsel.

M ülle r (1903) konnte an 2 Fällen die anatomischen Veränderungen studieren:

1. Bei einem Mädchen, 4 Jalıre, ergab die anatomische Untersuchung normale Verhältnisse, 2 Jabre post., repos.

2. Bei Mädchen, $2^{1} 2$ Jahre - Tod 6 Wochen post op. an Pneumonie ergab Schrumpfung der Kapsel und Lmgestaltung des Pfannenbodens.

Walther Lange (1902) hat an der Hand zahlreicher skiagraphischer Untersuchungen den Wahrscheinlichkeitsbeweis geliefert, dass beim Neugeborenen mit Luxatio coxae der Kopf noch Berührung mit der Pfanne hat und erst später durch die Belastung beim Gehen nach oben entsteht. Infolgedessen muss es Aufgabe sein, den bei der Geburt bestehenden günstigen Zustand zu erbalten. Lange İisst in diesen Fällen Beckenring tragen.

Durch die Sektion einer 50 jährigen Frau mit kongenitaler Luxation konstatierte Cambet (1903) Unregelmässigkeit der Kopfkonfiguration, sowie solche der Pfønne, welche sehr rudimentär und 1 Frankstück gross war.

\section{Symptome.}

Dupuytren, Malgaigne, Pravaz machen auf die Schaukelbewegungen aufmerksam. Ersterer gibt schon eine genaue Beschreibung des Ganges, sowie der Eigentūmlichkeiten beim Springen und beim Laufen. Malgaigne betont, dass die Spitze des Schenkels sich in die Weiche zu versenken scheine. 
Lorenz liefert eine ausfübrliche Beschreibung des ganzen Symptomenkomplexes, sowohl bei einseitiger als bei doppelseitiger Verrenkung. Es handelt sich um die äussere Form der Hüftgelenksgegend, dann um den Einfluss der Lageveränderung der Gelenkkörper zu einander auf die Gestaltung des ganzen Rumpfes, endlich um die Funktion des pathologischen Gelenkes.

\section{a) Symptome bei einseitiger Juxation.}

Die charakteristisch konturierte Gesässhälfte ist auf der kranken Seite verstrichen, abgeflacht, nicht prall, sondern schlapp. Die Trochanterendistanz von der Crista ilei ist auf der kranken Seite geringer. Der Trochanter ist manchmal auffallend prominent. Der Stand der Glutealfalte ist bald tief, bald gleich hoch, bald böher, derselbe wird inmer im Zusammenhalt mit der Art und Weise betrachtet werden müssen, in welcher die vorhandene Verkürzung von Patienten verarbeitet wird.

Das Becken bängt über, es besteht eine Beckenneigung, dementsprechend eine Verstärkung der Lendenlordose.

Die Beinrerkürzung bedingt eine, jedoch nicht konstante, statische Skoliose, deren Lendenkonvexität nach der Seite des luxierten Beines gerichtet ist. Die seitlichen Ausschläge der Wirbelsäule sind in ihren Exkursionen beträchtlich gesteigert. Die statischen Verhältnisse beim Gehen und nicht die beim Stehen sind für die Richtung der Skoliose massgebend. Es entsteht bei der einseitigen Hüftluxation prinär eine lumbale oder dorsolumbale, kontralateral konvexe Skoliose. Letztere erreichen meist keinen hohen Grad, es sei denn bei vorhandener Disposition (Rachitis).

Der Oberschenkel zeigt Atrophie bis zu $2 \mathrm{~cm}$ und mehr, bedingt durch den eingeschränkten Gebrauch des Beines.

Verkürzung ist durch die Luxation bedingt, zuweilen bei jungen Kindern in horizontaler Lage of vollkommen ausgeglichen.

Die Beweglichleit ist vergrössert, da ein Schlottergelenk gewissermassen vorhanden ist. Besonders vermehrt ist die Adduktion, welche fast bis zu einem rechten Winkel zur Körperachse zu bringen ist, ferner lüsst sich die Exkursion in Hyperextension überführen.

Rotation mach innen and aussen ist vermebrt. Die Flexion ist nicht vergrössert, bei älteren Patienten sogar eingeschränkt, die Abduktion ist um wenigstens $1 / 3$ herabgesetzt.

Schmerzen im Gelenk bestehen nicht. Jedoch treten nach Uberanstrengung, nach kürzerem oder lüngerem Gehen leicht Ermüdung, auch Schmerz ein.

Das Hinken ist bei Einseitigen noch auffallender als bei Doppelseitigen. Mit Zunahme der Ermüdung nimmt das Hinken zu.

Mehr als jede Beschreibung wird sich dem aufmerksam Beobachtenden der Anblick des Luxationshinkens einprägen. Wer halbwegs Blick für die Dinge hat, wird die Dingnose stets auf Distanz machen können.

\section{b) Symptome bei doppelseitiger Laxation.}

Dupuytren, Pravaz, Malgaigne, Howard - Marsh liefern uns schon eingehende Schilderung des Krankheitsbildes. Eine genaue Beschreibung gibt uns Lorenz. Nach diesem Autor ist eine gleichmäszige Steilstellung des Beckens mit entsprechender Lordose vorhanden, welche das auffallende Herüberhängen des Unterleibes zur Folge hat.

Beide Hüftgelenke befinden sich in permanenter Beugelage, welche entweder durch die Lordose kompensiert wird, oder bei ungenügender Beweglichkeit der Wirbelsäule durch die Flexion der Kniegrelenke. Von hinten gesehen, zeigt das Gesüss eine ausgesprochene Verbreiterung. 
Skolinse kommt nicht häufig vor, ist dann nur die Folge von ungleichem Stand der Schenkelköpfe. Im Gegenteil, die perpendikelartigen Schwankungen der Wirbelsäule geben eine gewisse Immunität gegen Skoliose.

Die grosse Distanzierung les Kopfes von der Pfanne ist die Regel - im Gegensatz zu der einseitigen Luxation, wo dies selten ist - und bedingt durch die permanente gleichmässige Schwankung des Körpers.

Der Gang ist durch Hin- und Herschwanken des Rumpfes charakterisiert, watscheliger Fintengang.

Der sicherste Weg zur Erkenntnis ist das Röntgenbild sagt Bade (1902). Da dies nicht immer vorhanden, so muss der Arzt die Inspektion, Palpation, Mensuration beachten. Asymmetrie der Adduktorengibtein sicheres diagnostizches Merknal. Fine verschiedene Höhenlage der Aduluktorenfaiten ist pathognomisch für einseitige Luxation.

Cohn (1903) demonstriert einen Säurling ron 3 Monaten mit Lux. sin. Als Symptom bestand Flexion des Femur und Unterschenkels, so dass letzterer dem Fenur anlag.

Ein trocknes Knacken mit einer sprungartigen Bewegung des Kopfes im Hüftgelenk bei aktiver Extension und Flexion ist ein von Gerdy gefundenes Symptom zur Diagnose der Lux. congenitalis, auf welches Gu yot (1903) hin rreist. Letzterer betont, dass es im vierten Monat zu konstatieren ist, wohingegen es rerschwindet, sobald die Kinder gehen.

\section{Therapie und Resultate.}

Je nach der Art der Behandlung unterscheiden wir 3 Perioden;

1. die orthopädische,

2. die blutig chirurgische,

3 . die unblutig chirurgizche Periode.

Die orthopädische Therapie hatte es sich zur Aufgabe gemacht, durch die verschiedenartigsten Stützapparate das Leiden zu beseitigen. Als Erster, welcher einen Beckengürtel anwandte, ist $1783 \mathrm{Paletta}$ zu nennen. Der 1826 von D upuytren beschriebene Beckengürtel ist demselben ähnlich; derselbe bat den Zweck, durch Druck ein weiteres Hinaufgleiten der Schenkelköpfe auf die äussere Darmbeinfläche zu verhindern, und zugleich durch Anpressung der Bildung eines neuen Gelenkes förderlich zu sein.

So wurden von Parow, Heiue, Bouwier Stützapparate verordnet, von denen das Modell des letzteren noch durch Zusatz von Achselkrücken verbessert wurde.

Verdnc spricht sich über die zur Heilung unternommenen Redulitionstersucbe dahin aus, dass durch solche nur die Cnwissenheit des Wundarztes, der sie unternähme, bewiesen werde.

Roser empfahl auf dem Chirurgen-Kongress 1879 die Abduktionsverbände, Gipsstiefel mit auseinanderspreizendem Querbrett.

Einen einfachen Stützapparat hat $\mathrm{K}$ rausshold 1881 angegeben, ähnlich dem von Nélaton und Bouvier, welcher durch Druck auf den Trochanter verbessernd wirken sollte. Ein nach Gipsabguss angefertigter mit Trochanterpelotten ausgestatteter Beckengürtel trägt eine der Wirbelsäule entsprechend verlaufende Stange, welche an einer Querstange die Armstützen bält und so ein Heraufrutschen des Beckengurtes verhindern soll.

A ngot hat 1883 ebenfalls einen Beckengürtel konstruiert, welcher einen Druck auf den Trochanter ausüben soll.

Landerer legte (1885) in Suspension und extendierter Stellung ein abnebmbares Korsett aus Wasserglas und Schlemmkreide an. Besonders modelliert wurden die Trochanteren.

Lorenz wurde auch Anhänger des Korsetts. Letzteres, unter Suspension nach dem betreffenden Rumpfmodell präpariert, unter besonderer Ausprägung der 
Trochantervorsprünge, wird seitlich durch Stahlschienen mit gelochten Zelluloidplatten gestützt und nach vorn und hinten durch einen Schnüreinsatz erg:inzt. Je fester die Schnürung um das Becken, desto günstiger bommt die Wirkung zur Geltung.

Thilo berichtete 1888 über ein Korsett, welches in Gestalt von kreistörmig gebogenen Yetallrühren die Trochanterenstützen aufuimmt. Letztere finden Gegenstütze in der Axilla.

Ebenso macht Bratz (1888) nach dem unter Suspension bergestellteu Gips-

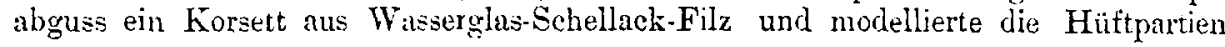
gut aus.

Auch $H$ offa hat in äholicher Weise mit Stützkorsetts eine Verbesserung erstrebt. Er verbindet dias vordere und hintere Ende der iliakalen Krücke eines gewöhnlicben Skoliosenkorsetts durch eine genau anliegende, horizontal verlaufende Schiene.

Die zielbewussten Versuche die kongenitale Luxation zur vollkommenen Restitutio ad integrun zu führen, sind ein Verdienst der französizchen Schule.

Humbert, Jaquier und Pravaz (1830) waren die Ersten, welche durch forcierte Extension in besonderen Streckbetten den Kopf in das Pfannenniveau zu bringen und durch Repositionsmanöver in die Pfanne einzurenben versuchten.

Pravaz der Ältere (1838), welcher nach Humbert mit einem etwas veränderten Verfahren die allgemeine Aufmerksankeit auf sich lenkte, betont, dass $\mathrm{Humbert}$ als erster die Möglichiseit einer Heilung der kongenitalen Luxation proklamiert habe.

Pravaz der Ältere (1838) hatte folgendes Verfahren eingetïhrt. Zuerst wurle 8-10 Monate eine Fxtensionsbehandlung vorgenommen. Unter Achselschlingen und Perinealgurt wurde an einem Hülsenzug des Obersehenkels mittelst Flaschenzug der Extensionsapparat in Bewegung gesetzr. Hatte der Kopf das Pfannenniveau erreicht, so wurde das Extensionsmanörer durch Abdulstion und Druck aluf den Trochanter ergüuzt. Pra $\mathbf{a}$ z erkannte die Einrenkung an einem sehr lehhaften Schmerz in der Hüfte und dem Unvermögen, den Schenkel zu flektieren, zowie an der Tatsache, dass der Kopf in einer vertieften Stelle am Becken festgestellt werden konnte, wobei der Vorsprung des Trochanters verschwand. Die flache Pfanne durch Bewegung des Kopfes auszuhöhlen, war ein besonderer Apparat konstruiert. Ein Karren, dessen Räder durch Hebel mil den Füssen unter Beugung und Streckung in Bewegung gesetzt wurden, während ein fester Beckengurt die Trochanter gegeneinander presste, leistete den Patienten gute Dienste, so dass nach 2 Jahren Gehübungen olhne Stütze aufgenommen wurden.

In Deutschland wurcle die Therapie der kongenitalen Luxation nur wenig gepflegt. Im Anschluss an das Verfahren Pravaz wurden Gehapparate vom Mechaniker $\mathrm{Hessing}$ in vollendeter Konstruktion ausgeführt. Ein Korsett, verbunden mit einem Schienenbülsenapparat, war so eingerichtet, dass das Bein reitend schwebte und zugleich in Extension gebalten wurde und seitlich durch Druck auf den Trochanter die Reduktion des Schenkelkopfes bewirken sollte.

Eine andere bereits von W. Roser inangurierte Therapie ist die Abduktionsbehandlung, welche besonders von Schede ausgebildet wurde. Zur dauernden Erhaltung der Abduktion verwendete $\mathrm{Sch}$ ede die ron ibm konstruierte Schiene. Er hat auf diese Weise Heilungen erreicht und konnte auf dem Chirurgen-Kongress 1894 ein 15 jühriges Mädchen geheilt vorstellen. Dasselbe, mit 11 Monaten in Behandlung gekommen, lag 3 Monate in Extension und wurde dann 1 Jahr mit der Abduktionsschiene behandelt. Unter 29 Fällen waren 8 Misserfolge. Die Schienenbehandlung dauerte $1^{1 / 2}-6$ Jahre.

Nach den Vorschlag von Hüter machte Margary 1885 bei einem 15 jährigen Mädchen die Eröffnung des Hüftgelenkes durch einen T-Schnitt, er meisselte die Gelenkpfanne auf, zwecks Aufnahme des halben Kopfes. Durch einen Periost- 
lappen konstruierte er die Gelenkkapsel. Der Erfolg war negatir, Exitus infolge von Pyämie.

Auf Grund dieser Misserfolge resezierte er dann die Femurköpfe 3 mal wegen einseitiger und $\$$ mal regen doppelseitiger Luxation.

Die Resektion der Hüften nach dem Vorgang von Margary machte Lam pugnani (1886), er bält die Pubertätszeit für die geeignetste.

Buckminster Brown (1886) bat einen Fall von doppelseitiger Luxation bei einem 4 jährigen Mädchen 1 Jahr in Bettruhe nach den verschiedensten Richtungen extendiert. Dann Gehversuche im Apparat machen lassen, welche ergaben, dass der Schenkelkopf sich nicht mehr verschob. $2^{1 / 2}$ Jahr nach Beginn der Behandlung war die Lordose verschwunden und die Trochanter in loco, der Gang normal.

Ebenso hat A dams (1887) bei einem 4 jährigen Mädchen mit doppelseitiger Luxation durch 13 Monate dauernde Lagerung eine Besserung erreicht, resp. die unangenehmen Folgezustände der Deformität beseitjgt.

Lampugnani beobachtete 1887, am Abschluss der Behandlung, ein deutliches Hinken bei einem resezierten 8 jährigen Mädchen. Er schlug daber vor, statt der Reseltion, die innere, untere Hälfte des Kopfes zu resezieren, zwecks Schonung der Epiphyse und Vermeidung der Verkürzung. Bei einem 20jährigen Patienten hat er diese Operation ausgeführt.

Eine Durchschneidung der an den Trochanter ansetzenden Muskulatur empfabl Guérin.

Teufels (1890) Arbeit bericbtete über die Resektion der Hüfte bei einem 14 jährigren Kinaben.

Im Jahre 1890 erstattete Rosenfeld Bericht über die in der Hoffaschen Privatklinik operierten Fälle. Es war in 27 Fällen die Reselstion ausgeführt, $17 \mathrm{mal}$ einseitig und $10 \mathrm{mal}$ doppelseitig. Von 16 einseitig Resezierten gingen 3 gut, 5 mittelmässig, 8 schlecht.

Heu $\_$ner, Israel haben auch nicht mit guten Erfolge reseziert.

Das Pfannendach durch Knochenperiostlappen zu bilden, hat König in Vorschlag gebracht. Von den Doppelresektionen gingen 3 schlecht, die anderen leidlich, eine rolle Heilung wurde nicht erreicht.

Auf Grund der schlechten Erfalırungen verwirft dann Hof $\mathrm{fa}$ die Resektion und proklamiert 1890 als Prinzip einer neuen Methode "Schonung des Skeletts auf Kosten der Weichteile“. Er beseitigt den Widerstand der Weichteile durch Langenbeckschnitt, Ablösung der Muskeln, Eröffnung der Kapsel. Alles wird mobil, so dass der Kopf leicht in Höhe der Pfanne gezogen werden kann. Bei Fehlen der Pfanne erfolgt Ausmeisselung derselben unter Herausdrängen des Kopfes und starker Adduktion. Bei starker Weichteilspannung ist Facia lata zu durchtremnen. So hat $\mathrm{H}$ of fa seinen ersten Fall operiert. Er hat jomal operiert und empfieblt die Operation für Kinder.

Lorenz schreibt in seiner Pathologie und Therapie der angeborenen Hüftverrenkung Alfonso Poggi das Verdienst zu, im Jahre 1888 als Erster die Methode $\mathrm{H}$ off a ausgeführt zu haben.

Diese Tatsache muss dahin berichtigt werden, dass nicht Poggi, sondern Riedel derjenige war, welcher im Jahre 1882 mit vollendetem Erfolge bei einem 5 jäbrigen Mädchen die flache Pfanne mit einem scharfen Löffel vertiefte und den Kopf reponierte. Riedel hat auf der Naturforscherversammlung zu Düsseldorf 1898 das mittlerweile 23 jährige Mädchen vorgestellt und den günstigen Enderfolg demonstriert.

An der Hand ron 3 Beobachtungen - 2 einseitige Luxationen, Mädchen $81 / 2$ Jahre, Knabe 6 Jahre - und eine doppelseitige, Mädchen 8 Jahre -, berichtet dann $\mathrm{P}_{\text {ai }}$ ci über seine Methode und deren Resultate. Unter Narkose macht Pac i starke Oberschenkelbeugung und erreicht ein Herabdrücken des Schenkel- 
kopfes nach unten, dann abduziert er und rotiext nach aussen und endlich extendiert er langsam progressiv, bis bei einseitiger Luxation beinahe gleiche Länge beider Extremitäten erreicht ist. Diese Janipulationen folgen innerhalb weniger Minuten. Zunächst ist 1-2 Monate fester Verband bei Bettruhe, dann monate. lang permanente Extension angezeigt, weiter, Gehen mit Krücken für einige Monate, und dann mit Stock. Resultate: In beiden einseitigen Fällen, mit Verkürzung von $5-41 / 2 \mathrm{~cm}$, war nach etwa $1 \mathrm{Jahr}$ die Differenz beseitigt. Alle drei Fälle zeigten gute Funktion und Fixierung des Oberschenkels an normaler Stelle.

Schüssler (1891) resezierte bei einem 14 jährigen Mädchen mit gutem Resultat, er tritt jedoch für die Schonung des Skeletts nach Hof fa ein.

Kirmisson (189l) hat 6 mal nach Hof $\mathrm{fa}$ operiert.

Resultate: 3 gute mit Beweglichkeit und gutem Gang, Verkürzung $1 \mathrm{~cm}$, 1 Todesfall nach Splitterbruch des Beckens, 1 schlechtes Resultat wegen Eiterung und Ankylose, 1 mittelmässiges Resultat, weil Kopf aus der Pfanne luxierte und 4 cm Verkürzungsresultate. Altersgrenze auf 7 . Jahr reduziert, Hoffa operiert bis 10 Jahren. Hoffa.

Denucé (1893) operierte ein 6jühriges Mädchen mit Erfolg blutig nach

Kirmisson (1894) schlägt bis zum 5. Jahre Immobilisation for, im 5. Jahre Operation nach Hoffa, später nach dem 7. bezw. 10 Jahre die Osteotomia subtrochanter ca. erdacht.

Phocas (1894) tritt für die Methode Paci's ein und hält sie für richtig

Nach Halsted (1895) werden alle mit zeitweiser Extension und Gehapparaten behandelten Fïlle spïter rückfällig. besteht

Weitere Mitteilung über seine Einsenkungsmethode macht Paci. Dieselbe

1. in der Beugung des Knie unl Oberschenkels gegen das Becken bis zur Grenze der physiologischen Müglichkeit. Die Gelenkmuskulatur wird dadurch gedehnt.

2. Langsame Abduktionsberwegungen des Knies. Wenn die Adduktoren geschrumpft sind, so dass Bewegung nicht möglich, ist die Methode nicht durchführbar und ist abzubrechen.

3. Rotation nach aussen unter Vermehrung der Abduktion bis der Unterschenkel senkrecht zur Sagittalebene des Körpers liegt.

4. Traktion am Bein, während der Unterschenkel gebeugt und aussen rotiert bleibt, solange bis alle Muskeln nachgeben und Korrektur erreicht ist.

In dieser Stellung wird 4 Monate unter Gipsverband mit 4-10 Kilo extendiert. Gipsrerbnnd wird uach 4 Wochen entfernt, es folgt dann nur Extension für 4 Monate.

Das Kind steht auf, mit Krücken gehend und mit der Weisung, den Fuss immer aussen gewendet zu halten. Nachts Extension, Elektrizität, Massage 2 mal täglich; dies damert 4 Monate.

Dann 8 Monate a) 4 Monate mit Stöcken, b) 4 Monate mit Korsett einhergehend. $\mathrm{Paci}$ hat 24 Falle behandelt.

Lorenz (1895) bespricht die operativen Methoden und erwäbnt, dass zuerst Magary ohne und dann Pozzi mit Erfolg operierten. Dann kam Hoffa, welcher die Operation weiter ausbildete.

In Gegensatz zu Hoffa schont er sämtliche Muskeln am oberen Femur. Unter 100 Operationen war kein Todesfall.

1. Nur einmal Wundstörung und Ankylose, dabei guter Gang.

2. $3 \mathrm{mal}$ geringe Beweglichkeit, Resultat wieder gut. 
3. 2 mal Reluration nach hinten.

$1 \mathrm{mal}$ Reluxation nach vorn.

4. Die anderen Fälle boten ein mit der Zeit immer günstiger werdendes Resultat dar.

Mikulicz (1895) ist kein prinzipieller Gegner der blutigen Operation, er will diese aber reserviert wissen für ganz schwere Fälle. $\mathrm{Er}$ hofft, dass die Indikation für die blutige Operation erheblich eingeschränkt werden könne, wenn man, wie auch Schede und Paci mit der unblutigen Methode völlig befriedigende Resultate erzielt hat.

Mikulicz bedient sich seit 3 Jahren eines unblutigen Terfahrens durch einen von ihm angegebenen sinnreichen und einfachen Apparat, wirkend durch Extension, Abduktion und Rotation nach aussen. Jahrelanges Liegen im Apparat ist nötig, zwiscbendurch stundenlanges Laufen im Filzmieder, Muskelübungen, Massage etc. Mikuliez hat unter 5 Fällen 3 volle Heilungen im Alter von $1 / 3-4^{1 / 2}$ Jahren.

Die Methode Hof fa's ergänzt Bradford 1894 dahin, dass er den Schnitt etwas nach vorn verlegt um das Lig. ileo femorale trennen zu können, dessen Anheftung in der Linia intertrochanterica er cöllig löst.

Dolega (189j) empfiehlt in Verbindung mit der Schede-Extension unter Abduktion eine Hessing-Hülsenextensions-Maschine mit gut sitzendem Zelluloidkorsett.

Gaudier (1895) macht ein künstliches Lig. teres, er durchbohrt den Kopf in seiner grossen Acbse. Der öfters stark wulstig verdickte vordere Pfannenrand wird modelliert und der $K$ opf durch eine Seidennaht fixiert.

Kölliker (1895) tritt für die orthopädische Behandlung der Hüftverrenkung nach Mikulicz ein, mit Aussen- oder Innenrotation. Zur Vornahme der Lorenzschen Operation stellt er folgende Bedingungen auf:

1. Schlechter Gang bei starker Verkürzung.

2. Schmerzen in Gelenk beim Gehen.

3. Geringe Abduktionsmöglichkeit.

4. Entzündliche Prozesse im Gelenk.

5. Kombination der durch einseitjge Hüftverrenkung verursachten statischen Skoliose mit rachitischer Skoliose.

Auf Grund ron 140 operativen Repositionen bespricht Lorenz (1895) die mechanische Therapie der angeborenen Hüftverrenkung. Unter Vergleich der Methode Pravaz, Schede, Paci, Mikulicz betont Lorenz, dass die Auturen die mechauische Reposition, das ist die Eintreibung des Kopfes in die Pfannentasche, noch nicht ins Auge gefasst hatten. Loren $z$ weisst darauf hin, dass die beiden Methoden $\mathrm{Pac}$ is und Mikulicz mit dem starken Aussenrotations-Manöver zwecks Eintreibung des Kopfes in die Pfanne unmogglich gewesen sind. Nach Lorenz ist das Eintreten des Kopfes nur durch Einwärtsrollen des Beines möorlich, nur dadurch kann ein stärkerer Druck auf den Pfannenort ausgeübt werden. Lorenz bält die Einrenkung Paci's nur für Transpositionen des Schenkelkopfes in die Näbe der Pfanne, ebenso die von Mikulicz. Durch die Auswärtsrollung des ausserbalb der Pfanne stebenden Kopfes wird die untere in eine vordere Luxation ungewandelt. In allen Fällen von Ausseurotation besteht Luxation nach vorn. Lorenz, welcher das Verdienst Mikulicz's, die mechaniche Bebandlung angeregt zu haben, hervorhebt, tritt für Einschränkung der operativen Behandlung ein, und gibt der mechanischen den Vorzug. Er macht für die mechauische Behandlung folgenden Plan, welcher die praktische Prüfung noch zu bestehen hat.

1. Herabholung des dislozierten Kopfes durch 8-14tägige Extension und starke Abduktion. 
2. Stellung des Beines in Innenrotation, so dass der Schenkelhals in der Frontalebene liegt.

3. Eintreibung des Schenkelkopfes in den Pfannenspalt - welches unmittelbar selten gelingt - erfolgt durch den medialwärts wirkenden direkten Druck an dem abduzierten leicht einwïrts gerollten Bein.

4. Das Bein wird in jener geringsten Abduktionslage, bei welcher der Kopf noch fixiert bleibt, festgestellt.

5. Unter strenger Wahrung der Einwärtsrollung wird die Abduktion etappenweise vermindert. Alsdann ist Gehen mit erhöhtem Schuh auf der gesunden Seite zu verordnen.

Für eine symptomatische orthopädische Behandlung der Fälle, welche weder blutig noch unblutig eingerenkt werden können, plädiert D olega (1895). Der orthopädische Apparat besteht in Korsett und Oberschenkelhülse.

Auf das Operationsverfahren von $\mathrm{H}$ of $\mathrm{f}$ a hinweisend, betont $\mathrm{He}$ e $\mathrm{n}$ e $\mathrm{r}$ (1895), lass er bereits 1884 auf der Naturforseherversammlung in Magdeburg eine Patientin nit dopp. Lux., welche er reseziert, rorstellte. Damals bat er darauf bingewiesen, dass da, wo beine Pfanne vorhanden, solche ohne Schwierigkeiten ausgemeisselt werden könne. Der operative Eingriff sei nicht ungefäbrlich.

Auf Grund seiner Beobachtungen - 2 Fälle - demonstriert $\mathrm{H}$ eus ner seine orthopälische Behandlung: Es ist dies ein Schienenhülsenapparat mit Korsett unter Verwendung der von ihn angegebenen Spiralfedern.

Hof fa (1895) hat unter 82 operierten Luxationen 7 Todesfälle, wovon 4 direkte Folge der Operation. In den letzten 47 Fällen trat kein Exitus ein, $\mathrm{H}$ of $\mathrm{f}$ a führt dies auf die Verbesserung der Methode zurück. Eine volle Restitutio au integrum hält $\mathrm{H}$ of fa für ausgeschlossen, auch bei bestgelungener Operation. Es ist dies bedingt durch die Coxa var. artefic.

Schenkelkopf und Pfanne lassen sich nie konsequent darstellen. Die normale Exkursion wird wenig erreicht, selten kommt sie über einen rechten Winkel hinaus.

In 9 Fällen (1 Vereiterung) trat volle Ankylose ein. In den letzten 00 Fällen wurde keine Ankylosenbildung mehr beobachtet. Nazchträgliches Steifwerden von ursprünglich beweglichen Gelenken hat $\mathrm{H}$ of $\mathrm{f}$ a nicht beobachtet, auch keine arthritischen Prozesse, nur 3 Fälle reluxierend aach hinten. Zweifellos vergrössern sich mit den Jahren Kopf und Pfanne gleichmässig. Das Bein bleibt nicht im Wachstum zuräck, Verkürzung wird sicher in Laute ler Zeit geringer.

Reluxationen nach rorn sind häufiger, 8 mal beobachtet. Sie geben ein recht gutes funktionelles Resultat.

Bei einseitiger Luxation ist das Hinken nicht völlig zu beseitigen, bei doppelseitiger wird die Lordose beseitigt und der watschelncle Gang auf ein Minimum reduziert.

Hof $f a$ schildert die Technik, Schonung der Muskeln. Die Pfanne muss breit und tief sein, eventuell Anwendung der Lorenzachen Schraube. Die Operation ist nach $\mathrm{Hoffas}$ fester Überzeugung die beste Heilmethode für die angeborenen Hüftluxationen. Geeignetses Alter ist 2-8 Jabre.

In Frankreich war Broca (1897) der Erste, welcher in Augūst 1891 die Luxation operativ behandeite. Bei starken Muskelretraktionen, besonders bei Kindern über 10 Jahren arbeitet Broca in 2 Sitzungen. In der ersten Sitzung werden die Muskeln offen durchscbnitten, in der zweiten Sitzung wird die neue Pfanne gemacht. 28 Gelenke hat Broca operiert, 4 mal erfolgre der Tod durch Septikämie.

Brodhurst (1896) berichtet über die Behandlung der kongenitalen Luxation in England. Zweeks Behanllung prüft Brodhurst die Pfanne mit einer Nadel, ob die Hohlform noch vorhanden ist, ist diese da, so versucht er die Reduktion des Kopfes.

(Schluss folgt). 
II.

\section{Verbände und portative Apparate.}

Sammelreferat über die im Jahre 1907 erschienenen, sowie die in Bd. $X$ der Zeitschr. fü diät. u. phys. Ther, and in Bd. XVIII der Hoffa'schen Zeitschrift referierten Arbeiten

ron

Dr. Wilheln Becker,

Spezialarzt für Orthopädio in Bremen.

\section{Verbände.}

\section{Allgemeiner Teil.}

1. Häberlin, Zur Behandlung granulierender.Wunden. Münch. med. Wochenschr. 190i, 42.

2. Meyer, Über die Behandlung frischer Wunden. Zentralbl. f. Chir $1907,33$.

3. Heine, Der Drahtzelluloidverband. Münch. med. Wochenschr. $1907,9$.

Häberlin bat granulierende Wunden mit bestem Erfolge mit gewöhnlichem Sonnenlicht, ohne irgendwelche Linsen, täglich in den Morgenstumden ron 9 bis 12 Uhr behandelt und rübmt die gute Austrocknung und schnelle Epidermisierung, die bei Anwendung seines Verfabrens eintrat.

Un den Nachteil des Mullverbandes, nümlich das Verkleben der Mullfäden mit Bindegewebs- und Nervenfasern, zu umgehen, bestreut Meyer frische Wunden mit sterilisiertem Zucker, dem 2\% Salizylsäure zugesetzt ist. Ein Vorteil sei die energische Austrocknung des Wundsekretes, die zugleich das sicherste Mittel gegen Infektion darstellt. Kontraindiziert ist die Zuckerbehandlung bei stark eiternden und stark blutenden Wunden.

Heine hebt die Verwendbarkeit angegipster Drahtbinden, wie sie von der Deutschen Drahtgipsbindenfabrik in München in jeder gewünschten Breite geliefert werden, zu den verschierlensten Verbandkombinationen hervor. Namentlich in Zelluloid-Azetonlösung eingetaucht sind sie zur Herstellung von Korsetts, Schienenhülsenapparaten und namentlich ron Plattusssohlen geeignet.

\section{Spezielle Indikationen.}

4. Finck, Gipshülsenverband zur Behandlung von Frakturen, besonders der des Oberschenkels. 36. Chir.-Kongr. 1907.

5. Riedl, Braucbuare Abänderung des Sayre'schen Schlüsselbeinbruehverbandes. Wiener kl. Wochenschr. 1907, 15.

6. Streissler, Das r. Hacker'sche Triangel für Oberarmbrüche. Bruns Beitr. 1907. Bu. 55.

7. Hammer, Behandlung von Fingerbrüchen. Zentralbl, f. Chir. 1907,40 .

8. Jottkowitz, dasselbe. Ibidem, 45 .

9. Ebner, Vereinfachung des Verbandes nach Operationer in der Achselhöhle. Wünch. med. Wochenschr. 1907, 38.

10. Karewsi, Zur Frage der Behandlung ron Rupturen des Quadriceps femoris. Deutscbe med. Wochenschr. 1907, 28.

1.1. Schmidt, Zur Behandlung der Ischias. Monatsschr. f. Unfallheilk. XIII, 6. 
Finc $\mathrm{k}$ legt bei Frakturen, z. B. des Oberschenkels, den Verband zunächst in zwei Teilen an: der zentrale geht ron der Bruchstelle - zur Mamilla, der periphere von ebendort - zu den Zeben. Auf diese Weise verwandelt er einen kürzeren peripheren oder zentralen Stumpf durch den starren Verband in einen langen Hebelarm, der eine hequeme und schonende Reposition - wenn nötig etappenweise - ermöglicht. Wie die beiden Verbandteile nun durch eine Mittelhülse verbunden werden und was alles dabei $z u$ beachten ist, muss im Original selber nachgelesen werden.

Riedl empfiehlt eine Kombination des Sayre'schen Clarikularverbandes mit der alten Stella thoracica. Die I. Tour ist die Sayre'sche Grundtour, dann folgt die Tour der Stella thoracica, die gleich der vorigen schraubenförmig am krankseitigen Oberarm beginnt, um dann über das distale Clavikularende schräg über die I. Tour nach abwärts zur anderen Achselhühle verläuft. Die II. 'Tour dient zur Fixienung der krankzeitigen Schulter und verlüuft über Oberarnkopf und Rücken nach der gesunden Seite hin.

Das r. Hacker'sche Triangel für Oberarmbrüche besteht aus einer Pappschiene von der Breite des gebrochewen Oberarms, die nach den von der gesunden Seite zu vehmenden 3 Maasen: Darmbeinkamm-Achsel, Achsel-Ellenbeuge, Fllenbeuge-Fingerspitzen zurecht gebogen und dann zunächst an den Tborax, dann an den gebrochenen Arm mit einer Flanellbinde fest anbandagiert wirl. Bei starker Verkürzung lässt sich ausserdem eine Extension anbringen.

Zur Behandlung von Fingerbrüchen empfiehlt $\mathrm{H}$ ammer die Anwendung von Schienchen und Heftpflasterstreifchen, während Jottkowitz einem Faustschlussverbande den Vorzug gibt, der üher einem in der Vola fixierten Watteballen bei gestrecktem Sagelgliede angelent wird.

Zur Erzielung freier Beweglichkeit im SchnItergelenk nach Operationen in der Achselhöhle hat Ebner statt der früheren Feststellung des Armes an die Thoraxwand den Verband durch einen über den Oberarm gezogenen Trikotzchlauch ausgeführt, der am Thorax durch Heftpflasterstreifen oder Bänder befestigrt wircl.

In einem Falle ron Quadricepsruptur, wo wegen des schlechten Allgemeinbefindens von einer Naht abgesehen werden musste, hat Karewski durch einen Heftpflaster-Zugrerband nit Gummizügen einen guten funktionellen Erfolg erzielt. Je 3 Heftpflasterstreiten umfassen gabeltörmig die rorderen bezw. seitlichen Partien des Ober- und Tnterschenkels; nachdem die Haut vorher durch Zug entsprechend genähert ist, rerlen sie in der Mitte durch 3 Gummizïge niteinander verbunden. Die Patella, über die der mittlere Gummizug binüberzicht, muss durch ein Polster ror Druck geschützt werden.

In Fällen ron hartnäckiger Ischins gelang es $\mathrm{Schmidt}$ eine röllige Heilung durch einen Streckverband herbeizuführen, der mit anfangs greringer Eleration des Beines verbunden wird. Allmählich wird das Bein immer hüher gelagert und die Belastung, die mit 2-4 Pfund beginnt, verstärkt. So gelingt es, das Bein bis um rechten 1 intel, selbst darüber hinaus zu beugen. Auffallend ist, dass diese tarke Dehuung, wenn sie nur allmählich erfolgt, gar keine Schmerzen hervoruft.

\section{Instrumentarium.}

12. Hofmann, Tereinfachtes Verfahrenzur Umsetzung der Längsextension in queren $Z u g$. Münch. med. Wochenschr. 1907, 34.

13. Zander, Eine neue Extensionsvorichtung. Zentralbl. f. Chir. $1907,7$.

14. Steinmann, Eine neue Extensionsmethode in der Frakturbehandlung. Ibidem, Nr. 32.

15. Langemak, Zur Frage der Beckenstütze. Hoffa's Zeitechr. Bd. XVIII. 
15. Kopits, Ein neues Instrument zur Anlegung des Gipsververbandes beim Klumpfuss. Ibidem.

17. Ritter, Eine einfache Vorrichtung zur erleichterten Anlegung des redressierenden Gipsverbandes bei Kindern. Dieses Arch., Bd. V.

18. v. Modlinsky, Zur Frage des Gipsgebrauches in der Ortbopädie. Hoffa's Zeitschr. Bul. XVIII.

Hofmann hat seine Methode weiter modifiziert. Zur Umwandlung der Längsextension in queren Zug benutzt er jetzt eine einfache Fadenrolle, un so die Extensionsrollen, mit ihren Stativen und Schrauben rurch das Einfachste, was in jedem Hause vorrütig ist, zu ersetzen.

$Z$ ander hat eine an jedem Operationstisch anzubringende Vorrichiung aus Stahlrohr mit Spindeltrieb konstruiert, die ihm zur Extension von Frakturen, Kontrikturen etc. grite Dienste geleistet hat.

Steinmann greift mit seinem Zuge den Knochen direkt an, indem er vernickelte Stahlnägel schräg in das mintere Fralaturende treibt und an den Nagelkopf die Extensionsschnur anhängt. Er hat zu diesem Zweck ein kleines Besteck anfertigen lassen, bestehend aus 6 paar Nägeln, 1 Zange und Drahtscbnur, welebes durch den Instrumentenmacher Kloepfer in Bern bezogen werden kann.

Als Nachteil gegenüber der Heftptlusterexteusion bleibt meist die Notwendig. keit einer burzen Narkose, als Vorteil wird gerühnt die Einfachheit des Verfabrens, der besser wirkende Zug, die absolute Schmeralosigkeit und das Fehlen jedreder Hautreizung -- ein grosser Vorteil namentlich bei komplizierten Frakturen.

Fine Kombination der Gocht-Lossen'schen und der Legal'schen Bechenstütze hat $L a n g e m a k$ angegreben, die es ernüglicht, einen selbst kräftigen Zug an den Extremitäten auszuüben, ohne eine Drehung der Stütze befürchten zu müssen. In dieser, wie bei den folgenden Arbeiten, muss auf dals Original verwiesen werden, da ohne Abbilulung eine Peschreibung zu schwer verstädlich unl zu weitschweifig würde.

Kopits nimmt in den Klumpfussterband eine Eisensohle mit hinein, die später entfernt wird. Sie ist an einem Handgriff befestigt, der ein sehr gutes Redressement in der Richtung der Pro- und Supination ermöglicht, jealoch bei der so wichtigen Aufrollung des inneren Fussranles, welche das Kriterium eines jeden guten Klunpfussverbandes darstellt, völlig im Stiche lässt.

Denselben Gedanken hat $\mathrm{R}$ itter in etwas einfacherer Form rerwirklicht; auch hier gilt dasselbe: völliges Versagen bei Aufrollung des Imnenrandes des Fusses.

Modlinsky hat einen Apparat zur Anlegung ron Gipsverbänden an Wirbelsäulen and unterer Extremiät beschrieben, der wenig Raum beansprucbt und für manche Zwecke, mamentlich für'Hüftrerbïnde, gauz gute Dienste zu leisten scbeint.

\section{Portative Apparate.}

\section{Allgemeiner Teil.}

19. Curcio, Apparecchi ortopedici ed arti artificiali. Turin 1907.

20. Vanghetti, Plastica e protesi cinematiche. Empoli 190ri.

21. Evier, Chromlederstreifen mit Schienen als einfacher Streckrerbind. Med. Klinik 1907, 11.

Curcio beschreibt in einem umfangreichen und mit zahlreichen Abbildungen ausgestatteten Buch ron ca. 300 Seiten Indikationen, Wirkungsweise und konstruktion der orthopädischen Stützapparate und Prothesen. 
Vaughetti behandelt das Problem, wie an den Amputationsstümpfen die noch vorhandenen Muskeln in Verbindung mit einer speziell dazu eingerichteten Prothese zu aktiven Bewegungen nutzbar gemacht werden können. Ein kurzes Referat dieser interessanten Arbeit ist nicht möglich.

Evler empfiehlt Chromlederstreifen, die durch eingenietete Blechstücke verstärkt sind und durch verstellbare Schienen miteinander verbunden werden. Gerühmt wird lie Einfachheit der Herstellung.

\section{Spezielle Indikationen.}

22. Wunsch, Ein Apparat gegen Schiefhals. Deutsche med. Wochenschr. 1907, 27 .

23. Heermann, Ein neues aktives Korsett. Ibidem. Nr. 8.

24. Rotschub, Eine a septische Wochen bettbinde. Münch. med. Wochenschrift $1907,13$.

25. Dembowski, Ein neuer Apparat zur Behandlung der Koxitis. Hoffa's Zeitschr. Bd. XVIII.

26. Mittermaier, Die Hammerzehen und ibre Behandlung. Münch. med. Wochenschr. 1907, 3.

27. Semeleder, Verwertung des Körpergewichtes zur Korrektur von Belastungsdeformitäten. Sitzungsbericht der K. K. Gesellsch. der Ärzte in Wien. Wiener klin. Wochenschr. 1907, 7.

28. Lengfellner, Eine Stablbandfeder für Plattfusseinlagen. Münch. med. Wochenschr. 1907, 21.

29. Derselbe, Technik des Gipsbreiabdruckes für Plattfussein. lagen. Münch. med. Wochenschr. 1907, 40 .

30. Derselbe, Zelluloidtechnik bei der Herstellung von Plattfusseinlagen. Münch. med. Wochenschr. 1907, 41.

31. Bardach, Ein Schub zur Prophylaxe und für leichte Formen von Pes falgus. Wiener med. Wochenschr. 1907, 22.

Gegen Schiefbals empfiehlt Wunsch folgende Bandage. Von einem Stirnband gebt von der Ohrgegend der gesunden Seite eine gebogene Stange nach binten zur krankseitigen Schulter. Diese Stange wird durch ein um beide Achseln geführtes Band angezogen und soll den Kopf redressiert halten. Hals und Brustkorb bleiben dabei vollkommen frei. - Fabrikant: H. Windler, Berlin.

Das Neue von Heermann's Korsett besteht im wesentlichen aus einem trockenen Gummischwamm, der als Pelotte auf die Gegend des Rippenbuckels wirken soll. Im übrigen vermögen wir die etwas sanguinischen Hoffnungen des Verf. nicht zu teilen.

Rotschuh hat mehrere ca. $9 \mathrm{~cm}$ breite Streifen aus waschbarem Baumwollstoff, die sich zu 1/3 decken, in Rückenteil zusammengenäht; vorn sind die losen Streifen mit Hacken und $O$ sen versehen. Die Binde scheint zur Verhütung eines Hängebauches einfach und praktisch zu sein.

Dembowski's neuer Apparat zur Behandlung von Koxitis und Resectio coxae stellt eine Kombination von entlastender Krücke und entlastender Schiene dar. Er sieht etwas plump aus und ist daher nur bei der Praxis non elegans zu verwerten.

Mittermaier empfiehlt eine sandalenartige Fusshandage mit keilförmigem Polsterkissen, die vielleicht als Improvisation brauchbur, sonst aber wohl kaum empfeblenswert ist.

Eine neue ingeniöse Scbienenkonstruktion für Belastungsdeformitäten der unteren Extremität hat Sem eleder angegeben. Er verwendet hierzu einen Winkelhebel, dessen kurzer Arm unter dem Fusse liegt, mährend der lange am Unterschenkel emporsteigt, wobei das Hypomochlion sich seitlich neben dem Knöchel 
befindet. Bei der Einwirkung des Körpergewichtes wird nun die Knöchelgegend nach der Seite gedrückt oder gezogen. Dies wird durch eine unter dem Fusshebelarm liegende Feder berrerkstelligt. - Die Konstruktion wird rom Verfasser vor allem bei der Behandlung rom Klump- und Plattfüssen verwandt.

Mit der Herstellung ron Plattfusseinlagen hat sich $\mathrm{L}$ e $\mathrm{n} \mathrm{gf}$ ell $\mathrm{n}$ e $\mathrm{r}$ eingehend beschäftigt. Er beschreibt zunächst eine Stablbandfeder, die unter jeder Einlage angrebracht werden kann und den Zweck hat, das Heruntertreten des Fussgewölbes zu verhüten. Ferner soll sie ein elastisches Auftreten berirken und endlich der Einlage in Schub einen gewissen Halt geben, so dass ein Verchieben derselben unmöglich wird. Sie wird in 2 wei Grössen hergestellt und kann leicht angepasst werden.

Des weiteren wird eine genaue Anweisung zur Herstellung einer durch eine Aluminiumsoble verstärkten Zelluloideinlage mit aufgenieteten Stahlband gegeben.

Was dio Herstellung seines Fussmodells betrifft, so hebt Verf. mit Recht hervor, dass der Gipsbreiabdruck ein viel besseres Fussmodell gibt als der Abdruck mit Gipsbinden. (Was aber hier entgegengehalten werden muss, ist folgendes: Es kommt gar nicht daraut an, ein naturgetreues, künstlerisches Modell herzustellen, sondern die Hauptsache ist und bleibt die Bearbeitung des Fuszgewölbes. Diese kann beim Bindenabdruck während des Ablruckes selber geschehen; beim Breiabdruck dagegren findet sie am fertigen Modell statt und fällt daher büufig allzu willkürlich aus. Ref.)

Bardach hat nach einem Gipsabguss in Supination eine Einlage aus Leder angefertigt, die das Fussgewölbe stützt, den Calcaneus sichelförmig umgreift und den Grosszehenballen etras erhōht, wodurch den Zehen Spielraum zur Plantarflexion gegeben ist. Beim Schuh selbst ist darauf zu achten, dass der Fussrücken vor Druck vollkommen geschützt ist.

III.

\section{Massage und Heilgymnastik.}

Sammelreferat über die Im Jahre 1907 erscbienenen, sowie die in Band X der Zeitschrift fiur diutetische und physikalische Therapie. in Band XVI-XVIII der Hoffa schen Zeit schrift und im V. Band dieses Archivs referierten Arbeiten

yon

Dr. Wilhelm Becker,

Spezialarzt für Orthopädie in Bremen.

Massage.

I. Allgemeiner Teil.

1. Colombo, Technik der Massage. Hof $f a$ 's Zeitschr. XVIII.

2. Hageubach-Burckhardt, Orthopädische Betrachtungen über Muskel. und Gelenkschlaffheit. Ibidem.

3. Hellmer, Leitfaden der Vibrationsmassagefürden praktischen Arzt. Berlin 1906 .

4. Klapp, Úber Luftmassage. Münch. med. W. 1907, 1. 
5. Bendersky, Massage unter Wasser. Wien. mell. Presse 1907, 12.

6. Arndt, Elektromassagehandschub. Iünch. med. IV. 1907, 19.

7. Schmidt, Massagedurchrbythmischen Druck nach Cederschiöld. Münch. J. W. 1907, 25.

8. Hovorka, Massageverletzung und $K$ nochendefekt. Wien. med. W. $1907,15$.

Colombo gibt uns in seiner Arbeit neben einem kurzen historischen Rückblick eine Ltbersicht über die rerschiedenen Formen der Massage, sowie über die Indikation und Technik ihrer Anwendung.

$\mathrm{H}$ age n bach-Burckhardt hebt hervor, dass bei allen Zuständen sog. Gelenkerschlaffung neben den überdehnten Bändern auch die erschlafitte Muskulatur eine Hauptrolle spielt und dass die Behandlung daher niemals der Milssage und Übung der betr. Muskeln entraten kann.

Hellmer's Arbeit ist im wesentlichen eine Empfehlungssebrift für den Handapparat , Venivici".

Ein starker Luftstrom, der durch einen besonderen, ron Eschbaum hergestellten Apparat unter hohen Druck gesetzt wird, wendet Klapp zu therapeutischen Zwecken an. Er soll obne Reibung der Haut durch mechaniscben Druck eine Art Massage bewirken. Als Vorteil wird völlige Schmerzlosigkeit gerühmt.

Bendersky ging ron der Beobachtung aus, dass unter Wasser der Druck innerbalb der Körpergerebe bedeutend berabgesetzt ist. Deshalb hat er im warmen Bade manuelle und vibratorische Massage angerandt. Er rühmt die Erfolge dieses Vorfahrens namentlich bei spastischer Obstipation und spastischen Diarrhöen.

Während mit den Begriffen „Elektro- und Thermomassage“ seit Einführung der bekannten Rollen der weitgehendste Lnfug getrieben wird, sucht Arndt eine wirkliche Vereinigung von Elektrizität und Massage herbeizuführen. $\mathrm{Er}$ massiert mit einem Fausthandschuh, dem durch ein feines Drahtgeflecht elektrischer (meist galvanischer) Strom zugeführt wird. Fabrikant: Reiniger, Gebbert und Schall.

Nach Cederschiöld wirken die meist üblichen Massage-Manipulationen entweder zu oberflächlich (Streichung), oder sie vergrössern leicht Gewebsrises und Gefässverletzungen (Reibung, Knetung, Klopfung). Deshalb will Verf. Gewebstrünmer, Extravasate etc. nicht durch Reibung fortscbaffen, sundern durch Druck, und zwar durch An-und Abschwellen dieses Druckes und allmähliches Fortschreiten desselben in zentripetaler Richtung.

Einen kasuistiscben Beitrag, der nicht ohne Interesse ist, gibt uns Hovorka. Durch Masiage sollte eine abnorme Beweglichkeit und Dislokation im Handgelenk entstanden sein. Die Röntgenuntersuchung hingegen ergab einen angeborenen Defekt des distalen Uinarendes.

\section{Spezieller Teil.}

a) Chirurgische Indikationen.

9. Liniger, Massage bei Gelenkerkrankungen. Zeitschr. f. diät. u. phys. Ther. $X, 1$.

10. Kouindjy, Le traitement massothérapique des arthrites tuberculeuses. Progrès Méd. 1906, 20.

11. Berne, La mobilisation des membres inférieur a dans le traitement des phlébites. Ibidem.

12. Maclaire et Zesas, Le massage direct du coeur dans le collapsus chloroformique. Arcb. internat. de chir. III, 1. 
b) Interne Indikationen.

13. Zabludowski, Zur physikal. Therapie der habituellen Obstipation und der sexuellen Neurastbenie. Zeitschr, f. diät. u. phys. Ther. $\mathrm{X}, 4 ; 5$.

14. Pinoli, Kurze Bemerkungen über Bauchmassicge. Grazetta intern. di med. 1906, 92.

15. Ekgren, Zur Massagetherapie bei Prolapsus ani. Zeitschr. f. phys. u. diät. Ther. $\mathrm{X}, 10$.

16. Bourcart, Manuelle Vibrotionsmassage bei Appendizitis. Rev. medie. d. 1. suisse Romande 1906, 10.

Die Arbeit von Liniger ist eine der interessantesten und lesenswertesten von allen, die bier referiert sind. An einer Reihe von Selbstbeobachtungen wird gezeigt, wohin eine allzu intensive Bearbeitung erkrankter Gelenke führt. "Wo rohe Kräfte sinnlos walten, dat kann sich kein Gebild' gestalten.: Die Lebtüre dieser Arbeit sei allen Kollegen, sowobl denen, die selbst massieren, als auch denen, die ron Massage beine Ahmung haben und ibre Patienten lieber einem Laienmasseur als einem spezialkollegen anvertrauen, aufs angelegentlicbste emptohlen.

Les extrèmes so tonchent: die Arbeit Kouiduly's ist nur mit grosser Vorsicht aufzunelmen. Denn Verfasser fordert Massagebehandlung bei allen Fällen ron trockener, kongestiver (? Ref.) Arthritis, selbst wenn er "ile für tuberkulös hält. Er warnt vor dieser Behandlung nur bei Fungus oder tuberkulöser Fereiterung. Die Arbeit erinnert an das Forgeben Calots bei Pott'schen Buckel. Berne warnt daror, Tenenentzündungen zu massieren. Erst nach einem fieberfreien Monat sei rorsichtige Gymnastik gestattet; Massage dürfe nur auf das allervorsichtigste angewandt werden. Im allgemeinen scheinen die Franzosen, wie auch aus der Arbeit Bourcart's herrorgeht, die Indikationen zur Massage viel weiter zu stellen.

Mauclaire und $Z$ esas veroffentlichen ihre experimentellen und klinischen Versuche über direkte Herzmassage beim Chloroformkollaps; auscerdem stellen sie in ihrer interesanten Arbeit 30 in der Literatur veröffentlichte Fälle zusammen. Sie kommen zu dem Schluse, dass hei schrerem Chloroformbollaps die direkte Herzmassage versucht werden müsse, da es andere gleich wirksame Hilfsmittel nicht gibt.

In ausführlicher Darstellung empfiehlt $\mathrm{Zabludl}$ ows $\mathrm{ki}$ gegen habituelle Obstipation manuelle und vibratorische Massage des Banches und des Anus; für leizteren ist ein Mastdarmansitz nach Art eines Spekulums angegeben, der zur Vibration in den After eingefübrt wirl. Die sexuelle Neurasthenie behandelt er durch Hodenmelssage und Hyperämisierung des Penis durch eine Luftpumpe, die ebenfalls abgebildet ist.

Pinoli matht darauf aufmerksan, dass die Bauchmassage ausser der lokalen auch eine intensice Reflexwirkung auf ortlichen und allgemeinen Kreislauf hat; daher wirkt sie üusterst günstig bei vielen Fornıen von Herzkrankheiten sowie bei der einfachen Anämie.

Bei Prolapsus ani hat Ekgren ein kombiniertes Massageverfahren angewandt, das macheinander aus folgenden Manipulationen besteht: 1. Bauchmassage; 2. Vibration der Flexura sigmoidea; 3. Nastdarmbebung; 4. Massage des Sphincter ani; 5. thernische Reize; 6. gymnasticche Bewegungen. Er empilichlt seine Methode als gutes Hilfsmittel, wenn es gilt, einen leichteren Prolaps zu heilen bezw. zu bessern, oder aber in schwereren Fällen post operationem zur Nachbehandlung.

Bourcart wandte die mit flach aufgelegter Hand unter baum sichtbaren Bewegungen ausgeführte manuelle Vibrationsmassage bei Appendizitis zunächst nur an, um die Schmerzhaftigkeit berabzusetzen. Dabei fand er, dass bald nacher die Temperatur steil abfiel und der Allgemeinzustand sich auffallend besserte. Er 
Berichte.

erklärt dies dadurch, dass die Zirkulation im Appendix und der Blutabfluss nach der Leber gefördert werde und dadurch der Körper leichter Herr über die Reaktion werde. Kontraindikationen sollen bei richtiger Ausführung nicht bestèhen (? Ref.).

\section{Heilgymnastik.}

\section{Allgemeiner Teil.}

17. Hasebroek, Die Zander'sche mechanische Heilgymnastik und ihre Anwendung bei inneren Krankheiten. Wiesbaden 1907, J.F. Bergmann.

18. Baldes, Heichelheim und Ifetzger, Untersuchungen über den Einfluss grosser Körperanstrengungen. Münch. med. W. 1906, Nr. 38.

Das Buch von Hasebrock ist ausführlich referiert in Band $\mathrm{V}$ dieses Archivs, pag. 392; es wird auf dieses Referat verwiesen.

Baldes, Heichelheim und Metzger haben ibre Cntersuchungen an den Teilnehmern eines Dauermarsches von $100 \mathrm{~km}$ angestellt. Sie fanden in der überwiegenden Mehrzabl der Fälle den Urin eiweiss- und zylinderhaltig; in vereinzelten Füllen fand sich auch eine Beimengung von Blut. Die Herzdämpfung war verbreitert, der Blutdruck gesunken. Die Reflexe waren zum Teil abgeschwächt, zum Teil fehlten sie ganz.

\section{Spezieller Teil.}

a) Chirurgische und orthopädische Indikationen.

19. Deutschländer, Funktionelle Bebandlung der Knochenbrüche. Berlin. klin. Wochenschr. 1906, 20--22.

20. Slomann, Nacbbehandlung nach mobilisierenden Operationen. Dieses Archir Bd. V.

21. Klapp, Behandlung der Skoliose mit dem Kriechrerfahren. Hof $f$ a's Zeitschr. Bil. XVI.

22. Chlumsky, Mobilisation der Wirbelsäule nach Klapp und deren Gefahren bei seiuer Skoliosenbehandlung. Wiener blin. R. 1906,14 .

23. Lange, Behandlung der Skoliose mit aktiver und passiver Überkorrektur. Hoffa's Zeitschr. Bd. XVIII.

24. Müller, Skoliosenbehandlung des prakt. Arztes. Ther. d. Gegenwart 1906, 3.

b) Interne Indikationen.

25. Lubinus, Entwickelung und Bedeutung derschredischen Heilgymastik für die Behandlung ron Herzkrankheiten. Med. Ges. Kiel, 1. XII. 1906. - Münch. med. Wochenschr. 1907, 22.

26. Lewandowski, Uber Gymnastik in der Schule, unter besond. Berücks. der Atemgymnastik. Berlin. klin. Wochenschr. 1907, 21,

27. Guse, Gymnastik bei Erkrankung der Atmungsorgane. Med. Ges. Kiel, 1. XII. 1906.

Deutschländer schildert die frühzeitige Behandlung der Knochenbrüche mit Massage und gymnastischen Übungen mit oder obne Schienen oder Verbände. Als grössten Vorteil hebt er die rasche Besserung der Funktion hervor.

An der Hand ron 4 Krankengeschichten sucht Slomann nachzuweisen, dass die Nachbehandlung nach mobilisierenden Operationen viel früher - of schon am 2. Tage nach der Operation - begonnen werden kann und dass dadurch so- 
wohl die Prognose als auch die Schnelligkeit des therapentischen Erfolges gegen früher sich sebr bessert.

Den Hauptteil dieses Abschnittes bildet naturgemäss die Skoliosentherapie. Zunächst zeigt uns $K$ lapp eine weitere Ausbildung eeines Kriechrerfabrens. Den ganz offenbaren Vorzügen dieser Methode stehen aber zweifellos eine ganze Reihe von Bedenken gegenüber. Neben Lange und Schultbess (vergl. die Arbeit des nächsten Abschnittes) ist es vor allem $\mathrm{Chlumsky}$, der die durch das Kriechverfahren erzielte ausgiebige Mobilisation der Wirbelsäule gar nicht für so erstrebenswert ansieht. Als Beispiel führt er eiven skoliatischen Schlangenmenschen an. Das zu erstrebende Ziel der Therapie muss gerichtet sein auf neue Wege zur Behandlung der Grundursacben des Leidens und zur Fixation des ein. mal erzielten Resultates. Verf. hält das Kriechverfahren noch nicht für spruchreif und warnt vor einer schabloneubatten Anwendung desselben.

L a nge schildert uns in einer sehr ausführlichen Arbeit sein Streben, mit moglichst einfachen, auch ausserhalb eines Institutes anwendbaren Mitteln eine wirksame Skoliosenbebandlung durchzuführen. Da die Arbeit ohne die zablreichen Abbildungen nicht zu referieren ist, muss auf das Original verwiesen werden.

Ähnliche Absichten rerfolgt M ̈̈ller, wenn auch mit weniger Glück. Er empfiehlt besonders seinen Autogymnasten, dessen gerühmte Vorzüge vor anderen Zimmerturnapparaten nicht recht ersichtlich sincl.

Lubinus rühnt die Erfolge der Massage in Verbindung mit geeigneten passiven Bewegungen bei Herzkrankheiten, bej denen die Heilgymnastik dasselbe bezwecke wie eine Terrainkur, vor dieser aber den Vorteil feinerer Dosierbarkeit und besserer Kontrolle habe.

Lew andowski wünscht, dass unser Turnunterricht sich mehr nach Art des schwedischen Turuens mit einer rationellen Atemgymnastik befasse. Er führt die Hauptpunkte eines derartigen Systems nach dem Lehrbuche von Hughes an.

Nicht uur zur Prophylaxe, auch zur Therapie ist eine geeignete Atmungs. gymnastik zwechmässig. Das zeigt uns Geese, der dieselbe bei Bronchitiden, Bronchiektasien, Pleuraverwachsungen und Finphysen mit gutem Erfolge angewandt hat.

\section{Apparate.}

28. Hohmann, Wie kann der Arzt diegymnastische Behandlung der Gelenkkontrakturen durebführen? Münchn. med. Wochenschr. 1906,31 .

29. Lossen, Ein neuer Daumenbewegungsapparat. Dieses Archiv, Bd. V.

30. Chlumsky, Bemerkungen zur mediko-mechanischen Behandlung in Osterreich, nebst Beschreibung eines neuen Apparates. Wien. klin. R. 1907, 23.

31. Machol, Die strömende Wasserkraftim Diensteder Orthopādie. Hoffa's Zeitschr. Bd. XVI.

32. Derselbe, Beiträge zur mediko-mechanischen Improvisationstechnik. Ibidem, Bd. XVIII.

33. Codivilla, Pendelapparat für die Deformitäten der Halswirbelsäule. Ibidem, Bd. XVII.

34. Schulthess, Zur Behandlung der Sboliose in borizontaler Lage der Wirbelsäule vermittelstaktiver Abbiegungen. Ibidem, Bd. XVI.

35. Blumenthal, Neue Redressionsvorrichtung fürdie Wirbelsäule. Ibidem, Bd. XVI. 
36. Kopits, Ein modifiziertes Wolm. Dieses Archiv. Bd. V.

37. Wohrizek, Schulen für Skoliotische. Hoffa's Zeitschr. Bd. XVIII.

38. Salaghi, Il Cormocinetro e sue applicatiozioni nella Orthopedia. Areh. di Orthop. A. XXIV, 1.

39. Johansen, Neuer Bauchmassageapparat. Zeitschr. f. diät. u. phys. Tber. $\mathrm{X}, 4$.

Die Arbeit ron Hohmann ist an die Spitze dieses Abschnittes gestellt weil man sie ebensogut noch zum vorigen rechnen könnte. Ibr Schwerpunkt liegt in einer gymnastischen Improvisationstechnik, indem uns an der Hand zahlreicher Abbildungen gezeigt wird, wie der Arzt auf dem Lande mit Hilfe einfachster, leicht herzustellender Apparate seine Kranken behandeln kann.

Lossen hat einen gleichzeitig als Widerstandapparat verwendbaren Pendelapparat speziell für die bisher zu wenig berücksichtigte Daumenbewegung konstruiert, der von der Firma Rossel, Schwarz u. Co. in Wiesbaden hergestellt wird.

Chlumsky hat einen Universalapparat angegeben, der für kleinere Betriebe genügen soll. Er kann durch auswechselbare Aneïtze für die verschierlenen Gelenke verwandt werden und ist sowohi für aktive Pendelvorrichtung als auch für passive Bewegungen eingerichtet.

Machol hat in sebr ingeniöser Weise die Kraft des unter Druck stehenden Wasserleirungsstrahles zur Konstruktion aktiv-passiver Apparate benutzt, denen er folgende Vorteile nachrühmt: 1. Einfachbeit und Vielseitigkeit in der Anwendung; 2. Möglichkeit feinster Abstufung und Dosierbarkeit; 3. als ganz neu: Registrierbarkeit der Menge der Arbeitsleistung. Es ist natürlich hier kein Raum für ausführliche Beschreibung und Illustrierung; Interessenten genüge der Hinweis, dass die Apparate von Georg Haertel, Breslau I, hergestellt werden.

Derselbe hat uns in verblüffend einfacher Weise gezeigt, nicht nur wie die verschiedensten Pendelübungen in einer Scharnierebene durch verschiedene Ansatzteile an einem einzigen Apparat improvisiert werden können, sondern auch wie durch eine sog. „Mitnehmergabel“ die Vertikalschwingung eines Pendels resp. die Rotation seiner Achse in Kreisbewegungen in der Horizontalebene äbergeführt werden kann. Auch diese Arbeit bietet des Interessanten soviel, dass die Lektüre der Originalarbeit dringend empfohlen werden muss.

Codivilla hat einen Pendelapparat für die Deformititen der Haiswirbelsäule konstruiert, der ihm namentlich zur Nachbebandlung des Schiefhalses gute Dienste geleistet hat.

Der "Inklinationsapparat" von Schulthess gestattet in horizontaler Lage aktive Abbiegungen der Wirbelsäule; er fällt zeitlich mit dem horizontalen Kriechverfahren Klapps zusammen. Er scheint diesem überlegen zu sein in der Lokalisation der Abbiegungspunkte, rermöge deren er eine viel sjcherere Indikationsstellung und eine exaktere Behandlung ermöglicht.

Blumenthal bat als "Redressionsgabel" eine neue Redressionsvorrichtung für Rückgratsverkrümmungen beschrieben. Es will uns bedünken, als ob nur der Name und die äussere Form neu sei, während das therapeutische Prinzip wohl längst bekannt und angewandt sein dürfte.

Den bekannten Lorenz'schen Wolm hat Kopits durch Anbringung eines Rabmens, der in zwei Fixierungsarmen läuft, derartig modifiziert, dass der neue Apparat gewissermassen eine Kombinatiou von Wolm und Beely'schem Redressionsrahmen darstellt. Er rühmt als Hauptrorzug die Möglichkeit, das Redressement ganz allmählich ohne Scbmerzen zu steigern. Der Vorgang erscheint sehr nachahmenswert.

Wahrizek empfiehls Sonderschulen für Skoliotische einzurichten und führt uns als praktischen Redressionsstuhl seinen bekaunten "Korrektor" ror, zu dem er zwei Modifikationen angebracht hat. Der Apparat ist einfach, billig und zweck- 
mässig. In ihm sitzend sollen die Kinder den Schädigungen der Arbeits- und Schulzeit begegnen.

Zur bequemen Ausführung verschiedener Ubuugen der manuellen Heilgymnastik hat Salaghi einen Sitz konstruiert, der drehbar und in der Höhe verstell. bar ist und eine Querstange zur Fixierung der Füsse trügt.

Endlich bat Johannsen einen Bauchmassageappurat konstruiert: eine über einem Gestell angebrachte Kurbel dreht eine Acbse, an deren unteren Ende zwei gepolsterte Holckugeln angebracht sind, die wäbrend der Rotation kreistörnig das Abdomen bestreichen.

\section{IV.}

Italienische Literatur.

Referent: Dr. Max Strauss in Nürnberg.

Archivio di Ortopedia. Anno XXI. 1904.

Monari, Umberto, Bologna, L'artrodesi nella lussazione acromioclaviculare superiore.

Verfasser berichtet über die Schwierigkeiten, die Reposition des luxierten Akromio-Klarikulargelenkes durch irgend welcben Verband zu erhalten und Heilung in guter Stellung zu erreichen, was er auf die Eigenart der Gelenkflächen und ihre Stellung zueinander zurückführt. In Anbetracht der lurch die Luxation bedingten Entstellung und Funktionsbehinderung der Schulter schlïgt nun Monari die Freilegung des Gelenkes und die Fixation der Gelenkenden vor. Diese werden, um eine absolut sichere Feststellung und Nabi zu ermöglichen, noch besonders gestaltet, inden aus dem Klavikularende ein $\bigvee$ förmiger Keil genominen wird, dessen beide Seiten in Rinnen des Acromialendes zu liegen kommen. Eine Seidennaht fixiert beide Knochen in dieser Stellung. In einem eingehend beschriehenen Falle wurde auf diese Weise sebr gute Heilung erzielt. Ausführliche Literaturangaben beschliessen die Arbeit.

Buschi, Attilio, Bologna, Sulle rarici ossee.

Ein kurzer Bericht über die selten beobacbteten Veränderungen der Unterschenkelknochen infolge starker variköser Entartung der Cnterschenkelvenen. Bei einer 26 jährigen Frau hatten sich seit dem 9. Lebensjahre obne nachireishare Ursache hochgradige Krampfadern am linken Unterschenkel entwickelt. Vielfache Geschwürsbildung veranlasste die Exstirpation des ganzen Saphenastammes, die keinerlei Heilwirkung zur Folge hatte. Häufige Blutungen machten die Amputation nötig. Die Lntersuchung des Präparates ergah Knochenusuren und viel verzweigte Löcher, die in weite Kanāle im Innern des Knochens führten, der hierdurch rarefiziert wurde und ein lakunöses Lückensystem aufwies. Mikroskopisch fand sich im wesentlichen Knocbenatrophie und -Rarefikation mit Erweiterung der $\mathrm{Ha}$ vers'schen Kanäle. Gute Abbildungen illustrieren die Veränderungen, über deren Pathogenese (Rachitis) der Verfasser nichts bestimmtes anzugeben wagt.

Bossi, Pietro, Milano, Anchilosi radio-ulnaresuperiore congenita. Ein Beitrag zur Kasuistik der angeborenen Ankylose zwischen proximalem Radius- und Ulnarende. In einem Falle bandelte es sich um einen 8 jährigen 
Knaben mit beiderseitiger Ankylose, bei dem eine ausgiebige Supination der Hand nur durch gleichzeitige Innenrotation der Schulter möglich war. Das Röntgenbild ergab ein Ankylose im Bereich des proximalen Radio-Ulnargelenkes beiderseits, die operativ beseitigt wurde, indem die beiden (fibrös?" der Referent) ankylosierten Knocben an der Gelenkstelle mit dem Messer getrennt und durch einen Muskellappen aus den Pronatoren auseinander gedrängt ssurden. Die fehlerhafte Stellung der Hand (forcierte Supination) änderte sich bei und nach diesen Eingriff nicht; es wurde daher der Radius gleichzeitig im unteren Drittel osteotomiert.

Der Operationserfolg war ein guter. Die Hand zeigte Mittelstellung zwischen Pro- und Supination und konnte in beschränktem Masse proniert und supiniert rerden.

In einem zweiten kurz geschilderten Falle fand sich bei einen $3 j$ jahrigen Knaben verhinderte Pro- und Supination in Bereiche des Ellbogen- und Handgelenkes, ohne dass sonstige Bewegungsstörungen vorhanden gewesen wären. Das Röntgenbill liess keine knöcherne Verbindung zwizchen Raddius und Ulna erkennen.

Zum Schlusse werden 16 Fälle aus der Literatur angeführt, die jedoch nur teilweise den beiden geschilderten Fällen entsprechen.

Giani, Rafaello, Torino, Due casi di esoztosi solitaria.

Der erste recht nerkwürdige Fall zeigt bei einem 17jührigen Minne eine Exostose des Oberschenkelbalses, die sich mit einer zweifelsohne gleichzeitig bestehenden Koxitis nach einem Trauma rascher entwickelte und schwere Bewegungs. störungen machte. Es wurde die Diagnose Luxatio-ileo-pubica gestellt und die Reseltion des Oberschenkelkopfes vorgenommen. Dabei fand sich neben dem wenig vergrösserten Kopfe noch eine mit hyalinem Knorpel überzogene knöcherne Exostose am vorderen Unfang des Schenkelbalses, die in Form und Grösse einem normalen Oberschenkelkopfe ähnelte und so die falsche Diagnose ermöglichte.

Im zweiten Falle handelte es sich um eine nussgrosse knorpelige Exostose an der Hinterfläche des Calcaneus, deren operative Entfernung leicht gelang.

Ätiologisch nimmt Verfasser nach einer kurzen Übersicht ïber die bisher in der Literatur niedergelegten Hypothesen in beiden Fällen einen versprengten enbryonalen Knochenkern als Uraache der Exostosenentwickelung an.

Codivilla. Alessandro, Bologna, Sulla tecnica dei trapianti tendinei. Verfasser berichtet in ausführlicher Weise über die Technik der Sehnentransplantation, wie sich ihm dieselbe in vielen Fällen erfolgreich zeigte. $\mathrm{Er}$ betont besonders die Notwendigkeit eines vorher ganz genau festgelegten Operationsplanes, der sich auf exakte Untersuchung der vorliegenden Deformität und der vorhandenen Muskelkräfte stützen muss. Es erscheint merkwürdig, dass die Beobachtung von Muskeln und Nerven mit dem elek trischen Strom hierbei völlig vernachlässigt und einzig und allein die Inspektion, Palpation und Funktionsprüfung empfohlen wird (Referent).

Bei stärkeren Deformitäten empfiehlt Codivill a zunächst die Behebung der Deformităt durch modellierendes Redressement. In einer 2. Sitzung folgt die Sehnentransplantation, deren verschiedene Arten ausführlich erörtert werden. Verfasser wendet vor allem die deszendierende Form an und bekänpft das schematische Vorgehen Langes, indem er möglichste Anpassung an die vorhandenen Huskelkräfte durch individualisierendes Vorgehen empfiehit. Die künstlichen Sehnen Langes will Codivilla nur in Ausnahmefällen verwendet sehen; als Nahtmaterial bevorzugt er fils de Florence.

Die weiteren eingehenden technischen Angaben über Operationswreise und Nachbehandlung bringen nichts wesentliches, wenn wir ron einer Kugelzange mit weit ausgebauchten Branchen absehen, die nach dem Prinzip des Bergmann'schen Scbiebers konstruiert ist und zur Adaption und vorläufigen Fixation der Sebnenstümpfe dienen soll. 
Rossi, Baldo, Milano, Come si possono correggere le guarigioni deformi delle fratture di femore e come si possono evitare.

Zur Behandlung deform geheilter Frakturen des Oberschenkels wird in erster Iinie die Osteotomie an der stelle der Deformität und die Nachbehandlung durch konstanten, sehr starken Zug empfohlen. In Anbetracbt der kräftigen Muskulatur und Faszien des Oberschenkels sind zu dieser Extension Gewichte ron 20-70 kg (!) nötig, die an dem üblichen Extensionsverband angebracht, erhebliche Unzuträglichkeiten (Decubitus, Gelenkerschlaffung) bedingen wïrden. Daher verwendet Verfasser die Übertragung des Zugres direkt auf das Skelett des Fusses, indem er nach Codivilla einen starken Nagel quer durch den Calcaneus schlägt.

$\mathrm{Um}$ bei älteren Leuten möglichst frühzeitiges Geben zu ermüglichen verbindet Rossi Extensions- mit Gehverband, indem er den Codivilla'schen Nagel mit einem Steigbügel verbindet, der in einen, Unterschenkel und distales Drittel des Oberschenkels umfassenden Gipscerband eingelassen ist. Der Zug wird hierbei durch regulierbare Federkraft, die zwischen Nagel und Steigbügel eingeschaltet wird, auzgeübt, nachdem der Verband auf dem Schede'schen Tisch angelegt ist.

Der Verfasser berichtet über 4 Fälle, die er Erfolgreich mit Osteotomie und starken Zug behandelt hat, und fügt bei, dass er diesen starken Zug auch bei frischen Frakturen verwendet, wo er gleichfalls den Gehverband berorzugt. In 27 derartigen Fälen batte er gute Erfolge, wobei auch sehr bohes Alter (jenseits des 70. Lebensjahres) keine Kontraindikation ergab. Diese ist lediglich durch die allerersten Lebensjahre und durch komplizierte Frakturen gegeben. Der Nagel im Calcaneus wurde in allen Fällen seiner Verwendung ohne besondere Beschwerden von den Kranken ertragen.

Die ausführliche Schilderung des Verbandes (siehe auch Arch. d. ortopedia 1902) würde den Rabmen eines Referates überschreiten.

Buschi, Attilio, Bologna, Sopro un caso di perdita di liquido cefalorachidiano per ferita della dura matre spinale.

Nach einem Stich mit einel Gabel gegen den 6. Halswirbeldorn traten bei einem 6 jührigen Kinde neben dauerndem Ausfluss von Zerebrospinalflüssigkeit meningitische und paralytische Erscheinungen (Astasie, Kopfschmerz, Kernik'sches und Babinsky'sches Symptom, Herabsetzung der Sehnenreflexe) auf. Der recht reichliche Flüssigkeitsstrom aus der Wunde - täglich ca. $70 \mathrm{ccm}$ - nötigte zur Freilegung der Wunde, wobei sich eine kleine Duralöffnung fand, aus der die Zerebrospinalflüssigkeit ausflose. Es gelang die Öffnung durch feine Catgutnähte zu schliessen, woraut alle bedroblichen Symptome rasch schwanden und Heilung eintrat. In der Gesamtliteratur finden sich nur 6 ähnliche und ein identischer Fall.

Motta, Marco, Torino, Plastica del calcagno per corregere nei bam. bini talune forme di piede torto congenita.

Verfasser betont zunächst den streng konservaticen Standpunkt, den er bei der Behandlung des kongenitalen Klumpfusses aller Grade einzunehmen pflegt. Es gibt jedoch Fälle 2. und 3. Grades, bei denen alle unblutigen Behandlungsmethoden nicht das gewünschte Resultat ergeben und für die die Achillotenotomie bezw, die Phelpsische Operation in Betracht kommen. Des weiteren sah Verfasser Fälle mit weit rorgeschrittener Deformation der Knochen, insbesondere des Calcaneus, für die reder die unblutigen noch die oben genannten blutigen Operationen ausreichten. Es bestand in diesen Fällen die Unmöglichkeit, den Calcaneus auf den Boden aufzusetzen. Verfasser entschloss sich nun in einem der letztgenannten Fälle zu einer Knochenplastik. Durch einen Längsschnitt etwas nach innen von der Mittellinie wird die dchillessehne und der hintere Fersenbeinhöcker nach Exzision des umgebenden Fettes freigelegt. Es zeigt sich, dass der Höcker statt horizontal gelagert mehr nach oben und innen geulrebt ist, und dass dio 
Acbillessehne an dem oberen Rande des Höckers inseriert. Es wird nun die Achillessehne von der Ferse gänzlich gelöst und der Fersenbeinhöcker durch einen Schrägschnitt so umgelegt, dass er horizontal gelagert ist und an seinem zehenwärts gerichteten unteren Unfang in Verbindung mit dem Knochen bleibt. Die bedeutende Diastase der Sehne blieb sich selbst überlassen. Das Resultat war ein vorzügliches, die Equinusstellung war dauernd verhindert, so dass sich Verfasscr entschloss, auch am anderen Fusse die gleiche Plastik auszuführen, die ein ebenso gutes Resultat hatte.

Putti, Vittorio, Bologna, Le deformita nella siringomielia e nella tabe.

Eine kurze Übersicht über die bisher bei Syringomyelie beobrchteten Knochenund Gelenkveründerungen, deren Kasuistik durch eine syringomyelitische Skoliose bereichert wird. Ausführliche Literaturangaben sind beigefügt.

Bossi, Pietro, Milano, Piede piatto.

Verfasser bringt eine austührliche, über 200 Seiten umfassende, recht beachtenswerte Monographie des Plattfusses, dessen Literatur ausgiebige Berücksichtigung findet. Nach einer eingebenden Schilderung der auatomischen Einzelheiten und Besonderheiten des normalen Fusses schildert Boss i zunächst den angeborenen Plattfuss, Die Statistik ergibt, dass der reine $P$ es valgus sich selten angeboren findet; häufiger findet sich beim Neugeborenen der reine Plattfuss, der ausserdem eine Rasseneigentümlichkeit der Juden, Kabylen und Neger ist. Nach einjgen Autoren soll sich der Plattfuss bei Epileptikern häufig finden und geradezu ein Degenerationszeichen darstellen.

Bezüglich der Pathogenese stellt sich Verfasser nach Anfübrung der hauptsächlichsten Theorien auf den Standpunkt des mechanischen Druckes, entweder direkt von der Uteruswand oder infolge falscher Lagerung der Füsse.

Bezüglich der Symptomatologie und pathologischen Anatomie weiss Verfasser im allgemeinen keine Besonderheiten anzuführen; doch berichtet er über 2 Fälle von angeborenem Plattfuss, dessen Ursache in einer Veränderung des Unterschenkel. skeletts gesucht werden muss. In beiden ausfübrlich mitgeteilten Fällen handelte es sich um eine wirkliche kongenitale Fussgelenksluxation, die sich von der nahe verwandten Volkmann'schen Fussgelenks-Deformität durch eine wirkliche Verlagerung des unteren Fibulaendes unterscheidet. In beiden Fällen wurde durch einen operativen Eingriff (Resektion des Fussgelenkes, bezw. Fixation der Fibula an passender Stelle durch Knochennaht) ein therapeutischer Erfolg erzielt.

Einen weit grösseren Raum beanspruchen die Ausfübrungen Bossi's über den erworbenen Plattfuss, der entweder traumatisch oder durch Weichteil- und Knochenerkrankungen oder durch pathologische Funktion statisch-mechanisch bedingt ist.

Der statische oder funktionelle Plattfuss ist vor allem bedingt durch Alter und Profession, indem ein noch nicht völlig entwickeltes Fussskelett durch zu starke Belastung deformiert rird. Daneben spielen Konstitutionskrankheiten, allgemeine Muskelschwäche, rasches Wachstum nach Länge und Gewicht, Ernährungsstörungen der Extremitäten durch Phlebektasien, for allem auch erbliche, degenerative Einflüsse und Rassenunterschiede (Differenzen in der geographischen Verbreitung in einzelnen Ländern) eive bedeutende Rolle.

All diese Einflüsse zeigen sich in mensurabler Grösse in der Fusswölbung und dem Winkel, den die einzelnen Fusswurzelknochen miteinander bilden. Dazu kommen noch die Einflüsse des sonstigen Körņerskeletts, soweit die Statik des Stehens und Gehens in Betracht kommt. Verfasser macht auf die bei Plattfuss häufigen Skoliosen aufmerksam und betont den Unstand, dass sehr oft der Schenkelbals eine von der $\mathfrak{N}_{\text {orm }}$ abweichende Richtung zeigt, indem die Torsion des Femur 
(Winkel zwischen Schenkelhalsachse und Kondylenhinterfläche) erheblicbe Schwankungen zeigt und sogar auf beiden Seiten desselben Individuums um einige Grade Fariieren kann.

Die bisher aufgestellten Theorien über die Pathogenese des Plattfusses werden sodann in einem weiteren Kapitel in historischer Entwickelung ausführlich wiedergegeben und eine Zusammenfassung der verschiedenen Ansichten versucht. Dabei kommt der Verfasser zu dem Ergebnis, dass die bisher vorgebrachten Anschauungen zu einer wirklichen Lösung des Problems nicht ausreichen, zumal sie grossenteils auf spekulativen Deduktionen und nur in ganz geringem Umfange auf experimentellen und pathologisch anatomischen Versuchen beruhen.

Bossi berichtet nun über seine eigenen Versuche, der Lösung des Plattfussproblems durch experimentelle Forschungen näherzukommen. Er studierte zu diesem Zwecke die Veränderungen des Fussskeletts unter dem Einfluss der Belastung. Der skelettierte Fuss wurde auf eine horizontale Platte gesetzt und daselbst zwischen Calcaneus und Metatarsusköpfchen fixiert. Der zur Hälfte erhaltene Unterschenkelstumpf wurde durch einen einarmigen Hebel belastet, wobei ein seitliches Ausweichen des Stumpfes verbindert war. Die Verschiebungen der einzelnen Knochen wurden dadurch sichtlich und messbar gemacht, dass in die Knochen $10 \mathrm{~cm}$ lange Nägel getrieben wurden, deren Bewegungen und Abweichungen unter dem Einflusse der Belastung durch einen besonderen, genau beschriebenen Visierapparat abgelesen werden konnten. Genaue Tabellen, zahlreichen Tafeln und Schemata, die die Abreichungen der Achse und die Verschiebungen der Knochenkonturen illustrieren, sind wiedergegeben. Wir können hier über die einzelnen beachtenswerten Tatsachen nicht ausführlich referieren und begnügen uns mit der Angabe der wesentlichsten Schlussfolgerungen Bossiz. „Der Fuss stellt einen Komplex von Gewölben dar, die durch Kugelgelenke miteinander verbunden sind und zwei Systeme bilden. Das eine ist aus zwei gelenkig verbundenen Bogen zusanimengesetzt und wird gebildet vom Talus als Lbermittler der Last, vom Calcaneus und Cuboid, sowie rom 5. und 4. Metatarsus. Das zweite System besteht aus 3 Bogen und wird gebildet vom Talus, Scaphoid und Calcaneus, die den 3 Bogen gemeinsam angehören, und den 3 Cuneiformia mit den 3 ersten Metatarsi. So kann der Plattfuss nur durch ein Abgleiten der vorderen Stützpunkte zustande kommen. Dieses bedingt wiederum eine Rotation des Calcaneus um seinen Stützpunkt mit sich und führt zu einer Verlängerung des ganzen Bogensystems und zur Senkung des vorderen Calcrneushöckers, wodurch die pathologisch-anatomischen Tatsachen eine natürliche Frklärung finden.

In der weiteren Scbilderung der Pathologie und Symptomatologie des Platt fusses bringt Verfasser nichts wesentlich neues, der traumatische, paralytische, spastische, tabische, rachitische Plattfuss rerden kurz erörtert.

Die ausführlich besprochene Therapie des Plattfusses bildet den Schluss der Abhandlung. Bossi führt bierbei die bisher angewendeten Verfahren chronologisch an, wohei er einzelne besondere Methoden hervorhebt, inden er über einige Fülle berichtet, die nach diesen Methoden behandelt wurden. In 4 Fällen wurde eine Sehnenplastik versucht, indem die Sehne des Tibialis anticus freigelegt und in zwei Hälften gespalten wurde. Die innere Hälfte wird dann nach Präparierung des Weges an der Seiten- und Unterfläche des Taluskopfes vorbei, den Navikulare entlang gezogen und am ersten Metacarpus befestigt, so dass sie wie ein elastisches Band den Fuss in die richtige Stellung zu bringen sucht. Die therapeutischen Resultate waren recht gute.

Zweimal wurde die Ogston'sche Operation am Talonavikulargelenke versucht. Aurch hier war der Erfolg ein guter.

Trotzdem kommt Bossi zum Schlusse, dass blutige Operationen an Sehnen und Skelett keineswegs genügen, um den Plattfuss zu heilen. Der Plattfuss ist für den Fuss, was die Skoliose für die Wirbelsäule ist. Dementsprechend ist die 
rationellste Therapie die unblutige d. i. das forcierte Redressement, dem ein Gipsverband folgt.

Negroni, Gioachino, Milano, Deformita scheletriche del tronco in un caso di malattia di Recklinghausen.

Sebr interessunte Kasuistik. Bei einem 8 jahluigen Mrädehen findet sich seit dem 5. Leben-jahre ein Rankenneurom auf der rechten Rückenhälfte, medial rom Schulterblatt. Eine 2. analoge Geschwulst trat nach einem Jahre in der recbten Achselhöhle auf, und nach einem weiteren Jahre zeigte sich eine deutliche dorsolumbale Skolio:e, deren Konkavitït der Rückengeschwulst entiprach. Ausserdem erschienen auf dem Rumpfe zahlreiche unbeharte Pigmentmale.

Die Geschwulst der Achsel wurle entfernt, die Rückengeschwulst konnte nur teilweise exstirpiert werden, weil sie in die MLuskulatur überging. Die entfernten Geschwulstteile zeigten das Bild des plexiformen Neuroms.

Nach einem kurzen Uberblick über die ausfübrlich zitierte Literatur kommt Negroni zum Schlusse, dass die Skoliose wohl mit Bestinmtheit anf die Allgemeinerkrankung zurückzuführen sei, indem sie entweder durch Muskelschwïche oder abnorme Knochenweichbeit bedingt sei.

(Sollte es sich bei der Rürkengeschwulst nicht un ein Neurom gehandlelt huben, das duret eine Spina bifida occulta mit cem Räckenmarb in Verbindung stand? Die Spina bifida occulta würde dann auch leicht die Skoliose erklären. Der Ref.)

Salaghi, Mariano, Firenze, Cura meceanica preventiva del bacino piatto rachitico.

Verfasser geht von den Erfolgen der methodischen Redressierung des mittelschweren Genu valgum der Kinder aus und befürwortet eine analoge Therapie auch für das Becken der rachitischen Kinder, um ein späteres plattes Becken zu verhüten. Er legt die 2-4 Jabre alten Kinder in Seitenlage auf eine starre Unterlage, schiebt unter das Becken ein flaches, hartes Kissen und übt mun mit beiden Händen einen Druck auf die Beckenschaufeln, un den geraden Durchnesser zu verlängern. Die Bebandlung erstreckte sich mehrere Mouate hindurch und zeitigte beachtenstrerte Erfolge, so dass der Verfasser dieselbe auch für ähtere Kinder empfiehlt, bei denen es zuweilen auch durch Richitis tardira zu Beckenveränderungen kommen kanu.

Beduschi, V. e Rossi, B., Milano, Considerazioni sopra un caso di cifosi traumatica.

Bei einem 18jäbrigen Minn findet sich nach einem Sturz aus der Höhe von vier Stockwerken neben Gehirnerschütterung und Vorderarmbruch noch eine Kontusion des Rückens. Daselbst lassen sich Schmerzen zwischen 7. und 8. Brustwirbel und geringe seitliche dbweichung der Dornfortsätze festatellen. Ausserdem bestanden noch Blasen- und Mastdarmlähmung und eine Lähmung des rechten Beines. Die Lähmungen schwanden allmählich, doch bildete sich nach einem Vierteljabr eine beträchlicbe Kyphose der Brustwirbelsäule aus, während gleichzeitig in linken unteren Quadranten des Bauches taktile und thermische Anüsthesie sowie Analgesie bestand und das linke Bein Hypästbesie und Hypalgesie nach. weisen liess.

Unter Berücksichtigung der ausführlich wiedergegebenen und zitierten Literatur nehmen die Verfasser eine traumatische Kyphose an, die sich infolge eines osteomulazischen Prozesses entwickelt hat. Diesen wiederum glauben die Verfasser auf nervöse Einflüsse zurückführen zu können, zumal die übrigen nerøösen Krscheinungen solche wahrscheinlich machen. 
Colivilla, Alessandro, Bologna, Sulla terapia dell' a c corciamen to nella deformiti dell' arto inferiore.

Bei winklig geheilten Knochenbrüchen mit bedeutender Verkürzung der Extremität ist ler Widerstand, der bei der Verlängerung des Gliedes zu überwinden ist, weniger durch der Verkürzung der Knochen als durch die Schrumpfung der Weichteile bedingt. Die Verkürzung der Knochen lässt sich eventuell leicht durch Osteomie ausgleichen, die der Weichteile lässt sich mit viel grösserer Mübe überwinden, zumal bisher nur recht ungenaue und unklare Angaben über die Kräfte existieren, die zur Behebung von Weichteilschrumpfungen nötig sind. Codivilla sucht nun die zur Überwindung der Weichteile nötige Kraft nach einer matbematischen Formel zu berechnen, wobei er jedoch alle näheren Umstände auf die einfachste Form zurückführt. Der Grad der Verkürzung bei winkeliger Verschiebungr wïre demnach gleich der doppelten Distanz der Weichteile rom Knochen, dividiert durch die Summe aus der Tangente des balben Winkels der Deformität und der Längsverschiebung. Fehlt die winkelige Knickung, so ist die Verkürzung gleich dem doppelten Abstande rom Knochen, dividiert durch die Tangente des halben Knickungswinkels.

Die verschiedene Zahl und Verlaufsrichtung der Muskeln, deren Verlauf für die Formel parallel zum Knochen angenommen wird, die Zusammensetzung der Muskulatur aus verschieden elastischen Muskel- und Sehnenfasern bedingen weitgehende Modifikationen der Formel, für die noch alle experimentell festgelegten Mittelmasse fehlen. Es kommt hinzu, dass die Ausübung des Zuges und die ziehende Kraft in sehr verschiedener, zum Teil irrationeller Weise verwendet werden. Codivilla empfiehlt zur Ausübung konstanten Zuges nicht die permanente $\mathrm{Ge}$ wichtsextension, sondern den immobilisierenden Gipsserband nach starkem ein-oder mehrmaligem Zug mit bedeutender Kraft $(25-70 \mathrm{~kg})$. Der einmal angelegte fixierende Verband wurde dabei in der Weise benützt, dass er mit einer Cipsiäge au der Stelle der Osteotomie zirkulär aufgeschnitten murde, worauf Zug und Gegenzug an den beiden Teilen des Verbandes wirkten. Die entstehende Distanz wurde durch einige Gipsbinden und Schienen fixiert. Un den kräftigen Zug ohne Schädigung des Fussrückens ausführen zu bönnen, lässt Codivilla den Gipsrerband nur bis zur Hälfte des Cnterschenkels reichen und bedient sich des Zuges, der direkt atm Skelett angreift, indem er durch den Calcaneus einen starken Nagel treibt und diesen durch zwei seitliche Schienen mit dem Gipsverband zu einem starren System vereinigt. Die Spannung des Fusses lässt sich durch Schrauben regulieren, die zwischen Nagel und Schienen eingeschaltet sind. Der Nagel wird vorzüglich ertragen; die geschilderte Extensionsmethode soll beachtenswerte gute Resultate ergeben.

Acevoli E., Napoli, Annotazioniallo studio del Dott. Bossidal titolo "piede piatto".

Weist darauf hin, dass er zuerst in die Statik des menschlichen Fusses den Beyriff der gelenkig verbundenen Bogen eingeführt habe und erklärt, auf welche Weise er zu der Annahme gekommen sei, dass es sich bei diesen Gelenken um zylindrische Verbindungen bandle.

Inzoletti, Augusto, Bologna, Piccoli appuntisulle condizionistatiche dell' arto inferiore.

Auf Grund von Literaturnachweisen schliesst- der Verfasser, dass der Tractus Alio-tibialis (Maissiati) von wesentlicher Bedeutung für die Statik und Mechanik des Stehens ist, indem ar wie das Ligamentum ilio-femorale (Bertini) für die Extension im Kniegelenk wirkt. 


\section{Archivio di Ortopedia 1905. Anno XXII.}

Muscatello, G., Pavia, Sul piede piatto postgonorroico.

Bei einem 21 jāhrigen Matrosen fand sich 18 Monate nach einer unbehandelten Gonorrhoe ein beiderseitiger, schmerzhafter Plattfuss, der zuerst 15 Tage nach Beginn der Gonorrhoe mit einer Anschwellung im Bereiche der rechten Fusswurzel einsetzte. Vertasser schliesst, dass es sich hierbei zuerst um eine gonorrhoische Arthritis im Bereiche der rechten Fusswurzelgelenke bandelte. Später kam eine ebensolche Erkrankung im Bereiche der linken Fusswurzel tinzu. In beiden Fällen war der Anamnese nach nur eine recht hartnäckige monartikuläre Infektion vorhanden, die Verfasser mit Sicherheit als gonorrhoisch betrachtet. Des weiteren wird die Tatsache hervorgehoben, dass die Knochen gonorrhoisch affizierter Gelenke eine lokale Erweichung zeigen, so dass sich der erkrankte Fuss bei Belastung leicht zu einem Plattfuss umgestalten konnte.

Delfino, Eugenio, Torino, Contributo allo Studio sui tumori dei nervi (Osservazioni cliniche ed istologiche).

Ausfübrlicher Bericht über drei Fälle von typiscber multipler Neurofibromatose, bei denen ein Fibrom des Nervus cubitalis, ein sarkomatös entartetes Neurom der Radialis und ein subkutanes Fibro-Neurom der Lejstengegend entfernt wurde. Des weiteren werden operativ behandelte Fälle von Fibrosarkom des Medianus, Spindelzellensarkom des Ischiadicus und Fibrom des Medianus in all ibren symptomatologischen und mikroskopischen Besonderheiten geschildert. Beachtenswert erscheinen die geringfügigen Symptome, die alle Tumoren machten (lediglich neuralgische Schmerzen) und die relati geringe Malignität der Sarkome. In allen Fällen war die Ausschälung des Tumors ohne Läsion des Nerrenstanmes möglich, es folgte daher auch der Geschwulstentfernung kein Ausfall irgendwelcher nervöser Funktionen; Rezidive wurden nicht beobachtet. Verfasser empfiehlt dementsprechend für die Therapie die Enukleation. Die Resektion des Tumors kommt erst dann in Frage, wenn der Tumor den ganzen Nervenstamm durchsetzt, was erst nach der Inzision der Geschwulstkapsel mit Sicherheit festgestellt werden kann.

Ausführliche Literaturangaben und sehr gute Bilder der histologischen Details ergänzen die Arbeit.

Ferrarini, Guido e Ventura, Claudio, Pisa, Sul modo di comportarsi delle terminazioni nervose nei muscoli degli arti sottopostiall' im mobilizzazione.

Ausgedehnte experimentelle Untersuchungen über das Verhaiten der motorischen nervösen Endorgane nach länger dauernder Immobilisation der Gliedmassen. Die Versuche wurden an Kaninchen gemacht, deren eine Hinterextremität durch Holzschiene, Stärke- und Lreimbinde immobilisiert wurde, so dass Tarsus, Metartus und Unterschenkel mit Sicherheit absolut ruhig gestellt waren. Zur Untersuchung wurden die Gemelli, der Solcus, Tibialis anticus und die Peronei verwendet. Die mikroskopischen Untersuchungen wurden an nach $R$ uffini's Methode vorbehandelten Muskelstückchen rorgenommen.

Unter Berücksichtigung der möglichen Fehlerquellen konmen die Verfasser zu nachstebenden Schlüssen, die durch sehr gute Photogramme illustriert werden.

Nach einer Immobilisierung bis zu drei Monaten treten nachweisbare Veränderungen an den neuro-ınuskulären Spindeln, den Golgi'schen Organen und den Pacini'schen Körperchen nicht auf. Ebenso fehlen an den motorischen Endplatten Verïnderungen der Achsenzylinderverzweigung. Dagegen zeigt sich die granulierte Substanz gewöhnlich geschwellt, und die Körnchen erscheinen deutlicher. Auch diese Veränderungen sind nicht konstant und können Kunstprodukte sein. Auf jeden Fall handelt es sich um recht geringfügige Modifikationen. Ausfübrliche Literaturangaben. 
Capelli, Lorenzo, Dei mezzi che conducono alla saldatura ossea nei casi di mancata consolidazione, nellefratture, nelle resezioni, artrodesi, ecc. Tre casi operati.

Literaturübersicht über die verscbiedenen blutigen und unblutigen Behandlungsmethoden der Pseudarthrosen und analogen Zustände. In drei Fällen (eine Tibiafraktur bei 83 jährigem Manne und zwei Klavikularfrakturen bei jüngeren Individuen) wurde durch blutige Anfrischung der Knochenenden und Nabt mit Seide ein funktionell und kosmetisch guter Erfolg erzielt.

V. Beduschi ed A. Jardini, Milano, Contributo all' anatomia pathologica della spondilosi rizomelica ed all etiologia della cavita midollari.

Kasuistischer Beitrag zur Kenntnis der Bechterew'schen Erkrankung, die bei einer 52 jährigen Frau während des Lebens lange beobachtet und post mortem durch die Sektion weiter untersucht werden konnte. Neben ausgedehnten Verknöcherungen der Lig. flava und interspinosa, der Kapseln der Gelenke der hinteren Wirbelbogen und der Rippenquerfortsätze fanden sicb ein normales Ligamentum longitutinale anticum und unveränderte $Z$ wischenwirbelscheiben. Das Rückenmark zeigte bämorrbagische Herde mit Höhleubildung. In beiden Hüftgelenken zeigten sich die Erscheinungen ausgedehnter chronischer Arthritis.

Unter Berücksichtigung der in Betracht kommenden Literatur und aller ausfübrlich geschilderten klinischen und anatomischen Einzelheiten des Falles kommen die Verfasser zu dem Scblusse:

Wirbelsüulenankylose kann von einer Starre der dem Rumpfe benachbarten Gliedmassengelenke begleitet sein, so dass das klinische Bild der Spondylosis rhizomelica entsteht, ohne dass die Extremitätengelenke selbst versteifen. Die Starre dieser Gelenke ist, wenn es sich nicht um schwere arthritische Prozesse bandelt, durch Muskelkontraktur bedingt, die die Bewegung der Gelenke und dadurch Schmerzen verbindern soll. Die Erscheinungen der Spondylosis rbizonelica sind der Ausdruck eines chronisch arthritischen Prozesses, der mit sekundären Veränderungen des Rückenmarkes einbergehen kann. Wenn es sich hierbei um Höhlenbildungen im Marke infolge von Blutungen handelt, so liegt nicht ein symmetrischer Schwund der grauen Vorderhörner vor, weshalb auch die Höhlen immer symmetrisch liegen.

Die Rückenmarksveränderungen sind durch gute Abbildungen veranschaulicht. Ein ausführliches Literaturverzeichnis ergänzt die Arbeit.

Comisso, Emilio, Bologna, Sulle alterazioni dei muscoli in seguito all' accorciamento.

Um den Zug zur Verlängerung verkürzter Muskeln mit einiger Genauigkeit berechnen zu können, wurden an Kaninchen experimentelle Uutersuchuugen angestellt. Das Olekranon wurde reseziert, so dass sich der Trizeps verkürzen konnte. Nach mehr minder langer Zeit wurde die Trizepssehne mit Gewichten belastet und die sich ergebende Muskelverlängerung mittelst eines Nonius abgelesen.

Die einfache Loslōsung des Muskels von seiner Insertion hatte eine Verkürzung ron $4^{0} \%$ der Länge zur Folge. Bei stärkster Beugung des Ellbogengelenkes ergab sich eine Verlängerung des von der Insertion nicht gelösten Muskelkörpers (Muskelfleisch + Sebne) von $31 \%$. Die stärkste mögliche Belastung des Muskelindividuums ergab eine Verlängerung von $41 \%$ der natürlichen Länge. Bei der Verlängerung von $43 \%$ kam es zum Zerreissen, wobei die Sehne früher riss als das Muskelfleisch. Die Verlängerung erfolgte nicht proportional dem steigenden Zuge, sondern bis unmittelbar vor dem Einreissen ungekehrt proportional.

Wesentlich andere Verhältnisse ergaben sich bei dem vorher von der Insertionsstelle gelösten Muskel, dessen Verkürzung zunächst kraft der Kontraktions- 
fähigkeii noch zunimmt, da die Kontraktion stärker ist als die entgegengesetzt wirkende Elastizitän, die einen Teil jhrer Kraft zur Cberwindung des Widerstandes der umgebenden Gewebe aufbraucht. Eine weitere Zunahme der Verkürzung ergibt sich aus der histologisch nachweisbaren Degeneration der Ifuskelfasern, die eine weitere Elastizitattabnahme und damit mehr ungehinderte Verkürzungs- und bebinderte Verlängerungsmöglichkeit mit sich bringt und bereits in den ersten Tagen am stärksten einsetzt.

Die Degeneration wird durch die später einsetzende Regeneration nur teilweise ausgeglichen, weil sich gleichzeitig der Einfluss der Muskelatrophie geltend macht, so dass der längere Zeit verkürzte Muskel schon durch einen geringereu Zug als der normale zerrissen werden kann, was von Tag zu Tag in gerader Proportion zunimmt. Imbibition der Wunden mit Blut und Vereiterung führt zu einer weiteren Scbädigung der Resistenz. Die hieraus sich ergebende Folgerung für die Praxis wäre demnach, dass stïrkerer Zug nach Tenotomien erst nach einem genissen Zeitraum ausgeübr werden soll, wenn die Gewebe nicht mehr imbibiert sind und die Muskelregeneration bereits in die Erscheinung getreten ist.

Negroni, Gionchino, Milano, Sopra un caso di mixoma purodello scheletro del metacarpo. Contributo alla casistica dei tumori della nano.

Bei einem 75 jährigen Manne fand sich eine schmerzlos im Laufe von zehn Jahren bis zu Faustgrösse herangewachsene Geschwulst des Daumenballens, die mit der Unterlage fest verwachsen, teils Fluktuation, teils Pergamentknittern zeigte. Da der Tumor in der letzten Zeit rascher wuehs, wurde die Amputation des Vorderarms vorgenommen; die pathologisch-anatomische Untersuchung ergab ein reines Myxom, das den Metacarpus pollicis grossenteils zerstört hatte. Literaturangaben über die relativ seiten beobachtete Greschwulst sind beigefügt.

Calamida, Fugenio, Torino, Ossificazioni muscolari traumatiche.

Ausfübrlicher Bericht über sieben Fülle von sogenannter Myositis ossificans traumatica, die genau yeschildert und analysiert werden. Im ersten Falle handelte es sich um eine zystische Geschwulst bei einem 53 jührigen Arbeiter, der 40 Tage vorher einen Hufschlag gegen den rechten Arm erlitten hatte. Verfasser führt die Zystenbildung, die sich auch in fünften Falle in den Anfängen zeigte, auf rasche Knochenproduktion un einen grossen Bluterguss herum zurück. Die Entfernung des Tumors, der die Beugung im Ellbogengelenk behinderte, gab ein recht gutes funktionelles Resultat. Der zweite Fall erscheint beachtenswert, da es sich eben um beginnende Ossifikation handelte und infolgedessen der pathologische Zustand in seinen ersten Anfängen beobachtet werden konnte. Er wurde bei einem 20. jäbrigen Manne beobachtet, den ein gieitendes Gepäckstück von $2 j \mathrm{~kg}$ Gewicht gegen die rechte Hüftgegend gefallen war und der nach 19 Tagen bereits wegen erschwerter Beugung im Hüftgelenke in Behandlung $\mathrm{kam}$, so dass an dem exstirpierten Muskel alle Veränderungen im Anfangsstadium studiert werden konuten. Im dritten Falle war die Verknöcherung bei einen 30 jährigen Arbeiter nach einem Stoss des Oberschenkels gegen eine Metallkante im Tensor fasciue latae und in den Oberschenkeladduktoren entstanden, ebenso im vierten Falle bei einem 10 jährigen Jungen durch einen Fusstritt gegen den linken Obersehenkel, während der fünfte Fall (Verknöcherung im Rectus femoris bei einem 35 jäbrigen Gärtner keineriei stärkere Gewalteinwirkung nachweisen liess. Der sechste Fall betraf den M. tenporalis einer 34 jährigen Frau und kam durch Fall von einer Treppenstufe zustande. Dagegen ist die Atiologie des siebenten Falles (Verknöcherung des M. pectineus recht unklar, so dass bier eigentlich nicht von einer Myositis ossificans traumatica gesprochen werden kann.

Eine ausführliche Schilderung der Symptonatologie, Ätiologie und Therapie unter kritischer Benutzung der in Frage kommenden ausführlich mitgeteilten Lite- 
ratur ergänzt die Ábeit, Bezüglich der Pathogenese kommt der Verfasser auf Grund ausgedehnter mikroskopischer Versuche zu dem Resultate, dass periostaler und vor allem muskulärer Ursprung (aus dem intermuskulären Bindegewebe) der Ferknöcherung vorliegen kann. Die Verknöcherung selbst ist ein chronisch-entzündlicher reaktirer Prozess, der der Geschwulstbildung nahe verwundt ist.

Anzoletti, Augosto, Bologna, Il tricipite surale nei trapiantitendinei.

Der Triceps surae stellt in gesundem Zustande eine reiche Kraftquelle für Sehnenverpflanzungen dar, die jedoch erst dann vorteilhaft verwendet wird, wenn dieser starke Muskel in seine einzelnen Komponenten zerlegt wird, die kraft ihrer besonderen Form und Zusammensetzung für die einzelnen paralytischen Muskelgruppen von besonderem Werte sind. Durch einen von der Kniekehle bis zum Fersenhöcker reichenden Schnitt kann der ganze Trizeps in die von der Natur gegebenen kraftspendenden Einzelkomponenten aufyeteilt werden, so lass sich zunäcbst eine Fülle ron verfügbarer Muskelkraft für die einzelnen Transplantationen ergibt. Die einzelnen Muskelteile haben je nach ihrer Lage eine reichliche Bewegungsfreiheit. $\mathbf{E}_{s}$ können daher auch entfernt liegende Muskeln ohne alizu grosse Schwierigkeit und schädigende Spamnung versorgt werden. Fin weiterer Vorteil ist die Aufteilung des Muskels, der durch seine Masse und durch den langen Hebelarm des Calcaneusansatzes am meisten fühig ist, das Gleichgewicht der Muskulatur zu stören. Dass diese Verminderung der übergrossen Kraft eines einzelnen Muskels obne Verlust von Muskelsubstanz for sich gehen kann, muss ebenfalls als Gewinn betrachtet werden. Weitere Vorteile sind die Möglichkeit, die entlehnte Kraft genau abstufen zu können und genau die Form des paralytischen Muskels durch den neuen Muskelteil zu ersetzen, da die einzelnen Komponenten des Triceps surae die verschiedensten Muskeltypen repräsentieren.

Die Einwände Langes gegen die Verwendung ron Muskelteilen werden abgeschwächt, dagegen wird der Nachteil des grossen Hautschnittes betont. Fbenso wird als Nachteil hervorgehoben, dass der als Flexor dorsalis oder peroneus verpflanzte Gastrocnenius veränderiche Fixationspunkte besitzt, so dass ex in gewissen Phasen seiner Exkursionen für die Gelenke, über die er hinwegzieht, eine Hemmung bililet.

Negroni, Gioachino, Milano, Dell' osteoartrite deformante giovanile dell' anca.

Bericht über drei Fälle jugrendlicher Arthritis deformans der Hüfte bei einem 21 jährigen Manne, 9jährigen Knaben und einem 13 jührigen Mädchen. Im ersten und dritten Fall wurde durch einen operativen Eingriff (Resektion des Schenkelkopfes bezw. Osteotomie des Schenkelhalses) Besserung erzielt. Der Verfasser betont die vielfache Variabilität der klinischen Symptome der Erkrankung, die auf Grund der Literaturangaben viel seltener zu sein scheint, als sie tatsächlich ist. Das Röntgenbild dürtte die Stellung der Diagnose in dern meisten Fällen ermöglichen und auch da aufklären, wo undeutliche Erscheinungen nicht gerade auf die in Frage stebende Erkrankung hinweisen. Bezüglich der Pathogenese des Prozesses kommt Negroni auf Grund histologischer Untersuchungen zu dem Sehlusse, dass dieselben Vorgänge rorliegen wie beim Malum coxae senile. Am Knochen und Kapselgewebe kommt es zu proliferierenden und regenerativen Veründerungen, während am Knorpel mehr degenerative Prozesse sich zeigen, die infolge der Bewegungen und des Druckes der Körperlast zur Abschleifung und Deformation führen. Literaturübersicht und gute Abbildungen.

Stampa, Franco, Milano, Un caso di piede valgo da esostosi solitaria dell' astragalo.

Bei einem 11 jährigen Schüler fand sich ein Tumor am inneren Fussknöchel, der langsam im Laufe von fünf Jahren zur Apfelgrösse herangewachsen war und 
zuletzt das Geben und die Bewegungen des Fusses schmerzhaft gemacht hatte, Spuren früherer Rachitis waren vorhanden, der Fuss stand in Valgusstellung. Das Röntgenbild ergab eine isolierte Exostose des Talus, die durch einen U-förmigen Schnitt entfernt wurde. Die Untersuchung des gelappten Tumors ergab spongiösen Knochen, der teils fibrōsen, teils knorpeligen Ưberzug hatte. Sonstige Exostosen wurden nicht gefunden. Volle Heilung. Literaturangaben.

Tulpius. Osear, Heidelberg, Apparechio ed operazione nella terapia or topedica.

Persönliche Erfahrungen über Wert und Wichtigkeit der blutigen und unblutigen orthopïdischen Behandlungsmethoden. Der Wert der nach Hessing. 'schen Prinzipien angefertigten Schienenapparate ist nicht durch die therapeutische Funktion derselben bedingt, sondern durch die Möglichkeit, mit Hilfe der Apparate die auf andere Weise erreichte Korrektion zu erhalten und zu sichern. Auch der beste Apparat bedeutet durch sein Gewicht eine Last für den Träger. Die chirurgischen Eingriffe haben im allgemeinen die Schnelligkeit der Heilung, die geringeren Unbequemlichkeiten und Kosten für sich.

Für die Skoliose empfiehlt Vulpius die möglichst frühzeitige gymnastische Behandlung, zu deren Vervollstāndigung und Ausnützung in schweren Fällen ein Korsett treten muss.

Bei der Spondylitis tuberculosa kommt zunächst ein portatirer Stützapparat in Frage, der eventuell durch ein Gipsbett unterstützt werden kann Das Calot'sche Verfabren soll nur in beschränktem Masse bei ausgeheilten Fãllen verwendet werden, chirurgische Eingriffe sind nur bei Kongestionsabszessen und Kompressionsmyelitis zulässig.

Zur Behandlung schwerer tuberkulöser Koxitiden und Gonitiden hält Vulpius chirurgische Vorbildung für unbedingt nötig. Die Therapie muss hier jederzeit obne Voreingenommenheit der Sacblage genau angepasst werden. Beim Kniegelenk bietet die konservative Resektion recht grosse Heilungschancen, doch soll auch bei fortschreitender Koxitis mit dem Eingriff nicht allzu lange gezögert werden. Für die Nachbehandlung kommt der Schienenhülsenverband zu seinem Rechte, während bei der Behandlung der Folgeerscheinungen der chirurgische Eingriff (Osteotomie) vorzuziehen ist.

Bei der kongenitalen Hüftluxation ist ein einfacher orthopädischer Apparat wertlos, die besten Erfolge zeitigt die unblutige Reposition, obwohl auch diese nicht alle optimistischen Erwartungen erfüllt.

Für den Klumpfuss kommt im wesentlichen die unblutige, allmähliche Redressierung in Frage, während für den Plattfuss eine genau angepasste Einlage in den meisten Fällen vollen Erfolg schafft. Vulpius zieht die Zelluloideinlage allen anderen Materialen vor.

Wesentliche Fortschritte brachte die chirurgische Therapie auf dem Gebiete der paralytischen Glieder, die durch die Sehnenverpflanzung zum Teil wieder gebrauchsfähig werden.

Anzoletti, Augusto, Bologna, Annotazioni intorno al piede equinocavo acquisito ed all' equino-cavismo quale sintoma di un' affezione nervosa non ancora descritta.

Ausführlicher Bericht über drei Fälle von doppelseitigem Hohlspitzfuss. Im ersten Falle war eine vor 16 Jahren überstandene spinale Kinderlähmung die veranlassende Ursache, in den beiden anderen Fällen hanclelte es sich um eine in der bisherigen Literatur nicht beschriebene spastische Parese, die mit Wadenkrämpten im jugendlichen Alter in die Erscheinung trat und allmählich zur stationär bleibenden Kontraktur führte, neben der die Reflexe gesteigert waren und Anästhesie im Bereiche der Peronei bestand. Erscheinungen ron seiten des Knies und der 
Hüfte fehlten dagegen in beiden Fällen völlig, ebenso alle Symptome, die für die Diagnose eines sonstigen Krankheitsbildes verwertet werden konnten. Das klinische Bild war in allen drei Fülen das gleiche. Gänzliche Atrophie der Extensoren und dadurch bedingte Equinusstellung, Hyperextension im Zehengrundgelenk, Hohlfuss und extreme, passiv nicht ausgleichbare Wadenkontraktur. Der Hohlfuss wird durch den Gehakt zu erklären versucht, bei dem einerseits die Belastung wirkte, anderseits das Bestreben, den durch die Equinusstellung zu hohen Fuss zu verkürzen. Die eigentliche Höhlung war durch Talus, Keilbeine und ersten Metatarsus gebildet, während die übrigen Fusswurzelknochen relativ starr blieben. Redressierung und Sebnentransplantation hatte in allen drei Fällen guten Erfolg.

Comisso, Emilio, Trieste, Contributo all' impiombatura delle ossa. In vier Fällen wurde die genau nach Vorschrift angefertigte Jodoformplombe mit Erfolg bei tuberkulösen Kn்ochenherden verwendet. Sehr schöne Röntgenbilkler illustrieren den allmählichen langsamen Ersatz der Plombe durch neugebildetes Knochengewebe. Literaturangaben.

Codivilla, dugusto, Bologna, L'elemento fungionale nella cura della tuberculosi articolare.

Mit Rücksicht auf die Funktionstüchtigkeit der Gelenke möchte Codivilla der Resektion einen breiteren Spielraum in der Therapie gewährt wissen, als dies bis in die letzte Zeit geschab, obwobl die Ausheilung konservativ behandelter Gelenktuberkulosen an der unteren Extremitä in einzeinen Fällen zu sicheren und vollkommenen Resultaten führt. Soziale Stellung und ähnliches ist hierbei jedoch sebr zu berücksichtigen. Von Wichtigkeit ist anch das Röntgenbild, das einzelne Herde offenharen kann, die sofortige Exzision nötig machen. Beim chirurgischen Eingriff ist der furktionelle Erfolg um so besser, je weniger die Muskulatur und die notwendigen Fixationen des Gelenkes gesehädigt werden und je länger das Glied im immobilisierenden Verband ist.

Das jugendliche Alter bildet keine Kontraindikation gegen die Kniegelenkresektion, wenn nur die Epiphysenlinien geschont werden. Nachfolgende Deformitäten lassen sich ohne grosse Schwierigkeiten vermeiden. Verikürzungen können durch schräge Osteotomie, Kontrakturen durch Tenotonien beboben werden. Für die Flexionskontraktur in Knie empfiehlt Codivilla ror allem die Verlängerung der Weichteile, die das grösste Hindernis für die Geradestreckung bilden, aus dem Knochen wird entsprechend den Oberschenkelkondylen ein zylinderisches Stück berausgenommen. Bei Hyperextension kommt ebenfalls die Exstirpation eines Knochenzylinders in Frage, während bei schweren lateralen Verschiebungen ledig. lich ein $\mathrm{Y}$-förmiger Keil entfernt werden soll, wie dies ähnlich Kruken berg für das Genu valgum angegeben bat. Schlotternde Pseudartbrosen sollen durch möglichste Erhaltung des Bandapparates vermieden werden; sind diese Veränderungen eingetreten, so empfieblt Codivilla die Knochennaht und die Schaffung künst. licher Bandapparate uus versenkten Seidenfäden.

Bei Resektioven im Bereiche der oberen Extremitüten lassen sich durch Schonung der Muskulatur bewegliche Gelenke erzielen.

Nach Schulterresektionen wird eine grössere Beweglichkeit des Oberarmes erreicht, wenn man die Articulatio acromio-clavicularis und damit die Scapula beweglich macht, während man gleicbzeitig den Humerus am Schulterblatt in stärkerer Abduktion fixiert.

Die konservative Behandlung der Gelenktuberkulosen ist ganz dem einzelnen Falle anzupassen. In jedem Falle erscheint die Immobilisierung in guter Stellung wünschenswert. Ist eine Kontraktur vorhanden, so kann dieselbe vorsichtig obne Schaden behoben werden. Die Immobilisierung darf erst verlassen werden, wenn keine Schinerzen mehr vorhanden sind - so lange ist Bettruhe nötig - und renn 
keinerlei Eutzündungserscheinungen mehr nachgewiesen werden können. Nach einfachen Kapselerkrankungen kann dann forsichtig mit aktiven und passiven Bewegungen des Gelenkes begonnen werden, nach Knochenveränderungen soli jeder Bewegungs rersuch unterlassen werden.

In rorgeschrittenen Fällen wären zuerst die Weichteilkontrakturen zu beheben, die Knochendeformitäten sollen stufenweise redressiert werden. Dauernde Immobilisation erscheint unumgänglich nötig. wobei jedoch Verkürzungen und Kontrakturen durch Osteotomien und Sebnentransplantation behobeu werden sollen. Die Lorenz"sche pelvitrocbantere Osteotomie wird verworfen, ebenso die fon $\mathrm{Calot}$ empfoblene subkutane Osteotomie des Schenkelhalses. Für doppelseitige Hüftgelenksankylosen käme die Helferich'sche Arthrolysis auf der einen Seite in Frage.

Putti, Vittorio, Bologna, Le deformita nella siringo-miela e nella tabe.

Siehe oben 1904 .

Ausführliche Besprechung der tabischen. Gelenksveränderungen, Knochenschädigungen (Spontanfrakturen, Kallusdefornitäten, Myositis ossificans), Wirbeldefornitïten (Neigung zur Fraktur und zur Kyphoskoliose) und des tabischen Plattfusses.

In allen Fällen ist das plötzliche Auftreten und die rasche Verschlimmerung mit Zunahme der Deformität beachtenswert, besonders zur Differentialdiagnose gegenüber der Syringonyelie.

Drei Krankengeschichten (beiderseitige Arthropathie des Kniegelenks, tabischer Plattfuss und einseitige Kniegclenksarthropathie). In zwei Fällen fanclen sich im Röntgenbild die von $K$ ie $n b \ddot{b c k}$ für Tabes als charakteristisch bezeichneten Veränderungen (deutlich sichtbare Kapsel, Veründerungen der Knochenstrukturen und Knochenachsen).

Angilotti, Giulio, Pisa, Sui tumori primitivi della rotula e sulla resezione di essa.

Verfasser berichtet über eine bisher noch nicht in der Literatur erwähnte primäre Geschwulst der Kniescheibe, die bei einem zehnjährigen Knaben zur Beobachtung kam. Sie hatte sich im Anschluss an einen Fall seit dem sechsten Lebensjahre langsam entwickelt und bewirkte einen Gelenkerguss und erheblich behinderte Beweglichkeit des Kniegelenkes. Die Geschwulst ging vom äusseren Drittel der Kniescheibe aus, dem sie mit einer scbmalen Basis aufsass, während sie den Rest der Patella wie eine Kapuze deckte, und wurde mit ihrer Basis abgetragen. Sie zeigte sich reichlich apfelgross ron derber, höckeriger Oberfläche und bestand aus Knochen und Knorpel, die beide in lebhafter Wucherung waren.

Der Condylus externus des Oberschenkels zeigte ausserdem eine kleine Exostose an der Stelle, wo die Kniescheibengeschwulst die Trochlea berührte; ein aualoger knorpelig-knöchener Tumor fand sich in der Gelenkkapsel an einer Stelle, die dem lateralen Teil der Patellargeschwalst entsprach.

Der Verfasser glaubt nicht, mit Bestimmtheit entscheiden zu können, ob es sich um eine Exostose oder Osteochondrom handelte; als Ausgangspunkt wird eine embryonale Keimversprengung angenommen und dabei betont, dass die Geschwulst von einem Knochen ausgeht, der keinen Epiphysenknorpel besitzt.

Die Symptomatologie der Patellargeschwülste wird ausführlich erörtert, zum Schlusse erwähnt der Verfasser noch die verschiedenen Möglichkeiten der Operationen an der Patella und die Indikationen der einzelnen Eingriffe. Die Entfernung der Kaiescheibe ist angezeigt bei primüren Geschwülsten derselben, bei Karies, Nekrose und der Osteitis neuralgica (Olliers). Die operative Technik ist verschieden je nach Entwickelung der Patella und Ursache der Entferuung. Bei noch nicht vollentwickelten Individuen kann eine Neubildung der Kniescheibe statt- 
finden, indem die Kontinuităt des sehnigen Apparates nicht unterbrochen wird. Bei Erwachsenen dagegen findet keinerlei Neubildung statt, so dass zur Erhaltung des Bandapparates plastische Eingriffe nötig sind, da sich die beiden Sehnenenden nicht obne weiteres vernähen lassen.

Ferrarini, Guido, Pisa, Sopra la fungione dei muscoljimmobilizati (Studi e ricercbe sperimentali).

Eine ausserordentlich fleissige, mühevoll experimentelle Arbeit über die Funktion immobilisierter Muskeln.

Die ausführlich geschilderten, durch 30 Kurven und 10 Tabellen illustrierten Experimente wurden an Fröschen und Kaninchen ausgeführt, wobei die Extremitäten der Frösche in der Weise immobilisiert wurden, dass die hinteren Extremitäten längs des Bauches geführt und mit einem Seidentaden an den Vorderfuss fixiert wurden. Die Dauer der Fixation war bei den Fröschen relatio gering, nicht üher zelnn Tage; der zur Prüfung verwendete Muskel war der Gastrocnemius.

Es zeigte sich nun zunächst, dass die elektriache Frregbarkeit in immobilisierten Muskel abnimmt. Die Abnahme ist nur bis $\mathrm{zu}$ einem gewissen Grade proportional der Immobilisierungsdauer und ist nicht sehr erbeblich. Bezüglich der Zuckung ergab sich durchwegs eine recht beträchtliche Abnahme der Kontraktionsenergie, ausserdem fanden sich Fon der Norm recht abweichende, jedoch inkonstante Unterschiede zwischen Schliessungs- und Öffnungszuckung. Auch hier war die Grösse der Veränderungen nur bis zu einem gewissen Grade abhänuig von der Dituer der Ruhigstellung. Das gleiche zeigte die Messung der Arbeitsleistung des immobilisierten Muskels, die ebenfalls im Mittel eine geringere ist, als die des gesunden Muskels. Die Ermüdung tritt dabei rasch ein, so dass die Kurve steil abfällt. Beim Zuckungstetanus fand sich ein rascheres Eintreten, geringere Intensität und langsames Abfallen.

Eine Zusammenfassung der gefundenen Resultate ergibt, dass der immobilisierte Muskel sich ähnlich verhält wie ein ermüdeter Muskel, er zeigt nicht allein anatomische Veränderungen, sondern auch funktionelle, indem er funktionsuntüchtiger wird.

(Schluss folgt.)

V.

\section{Zur Osteotomie-Frage.}

Sammelreferat von

Dr. Roichenbach in Leipzig.

\section{Arbeiten aus dem Jahre 1905 .}

v. Aberle, Subkutane Osteotomie. Zeitschr. f. ortb. Chir. XIV.

Broca, Ref. im Zentralbl. f. Chir. 1905. S. 1306.

Destot, De la perte des mouvements de pronation et de supination dans les fractures de radius. Ref. in Hildebrand's Jahresbericht. 1905. S. 1144. Lyon inéd. 1005. No. 53.

Deutschlïnder, Zur operativen Behandlung des Genu recurratum. Zentralbl. f. C'bir. 1905. Nr. 36 . 
Berichte.

Gaudier, A propos d'un cas de coxa vara traumatique de l'enfance traité par l'ostéotomie cervicale et guéri. Rev. dorthop. 1905. No. 2. Ref.: Zentralbl. f. Chir. 1906. S. 172 .

Ghiulamila, Die Verwendung der Osteotomie zur Ausgleichung ron koxitischen Ankylosen. Med. klin. 1905. No. 5. Ref. im Zentralbl. f. Chir. 1905. S. 322 .

Härting, Zwei Fälle von Coxa varæ. Münch. med. Wochenschr. 1905̃. S. 1563. Kölliker, Über Coxa valga. Münch. med. Wochenschr. 1905. Nr. 36.

Lund, Reports of de Boston city hospital, XV. 1905. Ref. im Zentralbl. f. Chir. 1906. S. 383.

Openshaw, The treatment of severe curvatures in the tibiae by means of manual osteoclasis. Lancet. 4. III. 05 .

Pätzold, Zur Frage der Osteotomie bei Genu valgum adolescentium. Beitr. z. klin. Chir 47.

Poulsen, Über die Madelung'sche Deformitït der Hand. Arch. f. klin. Chir. 75 .

Sonnenberg, Beiträge zur Kenntnis der Ostitis deformans (Paget'sche Krankheit der Knochen). Fortschritte auf dem Gebiete der Röntgenstrahlen. VIII. Ref. im Zentralbl. 1905. S. 1098.

Wette, Zur operativen Behandlung des schmerzenden Hohlfusses. Beitr. z. klin. Chir. 47 .

Wittek, Zur operativen Therapie der seitlichen Kniegelenksverbrümmungen. Beitr. z. klin. Chir. 46.

v. Aberle gibt einen geschichtlichen Überblick über die Entwickelung der Osteotomie, ibre Entstehung unter ₹. Langenbeck und Mayer, die Ausbildung eines radikaleren Charakters unter dem Schutze der Antisepsis, die Beziehung zur Osteoklase und die Herausbildung der jetzigen "subkutanen" Verfahren. Das von ihm im Verein mit Lorenz ausgebildete und geübte Vorgehen lebnt sich an die Billroth'sche Durchmeisselung der Kortikalis und die Reiner'sche Zirkumferenzosteotomie an. Er benutzt einen einfacben, beiderseitig geschärften Meissel mit einer schneidenden Kante von $1 \mathrm{~cm}$ und durchmeisselt, unter Erhaltung der Spongiosa, die Kortikalis in etwa ${ }_{1 / 3}^{1}{ }^{1 / 2}$ der Peripherie prinzipiell auf der konkaven Seite der Deformität; der so geschwächte. Knochen wird manuell eingebrochen, wobei keine Kortikalis auf Zugfestigkeit beansprucht wird. Bei der Behandlung der Adduktionskontraktur der Hüfte ist allerdings aus anatomischen Gründen die Anmeisselung aus der konvexen Seite erforderlich und hat die Frakturierung zunächst im Sinne einer Deformitätsvermehrung zu erfolgen. In 63 Fällen hat sich das Verfahren als gut erwiesen.

Die Osteotomie bei Paget'scher Krankheit erscbeint bedenklich infolge der überaus geringen Neigung zur Konsolidation. Ein von Sonnenberg beschriebener Fall, ein 16 jähriges Mädchen, wies 13 Monate nach der Operation noch keinerlei Kallusbildung auf.

Die Osteotomie bei Genu valgum behandelt Wittek in einer Arbeit aus der Grazer Klinik. Der Epiphyseolyse spricht Verf. sowohl den Vorzug, am Punkte der grössten Deformität anzugreifen, ah, als auch besonders unblutigen Charakter; sodann müssen nach Verf. die später sich einstellenden Verkürzungen als ein Nachteil der Epiphyseolyse berücksichtigt werden. Den einzigen Vorzug der Epiphyseolyse, die Ungehung der nach einfachen lineären Osteotomien beobachteten unschönen Dislocatio ad axin mit Bajonettstellung, versuchte Verf. zu erreichen durch eine bogenförmige Trennung des Femur, gab aber ditses Vorgehen wegen technischer Schwierigkeit auf und verwendet nun die schräge lineäre Osteotomie, die Trennungsebene von hinten unten nach vorn oben legend. Der Hautschnitt wird innen angelert, der Knochen durchmeisselt. Streckverband. Befindet sich der Sitz der Verbildung in der Tibia, so wird diese durchmeisselt; die Fibula wird nicht durchtrennt. 
Üher die Erfahrungen der Königsberger Klinik auf diesem Gebiet berichtet

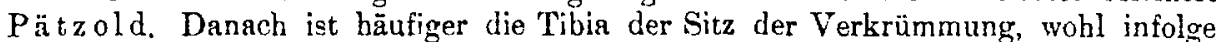
der frübzeitigen Verknöcherung der Femurepiphyse. Bei wagerechter Gelenkspalte wird daher stets die Tibia osteotomiert, zuweilen sogar auch bei schräger Gelenkspalte. Techuisch erweist sich die Tibiaosteotomie leichter und bietet weniger Gefahr einer Heilung unter Verkürzung. Sie wird keilförmig mit dem Meissel gemacht, der Keil hinten etwas breiter genommen. Die Fibula wird im unteren Abschnitt osteotomiert. In schweren Fällen käme zweizeitige Osteotonie an Tibia und Fenur in Betrachr. Die der Tibiaosteotomie zum Vorwurf gemachten Peroneuslāhmungen hat Verf. auch bei Femurosteotoniee beobachtet und fübrt sie, nach v. Aberle, zurück auf Zerrung des am Fibulaköpfchen und bein Durchtritt durch die Peronealmuskulatur mittelst kurzer Seitenäste ziemlich unverschieblich fixierten Nerven. Die Resultate des allmählichen Redossements nach v. Mikulicz, desgleichen die der Osteoklase waren weniger gut. Vergl. Referat dieses Archiv VI, S. 264.

Zur Behandlung eines Falles von Genu recurvatum hat Deutschländer den Weg der Osteotomie beschritten. Er durchmeisselte das Femur suprakondylär schrïg und drehte den unteren Knochenabschnitt so um dessen Querachse, dass die abnorm weit nach vorn reichende Gelenkfläche nach unten gericbtet wurde und mit der Tibia in normaler Richtung artikulieren konnte. Das Ergebnis war gut. Vergl. Referat in Bd. VI.

In zwei Fällen von Coxa vara hat Härting durch die Hoffa'sehe subtrochantere Osteotomie gute Heilung erzielt. Desgleichen Gaudier durch Schenkelhalsosteotonie.

Zur Coxa valga berichtet Kölliker über zwei Fälle und empfiehlt bei Frwachsenen, wenn die Beschwerden gross sind, die keilförnige Osteotomie des Schenkelhalses.

Zwei Fälle ron Hoblfuss beschreibt Wette aus der Rostocker Klinik. Wegen bedeutender Beschwerden wurde ein Keil aus den Ossa navicul. et cuooid. bezw. aus dem Os cuboid. reseziert. Form und Brauchbarkeit der Füsse wurden wesentlich besser.

Poulsen behandelte zwei Fülle Madelung'scher Deformität durch Osteotomie des Radius, um auf diese Weise die nach vorn konkave Verkrümmung desselben in Angriff zu nehmen. Er legte die Trennungsebene geradinig schräg von vorn unten, $1 \mathrm{~cm}$ oberhalb des Gelenkes, nach hinten oben mit dem Meissel. In hochgradigen veralteten Fällen hält Verf. die Ausichten für dauernde Korrektion für gering wegen starker Spannung der Weichteile an der Beugeseite. In geringgradigeren Fällen ist ein gutes Resultat zu erwarten.

Für rachitische Verkrümmungen der Tibia bei Kindern im Alter bis zu etwa 10 Jahren befürwortet $O$ pensbaw die manuelle Osteoklase. Er betont als Vorzüge der Osteoklase gegenüber der keilförmigen Osteotomie besonders die Vermeidung von Verkürzungen und Einfachheit des Vertahrens, wie der gesetzten Verletzungen. Er hat etwa 40 Fälle ohne Misserfolg behandelt und erzielte die Frakturierung stets an zreckmässiger Stelle.

Zur Korrektur der in schlechter Stellung ausgebeilten Gelenktuberkulosen empfiehlt Broca auf dem Internationalen Kongress für Chirurgie 1905 die Osteatomie oder Resektion, jedoch womöglich nicht bei Individuen unter 1 o Jahren. Für koxitische schlechte Ankylosen empfiehlt Ghiulamila die einfache trochantere, die schrige subtrochantere mit Trennung der Adduktoren und der Muskelansätze an der Spina ant. sup., schliesslich die keilförnige Osteotomie, die allerdings die Verkürzung vermehrt.

Über Osteotomie bei deform geheilten $K$ nochenbrüchen berichtet Lund auf Grund von 10 Fällen alter Colles'scher Brüche. Danacb ist nach Ablaut der ersten 3 Wochen seit der Verletzung eine Besserung nur ron der 
Osteotomie zu erwarten. Bei Verletzungen, die über 2 Monate alt sind, ist ein Erfolg nicht mehr bäufig. Zur Beseitigung der seitlichen Verschiebung hält Verf. die Osteotomie der UIna für indiziert.

Destot beschreibt einen Fall von Diaphysenbruch des Ralius, der in Supinationsstellung des oberen und in Pronationsstellung des unteren Fragmentes beilte mit Verlust der Pro- und Supinationsmöglichkeit. Nach Osteotomie wurde der Arm in Supination mit Eyfolg zur Heilung gebracht.

\section{Arbeiten aus dem Jahre 1906.}

1. Anschütz, Ref. in Hildebrand's Jahresber. S. 530. (Allg. med. Zentralzeitg. Nr. 14.)

2. Ritter $\nabla$. A uffenberg, Osteoplastische Verlingerung des Unterkiefers bei Mikrognathie. Arch. f. klin. Chir. 79.

3. v. Bramann, Behandlung der angeborenen retroglenoidalen Schulterluxationen. Arch. f. klin. Chir. 81. II. S. 351.

4. Codet-Boisse, Un cas de genu ralgum de l'alolescence. Double ostéotomie. Guérison. Ref. in Hildebrand's Jahresber. 1242. (Journ. de Bord. S. 745 .)

5. Codivilla, Sur la valeur des objections faites ì la métborle du redoessement forcé dans le traitement du genu valgum. Ref. in Zeitschr. f. orthop. Chir. 18, 311. Revue d'orthopédie. No. 2.

6. Curcio, Cinque auni di clinica ortopedica. (Napoli.) Ref. in Zeitschr. $\mathrm{f}$. orth. Chir. 18. 240.

7. Deutsch länder, Die Behandlung der Knochenbrüche mit Stauungshyperämie. Zentralbl. f. Chir. Nr. 12.

8. Derselbe, Die Anwendung der Staungshyperämie bei ortbopädischen Operationen. Zeitschr. f. ärztl. Fortbillung. Nr. 9.

9. Ewald, Uber Hallux malleus und verwandte anormale Stellungen der Grosszehe. Zeitschr. f. orth. Chir. 17. 489.

10. Galeazzi, On coxa valgn. (Amer. journ. of orthop. surg. IV. No. 3.) Ref. im Zentralbl. f. Chir. 1907. Nr. 24.

11. Guradze, Die Behandlung des Genu valgum. 78. Vers. deutecb. Naturf. u. Ärzte. Wien. med. Wochenschr. Nr. 51.

12. Helbing, Die Coxa vara. Zeitschr. f. orth. Chir. 15. 002.

13. Hohmann, Knocheuhebel für Osteotomien. Zentralbl. f. Chir. S. 900.

14. Kirmisson, ref. in Deutsche med. Wochenschr. S. 982.

15. I a mboth, Lintervention opératoire dans les fractures. Ref. in Zeitschr. f. Chir. 1165.

16. Lardennois, Application au traitement des ankyloses vicieuses du genou chez l'enfant de l'ostéotomie chautournante des condyles du fémur. (Revue de Chir. No. 11.) Ref. in Hildebrands Jahresber. S. 1273.

17. Lorenz, Behandluug des Malum coxae senile. 78. Naturforscher-Versamml. Ref. in Zentralbl. f. Chir. Nr. 48.

18. Derselbe, Die Endziele der Coxitisbehandlung und ihre einfachsten Mittel. Zeitschr. f. orth. Chir. 17. 362.

19. Müller. (78. Naturforscher-Versamml.) Ref. im Zentralbl, f. Chir. Nr. 48.

20. Phocas, Un genu valgum ì la suite d'une vieille ostéomyélite. (Rev. de Chir. Nr. 11.) Ref. im Zentraibl. f. Chir. 1907. S. 472.

21. Putti. La deformitì di Madelung. (Arch. internat. de Chir. Vol. III. Fasc. 1.) Ref. im Zentralbl. f. Chir. S. 1011.

22. Ranzi, Beiträge zur operativen Bebandlung der Frabturen. Arch. f. klin. Chir. 80 . 
23. Rossi, Le trazioni applicate direttamento allo scheletro degli arti inferiori col metodo Codivillat. (XIX. Congresio della soc. itil. di chir.) Ref. in Zeitschr. f. ortb. Chir. 18. 31:.

24. Schanz, Zur Nachbehandlung der tuberkulösen Coxitis. Zeitschr. f. orth. Chir. 15.468.

25. Sourdat, Double crenu valgrum. Condylotomie verticale ì droite et ostiotomie supracondylieme à gauche. (Rev. d'orthop. No. 55.) Ref. in Ilildebrand's Jahresber. S. 1241.

26. Taddei und Prampolini, Di alcuni casi poco comuni di deformita congenite degli arti. (Arch. di ortopedia. No. 3.) Ref. in Zentralbl. f. Chir. S. 1177 .

27. Turner, Pathologie und Therapie des Genu valgum. (Wratsch. No. 38.) Ret. in Deutsche mel. Wochenschr. S. 1838.

28. Vulpius, Die Behandlung ler tuberkub̈sen Koxitis in Kindesalter. Zeitschr. f. ärztl. Forthilil. Nr. 20. Ref. in diesem Arch. VI. S. 263.

Aus der Lange'schen Anstalt beschreibt Hohmann (13) einen Hebel, mittelst dessen der Knochen gebalten wird, die Weichteile zurücksredrüngt und vor dem Meiszel geschützt merden. Der Hebel dürfte ein willkommener Ersatz für die als Notbehelf dienenden Elevatorien sein.

Auf Grund ron 16 Fälen von Knochendeformität mit Osteotomie, die Rossi (23) nach der Codivilla schen Zugmethode mit Nageleintreibung behandelte, befürwortet er dieses Verfahren. Er gibt an, Verlängerungen bis zu $7-8 \mathrm{~cm}$ erreicht zu haben Dis Alter der Pationten lag zwischen 7 und 59 Jahren.

Deutschländer (7) berichtet über seine Beobachtung an einem osteomalazischen Mïdchen, dem er zu einer Zeit, als der Prozess anscheinend im Abheilen war, eine beiderseitige Osteotomie der Femora und später der Tibiae machte. Un die Callusbildung zu erböhen, wandte or von 8. Tage nach der Operation Staunng an. Sechs Wochen nach der Operation erwiesen sich die Femora gut kunsolidiert; bei den Tibien watr der Verlauf ebenso. Ferner 8 ; ref. d. Archiv VI, 258) berichtet er über seiue Erfahrungen mit Stauung an 14 osteotomierten Kindern; er findet, dass durch Anwendung der Stauung eine wesentliche Abkürzung der Immobilisationsdauer und der Nahbehandlung erzielt wird.

Ober Stellungskorrekturen bei deform geheilten Knochenbrüchen berichtet Ranzi (22) aus der Wiener Klinik. Es wurde osteotomiert und die Fragmente quer, schrär oder treppentormigr angefrischt und geniht ouler ineinander eingekeilt. Die treppenfömige Anfrischung mit Drahtnaht ergab die besten Resultate, jedoch machte sich boi Oberschenkelbrüchen muskelkrüfticer Individuen cine weitere stützende Prothese erwünscht. Auch glaubt Verf. durch ausgiebigere Anwendung ler Zugrerbünde statt der Gipsverbände bessere Resultate erzielen zu können. - La mbotte (15) verwirft bei schief geheilten Knochenbrüchen die unblutige Osteohlase und befürwortet die Freilerung der Bruchstelle.

Uber die Behandlung des "Vogelgesichts" berichtet v. A uffenberg (2) aus der Wiener Klinik. Drei Fille erworbener Mikrognathie wurden mit Durchsigung des Lnterkieferkörpers erfolgreich behandelt. Verwendet wurde die Gigli'sche Säge; eine anderwärts trüher ver'suchte Durchmeisselung bei einem der Fälle ergab Splitterung und war erfolglos. Uber einen weiteren Fall berichtet Ansehütz (1); ebenfalls erworbene Mikrognatbie, Durchtrennung im horizontalen Ast, Besserung.

v. Bramann (3) behandelte einen Fall von angeborener retroglenoidaler Luxation des Schultergelenkes, bei welchem die Brauchbarbeit des Armes infolge der Stellung sehr gering war, mit Osteotomie des Humerus und Drehung um etwa 90". Der Erfolg war ausgezeichnet. Braman empfiehlt dieses Vorgehen zur Beseitignng der durch Innenrotation und Pronation des Vorderarmes bedingten Funktionsstörungen in allen den Fällen, wo die unblutige Reposition unmög-

Arch. f. Orthop, Mechanoth. w. Gnf.-Cbir. VII. 1. 
lich ist und die blutige die Erbaltung eines beweglichen Gelenkes fraglich erscheineu lässt.

Die schrigge Osteotomie des Radius beseitigte in dem von Putti (21) berichteten Falle II adeIung'scher Deformität die funktionellen Störungen und subjektiven Klagen.

Bei Ausbildung einer schlechten Stellung nach ausgeheilter Coxitis tub. (Entwickelung der Coxa vara) nimmt Schanz kein Redressement vor, wegen der Rezidivgefahr und der Vergriosserung der Verbildung, sondern empfiehlt die intraoder subtrochantere Osteotomic ohne Tenotomie der Adluktoren, Streckverband. „Federnde Hüftkücke“, nachts Streckverband. Zu der Stellungsverbesserung nach Koxitis äussern sich auch Lorenz (18) und Vulpius (28) dahin, das diese durch Osteotomie im Bereiche des Trochanter erstrebt werden müsse.

Für die Bebandlung des Malum coxae senile empfiehlt Lorenz (17) mehrmonatige Fitation mit kontralateraler Beckenstütze, bei funktioneller Kontrakturstellung die subtrochantere $O$ steotomie als das schonendste Korrektionsmittel.

Bei Unmöglichkeit der unblutigen Reposition einer angeborenen Hüftrerrenkung empfiehlt auf dem internationalen medizinischen Kongress in Lissabon Kirmisson (14) die subtrochantere Osteotomie. Lorenz (dasellsst) verhält sich dazu ziemlich ablehnend, hingegen stehen Lima, Codivilla der Frage positiv gegenüber.

In seiner ausführlichen Abhandlung über Coxa vara auf Grund des Hoffa'. schen Materiales widmet $\mathrm{He}$ ebling (12) das Schlusskapitel einer zusammenfassenden Besprechung der Behandlung, die je nach der Ätiologie des Leidens und nach dem Stadium verschieden sein muss. „Erst wenn die Deformierung des koxalen Femurendes so hochgradig ist, dass eine starke Beeintrïchtigung des Gehvernügens auch im stationären späteren Stadium resultiert, besonders aber dann, wenu die Affektion doppelseitig ist, konmen operative Eingriffe in Betracht." Die Operationsverfahren, die den Schenkelhals angreifen, betrachtet $\mathrm{H}$. als wenig empfehlenswert wegen der Gefahr der Geleukeröffnung und der mit ihnen verbuncenen Weichteilsverletzungen; sie erscheinen ihm auch theoretisch nicht einwandsfrei. Von den am Femur angreifenden Nethoden erscheint ihm die $\mathrm{H}$ of fa'sche Osteotomia subtrochant. obliqua zweckmässiger als die Terrier-Hennequin'sche mit ihrer Meisselrichtung nach unten innen, weil sie eine grössere Berührungsfläche der Trennungsebene gewährleiste und die Pseudarthrosengefahr verringere. Das $\mathrm{H}$ of $\mathrm{f}$ a'sche Verfahren wird genau beschrieben. In schweren Fällen Keilresektion. Die Resektion des Schenkelkopfes wird nur in den allerschwersten seltenen Fälen ausgeführt.

Coxa valga behandelte Galeazzi (10) in zwei Fällen (Alter von 12 und 13 Jahren) nit extrakapsulärer Osteotomie des Schenkelhalses an der Basis.

Zur Behandlung der Ankylosen des Kniegelenkes empfiehlt Larde n nois (16) die bogenförmige Osteotomie mit Gigli'scher Säge; die Kondylen sollen im grossen Bogen durchsingt werden.

Zur Genu valoum-Frage liegt eine Reihe von Äusserungen vor. Auf der Naturforscher-Versammlung zu Stuttgart berichtete Guradze (11) darüber und empfahl das MacEwen'sche Verfabren. Osteoklase macht er nie. Auch unter 16 Jahren wendet er bei starren sklerotischen rachitischen Knochen die Osteotomie an, da die redressierenden Verbände zu zeitraubend und schmerzbaft sind und Lockerung des Gelenkes hinterlassen. In der Diskussion emptiehlt Loren z die lineäre suprakondyläre Osteotonoklasie, von aussen gemacht, unter Erhaltung des Periostes der Innenseite. Schultze wendet im ersten Jahrzehnt Redression oder Osteotomie an; letztere wird von aussen genacht, die Korrektur erfolgt erst nach zehn Tagen. Nach Bade genügt auch für die hochgradigsten Fälle von Genu valgum die einfache lineäre Osteotomie. Turner (27) empfiehlt die Osteotomie für schwere Fälle. Codet-Boisse, Sourdat, Phocas $(4,25,20)$ berichten über besondere Fïlle. 
Als Anhänger des gewaltsamen Redressements bekennen sich zwei italienische Autoren: Codivilla (j) und Curcio (6). Codivilla stützt sich auf eine Statistik von etwa 2000 Fïllen, die zum Teil nach Jahren nachgeprüft wurden und alle obne nenneuswerte Wachstumsstörung verliefen. Er befürwortet das Redressement forcé besonders für das Genu valgum adolescent. und die Fälle von Genu valgum rachit, welche jeuen nahe kommen. Er meint, dass eine ebenso ansgedebnte Zusammenstellung der Osteotomiefälle die Überlegenheit des Redressement forcé dartun würde, dem ausserdem der Vorzug der Einfachheit, geringerer Knochenverschiebiang und rascherer Heilung gebühre.

Keilexzision aus den Tarsus zur Behandlung des Klumpfueses Erwachsener empfahl auf der Naturforscher-Versammlung M üller (Stuttgart) (19). Dageger verwerfen v. Aberle, Schultze (daselbst), sowie Lange (Strassburg) (Kongr. d. deutsch. Ges. f. orth. Chir, 1906; Zeitschr. f. orth. Chir. XVI) diese blutigen Verfahren sebr entschieden.

Bei einem Falle von Hallux malleus wurde, wie $\mathbf{E}_{w}$ ald (9) berichtet, durch Keilresektion aus dem Metatarsale I. ein gruter Frtolg erzielt. Lber einen anderen Fall von Osteotomie des ersten Metitarsale zur Verbesserung der Zehenstellung berichtet Taddei und Prampolini (26).

\section{Biicher.}

Kirchner, Dic Frakturen des Mittelfusses. Berliner Klinik, Heft 236 Februar 1908. 24 Seiten. Fischers Mediz. Buchhandlung, Berlin. Preis 60 Pfg. Verf. stellt in dieser kleinen Monographie seine Erfahrungen über die Frakturen der Metalarsalknochen, in denen er Autoritait ist, zusammen. Besonders bemerkenswert sind bei der Diagnose seine Mitteilungen über das oft röllige Ver, sagen der Röntgenuntersuchung; ferner seine Angaben über den Mechanismus der Entstehung ohne jedwedes Trauma, einfach durch Tritt auf einen bleinen Stein. Als Therapie schlägt Verf. Hochlagerung und ev. Fixation im Verband ror, bei starker Dislokation Extensionsbehandling nach Bardenheuer, bei rerzögerter Konsolidation oder auch ron rowe berein wirl Bier'sche Staunng warm empfohlen. Von besonderem orthopädischen Interesse ist es, lass eine genau gearbeitete Plattfusseinlage mit entsprechender Modifikation überhaupt nicht erwähnt ist. Wir verstehen jetzt, warum so unil so viele Patienten noch nach wochenlanger Behandlung nicht von ibren Beschwerden befreit wurden. Die Unterlassung einer derartigen Verordnung muss als Kunstebler bezeichnet werden! Wir geben dem Verf. den dringenden Bilt, bei einer Neuauflage das Versäumte nachzuholen.

W. Becker (Bremen).

L. Becker, Die Simulation von Krankheiten und ihre Beurteilung. Jeipzig, 1908, bei Georg Thieme, 298 Seiten, broch. Mk. 7.

Unter Mitwirkung ron Stier, Leppmann. Wessely und Hartmann gibt Becker eine Ubersicht über die mannigfachen, oft recht komplizierten Erscheinungen der Simulation von Krankheiten, um dem Praktiker und Gutachter die Erkennung und Beurteilung der Simulation zu erleichtern und andererseits die auch heute noch allzu bäıtige Verkennung tatsächlicher Erkrankung nach Möglichkeit auszuschalten.

Das Buch bringt nicht allein eine Fülle des Beachtenswerten für den praktischen Arzt, sondern ist auch für den in Unfallsachen recht bewanderten Spezialarzt sehr 
wertvoll, da es die etwas ferner liegenden Spezialgebiete der Augen- und Ohrenschädigungen, sowie der Geisteskrankheiten mit umfasst. Besonders beachtenswert erscheinen die von Becker ausführlich begründeten Anschauungen über dlas Wesen und die Häufigkeit der Simulation und deren Abgrenzung ron der mehr minder bewussten Übertreibung. Ebenso bringt das von Leppmann geschriebene Kapitel über die Simulation von Nervenkrankbeiten eine besonders hervorzuhebende, klare Schilderung des Wesens der Hysterie und der verwandten Zustände, so dass es an der Hand der vorgetragenen Anschauingen jedem Arzte gelingen kann, auch auf diesem schwierigen Gebiete die Grenze zwischen wirklicher Krankbeitsïusserung und Simulation zu ziehen.

Die übrigen Kapitel bringen eine Reihe von Einzelheiten, deren Studium durch die Einstreuung reicher Kasuistik fesselnd und anregend wirkt.

Zahlreiche Hinreise auf spezielle Arbeiten und Literaturangaben ergänzen das Buch zu einem guten Nachschlagewerk, das in der Bibliotbek keines Arztes fehlen sollte, der zur büufigen Gutachtenabgabe herangezogen wird.

$$
\text { Straus (Nürnberg). }
$$

F. C. Miiller, Liber die traumatische Neurose. (Separat-Abdruck aus Zeitschrift für die gesamte Versicherungs-Wisenschaft VII.) Berlin, Mittler und Solnn. 1907.

Verf. weist hin auf die grosse Zunahme der Hänfigkeit dieser Diagnose im allgemeinen und auf auffallende Verschiedenheiten der Hüufigkeit in verschiedenen Provinzen, Stidten, bei rerschiedenen Gutachtern. Eine wirkliche traumatische Neurose hält Verf. für weit seltener, ils man anzunehmen pflegt, doch bestreitet er nicht das Bestehen dieses Leidens. Verf. führt verschiedene Momente an, welche dazu geführt haben, dass es so ausserordentlich viel Rentenempfänger wegen Unfallsneurosen gibt, und verlangt für die Zuerkennung der Rente den Nachweis, warum die vorbandenen Störungen die Frwerbsfähigleit wirklich beeinträchtigen; er betont, dass sehr oft schwer neurasthenische Individuen verantwortungsvolle Berufe voll ausüben. In der Hochflut der Fälle von traumatischer Neurose sieht Verf. eine grosse ethische Gefahr und einen wirtschaftlichen Schaden für unser ganzes Yolk. Zum Schluss erörtert Verf. eine Reihe von Mrassnahmen zur Verhütung der "traumatischen Neurose". Wegen Einzelheiten muss auf das Original verwiesen werden. Reich enbach (Leipzig).

Strasser, Lehrbuch der Muskel- und Gelenkmecbanik. I. Band: Allgemeiner Teil. $212 \mathrm{~S}$. mit 100 'Textfiguren. Berlin 1908, Julius Springer. Preis ungeb. Mk. 7.

Für das Studium der Muskel- und Gelenkmechanik fehlte es leider an einem Leitfarlen, der den Anfünger mit Beschrünkung auf das Notwendige in die Grundzüge der theoretischen Mechanik einfübrte. Mit Rücksicht hier:̣uf ist diesem wichtigen Gebiete der ganze I. Abschnitt des vorliegenden Buches gewidmet. Die Darstellung ist so gehalten, dass höhere mathematische Kenntnisse nicht vorausgesetzt werden. Deshalb war eine gewisse Breite der Ausführungen nötig, um allgemein verständlich zu bleiben, und wer sich durch die zahlreichen mathematischen Formeln hindurchgenrbeitet hat, dem kommt die Wahrheit zum Bewusstsein, dass die Götter vor die Tugend den Schweiss gesetzt haben.

Der II. Abschnitt behandelt die allgeneinen Verhältnisse des Skeletts und der Muskeln: die Arten der Bewegungen, die Haupttypen der Gelenke, die Vereinigung der Muskelfasern zu Muskeln und ihre funktionelle Anpazsung an die Arbeitsleistung.

Der III. Abschnitt ist der praktisch wichtigste: er führt uns allgemeine Probleme der Gelenk- und Muskelmechanik vor. In einzelnen Aufgaben wird uns die Wirkung der verschiedensten Kräfte auf die Gelenke gezeigt. Dieser Teil ist 
äusserst interessant und lehrreich, enthält er doch vielfach die Grundlagen für unser spüteres therapeutisches Handeh.

Wir sehen mit Interesse dem II. Bande entgegen, der dem speziellen Studium cler mechanischen Verhälnisse der Muskehn und Gelenke gewidmet ist.

W. Becker (Bremen).

Schauz, Über Krüppelnot und Kräppelhilfe. Mit besonderer Berücksichtigung der Verhältnisse in Königreich Sachsen. Dresden 1908, bei von Ziahn \& Jaensch.

Mit beredten Worten schildert Verf. die Krüppelnot, die sich zusammensetzt aus den drei Faktoren: Körperliches Gebreshen, seelisches Leiden und rerminderte Erworbsfühigkeit. Ans diesen drei Faktoren wird der einzig richtige Weg einer wirksimen Krüppelhilfe abgeleitet, nümlich Gründung von Krüppelheimen, die orthopäalische Behandlung, Schulbildung und Berufserziehung ernöglichen.

Die Forderungen des Verf. sind präzise gestellt und klar begründet und jeder Arzt wird ihm aus rolister Seele beipflichten. Nur in einem Punkte vermisst Ref. eine deutliche Stellungnahme: Wel soll Leiter dieser uun zu begründenden Heime werden? Und darauf kinn es unseres Erachtens nur eine Antwort geben: nicht der Pfarrer und nicht der Pädagoge, sondern einzir und allein der Orthopäle! Es grenügt eben nicht, dass Orthopäden an den neuen Anstalten nur tätig sind, sondern sie müssen stïndige Leiter derselben werden. Gerade hier gilt die WVarnmg

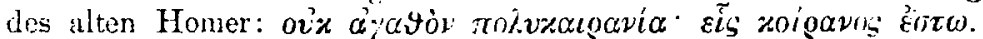

W. Becker (Bremen).

Braun, Die Lokalanästhesie, ihre wissenschaftlichen Grundlagen und praktische Anwendung. Ein Hand- und Lebrbuch. 452 Seiten mit 128 Abbildungen, II. teilweise ungearbeitete Auflage. Leipzig 1907, bei Joh. Ambr. Barth. Preis ungebunden Mk. 10.

Wie der Titel bereits sagt, zerfällt das Buch in einen theoretischen und ainen praktischen Teil. Ersterer behandelt die verschiedenen Anästhesierungsmetholen und Anästhesierungsmittel, letzterer beschreibt ausführlich an der Hand zahlreicher instruktiver Abbilduneren Indikarionen, Kontraindikationen und Technik der Lokalanästhesie bei allen Operationen der einzelnen Körperregionen. Im Gegensatze zu der 1905 erschienenen ersten Auflage sind die Kapitel über nenere Anästhetica eingefügt worden und namentlich bat der Abschnitt äber Medullaranästhesie eine fast völlige Cmarbeitung ertahren.

Die rasche Aufeinanderfolge der Auflagen ist ein zweifaches Symptom: einmal für das grosse Bedürtuis eines solehen Werkes und zum andern für die vortreffliche Bearbeitung desselben. Ier theoretische Teil ist so klar und sachlich darrestellt, dass die Lektüre desselben lirekt zum Genusse wird. Das gilt namentlich ron dem intereseanten Kapitel über die Geschichte der Lokalanästhesie, die fast bis auf die Urgeschichte der Kultur zurückreicht. Auch die verschiedenen Kapitel über die Sensibilitït und Schuerz, über die Anä:thesierung durch Nervenkompression und Anämie, dnrch Kälte und osmotische Spannung sind äusserst anrecend behandelt und bieten eine Fülle des Interessanten. Der praktische Teil unterscheidet sich dadurch ron den früher bereits über dieses Thema veröffentlichteu Monographien, dass er nicht in allen Fällen eine einzige Methode empfiehlt, sondern dass er für jede Körperregion, für jede Operation die nach den zahlreichen Erfahrungen des Verf. brauchbarsten Methoden darstellt. Wer unter Lokalanästhesie operieren will, muss zunächst die genaueste Kenntnis der Innervation les Operationsfeldes haben; deshalb ist diese einer jeden Operation rorangestellt. Daran schliesst sich an eine auf die Lokalanästhesie zugeschnittene Operationslehre, welche die Technik an der Hand zahlreicher Abbildungen erörtert.

So ist es dem Verf. aufs glücklichste gelungen, ein $\mathrm{Handbuch}$ zu veröfentlichen, welches dem Leser dis mähevolle Studium vieler Einzelarbeiten und 
die Notwendigkeit einer längeren persönlichen Frfahrung erspart. Es wird jodem, der sich seiner zur Ausführung einer schmerzlosen Operation bedient, ein zuverlässiger Führer sein. Wir wüuschen ihm einen grossen Leserkreis.

$$
\text { W. Becker (Bremen). }
$$

Iloffa und Wollenberg, Arthritis deformans und sog. chroniseher Gelenkrheumatismus. Fine röntgenologische und anatomische Studie. 229 Seiten mit 178 Abbildungen im Text. Stuttgart 1908, Ferd. Enke. Preis ungeb. Mk. 12.

Das vorliegende Werk zerfällt in 5 Haupttcile; im 1, wird die Arthritis deformans behandelt, im 2. die primüre chronische progressische Polyartbritis, im 3. dor sekundäre chronische Gelenkrheumatismus, in 4. die Anatomie der sub 3 und 4 behandelten chronischen Polyarthritiden, endlich in 5 . ibre Differentialdiagnose.

Bei der ganzen Dirstellung wurde, wie schon der Titel besagt, der Schwerpunkt auf das Röntyenbild einerseits, auf die an:itomische und histologische Cnter. suchung andererseits gelegt. Daneben treten Symptomatologie, Itiologie, Prognose und Therapie zurück, sind aber doch bei jeden Abschnitt kurz behandelt. Auch ist jedem Abschnitt eine grössere oder kleinere Anzahl von Krankengeschichten beigegeben, die das Resultat der Untersuchungen illustrieren.

Dasselbe lässt sich kurz dahin zusammenfassen, dass Arthritis deformans und chronische progressive Pol yarthritis z wei in Beginn, Verlauf und Endeffekt völlig verschiedene Prozesse darstellen: bei Arthritis deformans Beginn am Gelenkknorpel, Proliferation und Wucherung der Gelenkenden, die erst bei beträchtlicher Deformierung die Beteiligung der Synorialis durch chronisch-traumatischen Reiz hervorrufen; fast niemals Kontrakturen orler Ankylosen. Im Gegensatz hierzu die chronisch-progredienten Polyarthritiden: Beginn in der Synovializ nit entzündlicher Wucherung, darauf Sehrumpfung derselben und Kontrakturbildung, häufige Ankylosen und erst sekundär in einzelnen Fällen Wucherung des Knochens und Gelenkdeformierung. Wenn heute noch beide Prozesse so oft durcheinander geworfen werlen, so liert dias grosstenteils daran, dass nur alte, seit langem bestehende Fälle von chronischer Polyarthritis zur anatomizchen Untersuchung kamen, die dann nebenbei auch die für Arthritis deformans charakteristizchen Knochenwucherungen zeigten. $\mathrm{Es}$ ist das grosse Verdienst der Verfasser, durch anatomische Untersuchungen von Frühfällen zum ersten Male den exakten Nachweis erbracht zu haben, dass die chronische progressive Polyarthritis niemals mit Knocbenwucherungen und Gelenkdeformationen, wie sie für Arthritis deformans so typisch sind, heginnt, sondern dass letztere sich höchstens als sekundäre Folge zu den Spätstadien binzugesellen kann.

Diese Arbeit ist $\mathrm{H}$ of $\mathrm{f}$ a Schwanenlicd geworden: es ist die letzte, die seinen Namen als Mitverfasser träıt, wenn auch der grōssere, anatomische Teil fon Wollen. berg bearbeitet ist. Und da freut es uns doppelt, hervorheben zu können, dass dieses Werk in seiner exakten Wissenschaftlichkeit, seiner blaren, erschöpfenden Darstellung und seinen zahlreichen, instruktiven röntgenologischen, anstomischen und mikroskopischen Abbildungen würdig ist des Mames, der die moderne Orthopädie als Spezialfach begründet und ihr die Wege gewiesen hat auf riele Jahre binaus.

$$
\text { W. Becker (Bremen). }
$$

Franz M. Groedel, Die Orthoröntgenographie. München 1908, J. F. Lehmann. $79 \mathrm{~S} .32 \mathrm{Abb}$. Preis Mk. 3.

Das Büchlein, welches in erster Linie für diejenigen bestimmt ist, die praktisch mit Röntgenstrahlen arbeiten, behandelt in ausführlicher Weise die Technik der Orthoröntgenographie. Von den gebräuchlichen technischen Konstruktionen findet eingehende Beschreibung der bekannte, rom Verfasser modifizierte Levy Dorn'sche Apparat. Die Instandsetzung und Handhabung desselben, sowie die 
Aufnahme der Herzorthodingramme in den rersohiedenen Strahlenrichtungen bezw. Körperstellungen wird ausführlich geschildert und durch viele instruktive Abbildungen illustriert. Zablreiche praktische Winke und Anweisungen zeigen die grosse Erfahrung rles Verfassers. Wertfoll ist die Beigabe orthodiagraphischer Normalmasse des Herzens in Form von Tabellen und zwar hat der Verfasser den bekannten Dietlen'schen Uassen, welche für horizontile Körperlage gelten, aus eigener grïsserer Untersuchungsreihe auch die mit Vertikalorthodiagraphen gewonnenen Normalwerte angrefügt, desgleichen die von Veit stammenden Normal. masse für Kinder. Neben der Orthodiagraphic des Herzeus findet auch die anderer Organe, spez. des Magens, welche Verfasser seinerzeit inaugurierte, ihre Besprechung. Endlich werden noch kurz die modemen Methoden der Orthophotographie und der Teleröntgenographie besprochen und geschildert. Das Bücblein ist lem Röntgenpraltiker wämstens zu enpfehlen. Faulhaber (Würzburg).

W. A. Frenud und L. Mendelsohn, Der Zusammenhang des Infantilismus des Thorax und des Beckens. Stutgart 1908, Ferdinand Enke, $70 \mathrm{~S}$, Prtis Mk. 2.40.

Während der Zustand des Infantilismus bisher fast nur nach klinisch-ätiologischen Prinzipien geschildert worden ist, behandeln die Verfasser, welche den Intantilismus als den Ausdruck des Stehenbleibens der Entwickelung des Individuums auf der kindlichen Stute in seinem Gesamtorganismus oder in einzelnen Gliedern auffassen, streng anatomisch. Das Ergebnis der Untersuchungen ist speziell eine gründlichere Darstellung, sebärfere Zeichnung und im weiteren eine wissenschaftlich befriedigende Aufklïrung über den organiseben Zusammenhang der charakteristischen Merkmale der infuntilistischen Hemmungsbildung des knöchernen Thorax und des Beckens. Dieser Zusammenhang bildet gewissermassen den Grundstock einer Skeletthernnungsbildung, an den sich anch die übrigen Skelettteile in gleicher Entwickelungshemnung anreihen.

Die für den Ausbau und die Funktion wesentlichen Teile sind die obere Apertur mit den ihre Grössenentwickelung beherrschenden ersten Rippenknorpel für den Thoxax (wichtig für die Pathogenese gewisser Lungenkrankheiten), femer die Lumbosilknalgelenke mit der Entwickelung der sekundären Gelenkflitichen am Kreuzbein für das Becken. Eine Entwickelungshemmung dieser Partien bedingt weitere Störungen an den betroffenen Organgebilden und prägt ihnen den infantilen Charakter auf. Die Tntersuchungen wurden an $3 \dot{0}$ Leichen in der Weise vorgenommen, dass in jedem Fall die obere Brustapertur in toto ans dem Zusammenhang gelüst, von Weichteilen freipräpariert und nach den von Freund angegebenen Durchmessern gemessen nurde, dass fermer in gleicher Weise das Kreuzbein, meist zusammen nit dem zneiten bis dritten untersten Lendenwirbel herausgelöst, von den Weichteilen freipräpariert und sodann der Mazeration unterworfen wurde. Ausserdem standen mebrere Präparate aus dem Berliner pathologischen Museum zur Verfügung.

Von Interesse im einzelnen ist besonders die Schilderung der Statik und Mechanik des Beckens, die sich zum Teil auf frühere Untersuchungen Freunds stütat.

Die Arbeit ist yon allgemeiner Bedeutung und verschafft in vielfacher Hinsicht Anregung und Belehrung. Nicht zum geringsten Teil wirkt sie fördernd auf die Kenntnis von der natürlichen Haltung und Gestalt des menscblichen Körpers.

$$
\text { J. Riedinger. }
$$

Seelmamn, Die ärztliche Begutachtung in Invaliden-und Krankenversicherungsa achen. Zum praktischen Gebrauch für ärate, Krankenkassen und Verwaltungsbehörden. Leipzig 1908, F. C. W. Vogel. 64 S. Preis ungeb. 2 Mk. $50 \mathrm{Pfg}$.

Durch Zusammenfassung, Ergänzung und Erweiterung von Artikeln, die in verschiedenen Zeitschriften veröffentlicht worden sind, zeight Vert. als erfahrener 
Jurist klar und dentlich, worauf es bei der Ausstellung von ärztichen Attesten in Invaliden- und Krankenversicherungsaachen den Behörden ankonmt. In allen Frigen ist die Rechtslage kur' dargelegt. Das Studium der Schrift wird jedem Arat oder Beamten, der nit Begutachtungen zu tun hat, von grösstem Nutzen sein.

$$
\text { J. Riedinger. }
$$

\section{Eingesandt.}

Fesselbandmas für genaue Unfangmessungen nach $\mathrm{K}$. Wahl (München). Fabrikant: E. Preisinger (München), D.R.G.M. Ein schmales Bandmass trägrt an einem Ende einen Ring, durch den das Bund gezogen wird, so dass es wie eine Fessel um das Glied herumgeschlungen ist. Das Bard lässt sich bei einiger Gewöhnung an die Hebhaltung desselben genauer als ein gewöhnliches Bandmass ankegen. (S. Hünchener med. Wochenschr. 1907, Nr. 47.)

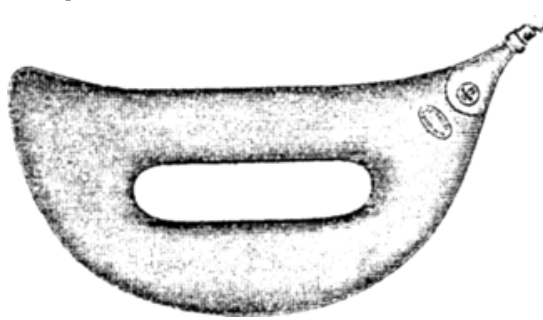

Halbkreisförmiges Luftkissen mit Iäglich oralem Loch. Gummiwarenfabrik Metzeler \& Co. (MIünchen), D.R.G.M. Das Luftkisien besitzt eine lïnglich ovale Offunung, in welche Arm, Bein oder Fuss eingelegt werden. Das Glied findet nicht nur eine sichere und feste Stütze, sondern auch eine weiche, nicht verschiebbare Enterlage. Bei seiner Anwendung lïsst sich auch der oft so lästige schmerzhafte Druck auf die Ferse ausschalten. Das neue Kissen wurde in der chirurgischen Klinik und in Krankenhaus rechts der Isar in München als praktisch befunden. Preis: $89,90 \mathrm{Mk}$, pro Dutzend brutto.

Instrumenter og bandager. Afbiluede og beskrevne ved Dr. Ejnar Nyrop. Kopenhagen 1908. Band I. Vortrefflich ausgestatteter und reich illustrierter Katalog in Form eines Atlas mit erklïrendem Text.

La médecine scolaire. Bulletin menstuel de la Scciété des médecins inspecteurs des écoles. Directeur scientifique: Prof. Dr. Méry. Rélacteur en chef: Dr. L. Butte. Band I, Heft 1. Nonatlich 1 Heft. Jahresabonnement: 6 Fr., nach Deutschland 7 Fr.

Die Behandlung les Krebses mittelst Fulguration. Von Dr. de Keating-Hart (Marseille), Ubersetzung von Jr. E. Schümann, Assistenzarzt der chirurgiscben Universitätsklinik in Leipzig. Leipzig 1908, Akademische Verlagsgesellschaft. $37 \mathrm{~S}$. mit 9 Tafeln (Abbiliungen). Preis brosch. $2,40 \mathrm{Mk}$. De Keating-Hart hat sein Verfahren in einer Broschüre beschrieben, deren Studium den deutschen Chirurgen durch die Übersetzung Schümann's erleichtert wird.

Third annul report of the Henry Phipps institute for the study, treatinent and prevention of tuberculosis. Herausgegeben von Dr. Josepb Walsh. Philadelphia 1907 . $\$ 10$ S. mit zablreichen Abbildungen. Der sehr sorgfältige wissenschattliche Bericht über las Jahr 190 j enthält Beiträge von Elick, Montgomery, Stanton, Fetterolf, McCarthy, Landis, White, Ravenel, Irwin, Walsh, Cummins und Hatfield. 